\title{
Usability of A Low Fidelity Wearable Device and App to Monitor COVID-19 out-patients
}

\author{
by
}

Norah AlJurbua

A thesis submitted to the Faculty of Graduate and Postdoctoral Affairs in partial fulfillment of the requirements for the degree of

Master of Applied Science

in

Human and Computer Interaction

Carleton University

Ottawa, Ontario

(C) 2021, Norah AlJurbua 


\begin{abstract}
Most wearable healthcare devices facilitate the continuous monitoring of physiological parameters (e.g., electrocardiography and respiratory rate). However, usability issues still arise in many wearable healthcare devices, leaving end-users dissatisfied with the service. To better understand patients' requirements, usability studies and user-centered design research must be conducted. In our study, we aimed to design a wearable health-tracking prototype that is catered for COVID-19 out-patients, we addressed this issue by including stakeholders in our design process. We investigated patients' needs while also understanding crucial metrics from physicians who worked with COVID-19 patients. From our preliminary research and our findings, we designed a wearable health tracking device and health application interface prototype. Then we conducted usability tests to ensure meeting user requirements and satisfaction. According to our system usability scale (SUS) score and other findings, our prototypes were considered usable and acceptable by users. However, due to COVID-19 restrictions, many limitations were placed.
\end{abstract}




\section{Acknowledgements}

I am writing these words with full gratitude and genuine appreciation to the people who have supported me throughout this long journey of learning. I would like to first thank my supervisor Victoria McArthur who supported me and had the patience to guide me through the entire process. I am also deeply grateful to Robert Biddle, who was a true mentor from day one. His support, knowledge, and wisdom will always be appreciated. I would like to thank my backbone, main supporter and love of my life, Abdullah. I could have never done this without his unconditional love and support. Special thanks go to my dearest family, who were patient through my stressful days, encouraged me to achieve more, and were a major part of this thesis. Thanks to my friends Salwa and Reema who understood my busy schedule and always brought a smile to my face when I was down. Thanks to everyone who supported in sharing and filling out the surveys. Thanks to my work managers for understanding my situation and allowing flexible hours to finish my thesis. I could not have done this without the support of those people and many others who have indirectly lifted me up and motivated me to go further. 


\section{Table of Contents}

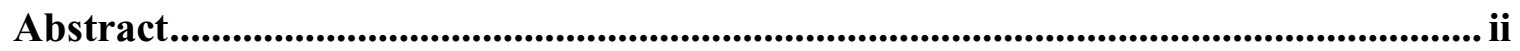

Acknowledgements .............................................................................................................................. iii

Table of Contents ............................................................................................................. iv

List of Tables ............................................................................................................................... viii

List of Figures........................................................................................................................... ix

Chapter 1: Introduction .............................................................................................................. 1

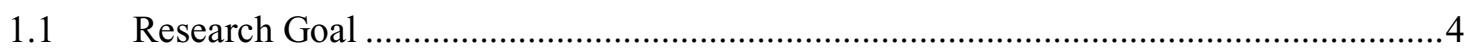

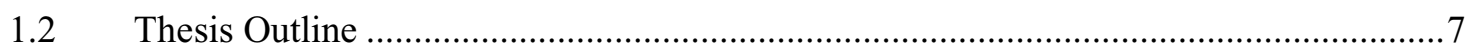

Chapter 2: Background and Related Work .............................................................. 9

$2.1 \quad$ Wearable Devices in Healthcare ………………………........................................

2.2 Wearable Devices During COVID-19 ………………………………………....10

2.3 Physiological Metrics for COVID-19 …………………………………………....12

$2.4 \quad$ User-centered Design and Usability ........................................................................13

2.5 Personal Health Information Privacy ………………….......................................15

2.6 Low-Fidelity Prototyping ……………………………………………………….... 16

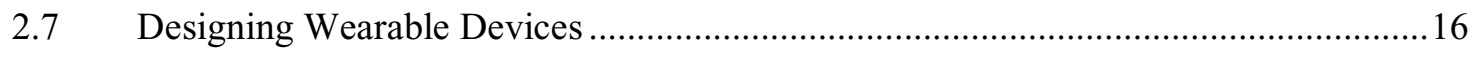

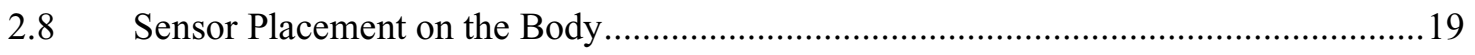

2.9 Wearable Materials and Device Architecture ……………………………………....22

Chapter 3: Online Survey Study ....................................................................................... 22

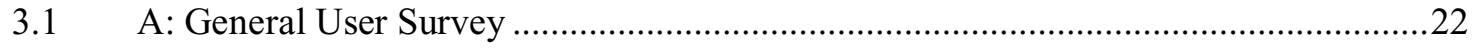

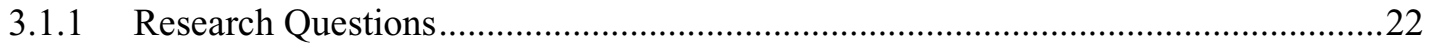

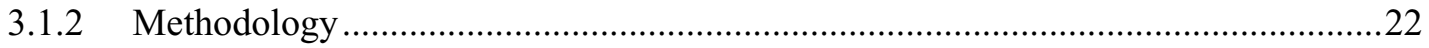

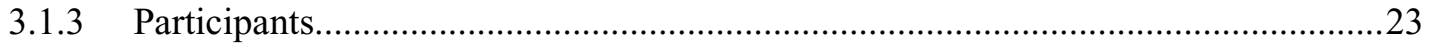




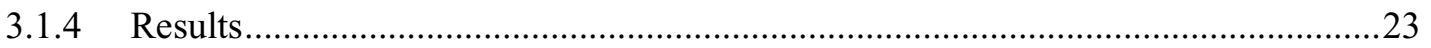

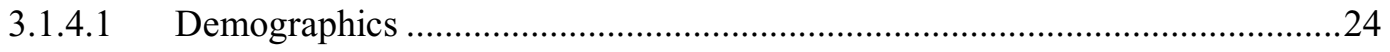

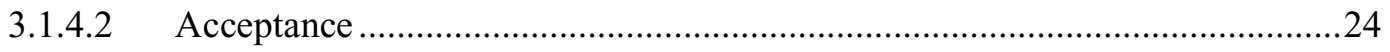

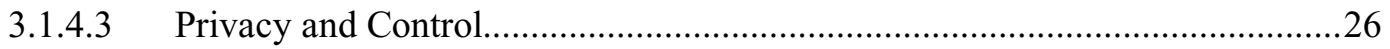

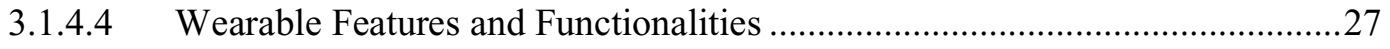

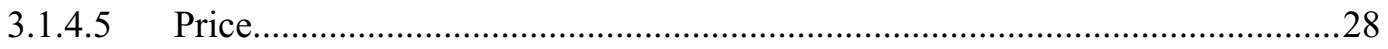

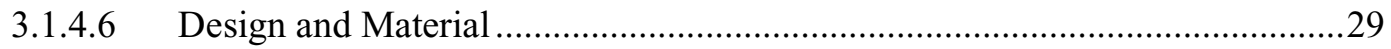

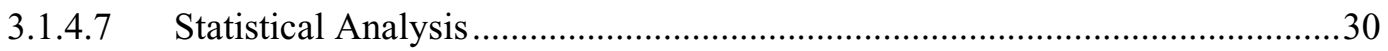

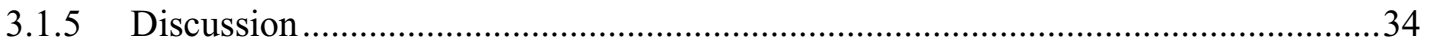

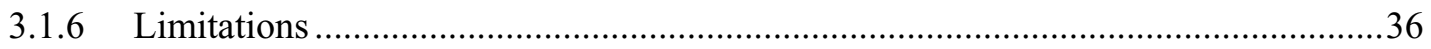

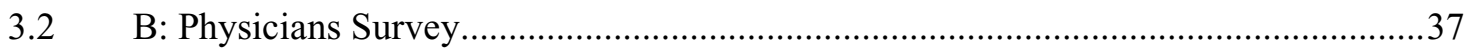

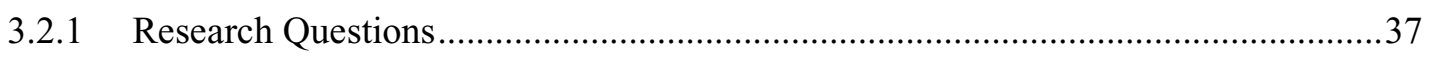

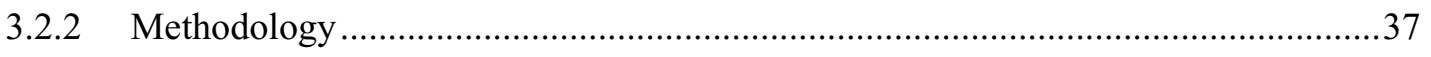

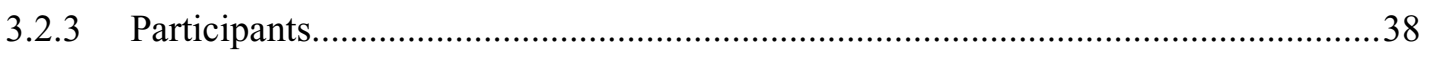

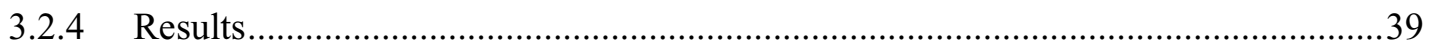

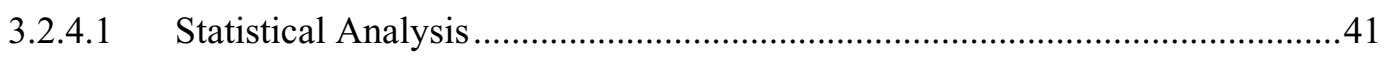

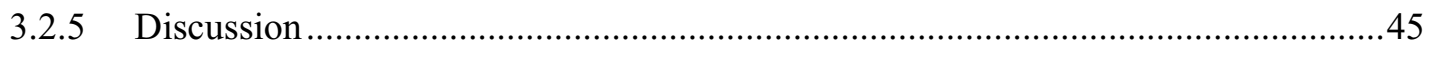

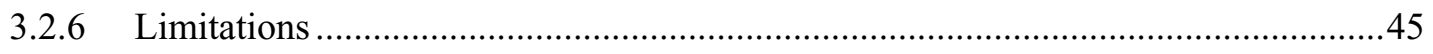

Chapter 4: Usability Study.............................................................................................. 47

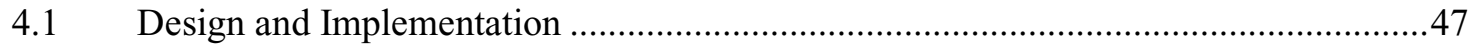

4.1.1 Body Placement of Wearable Prototype ..................................................................

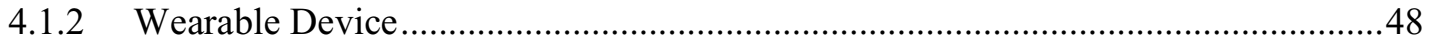

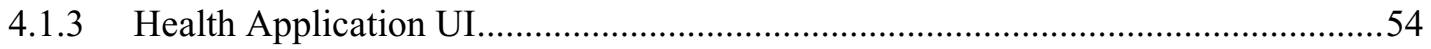

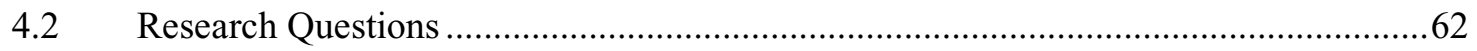

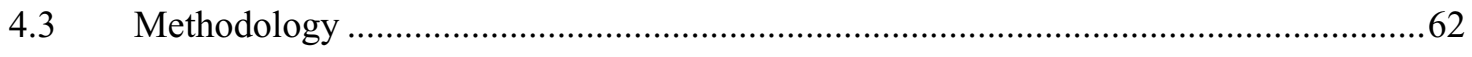

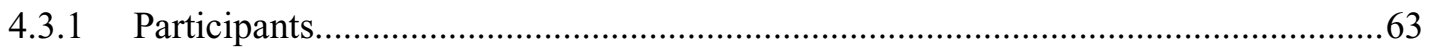


4.4 Results.

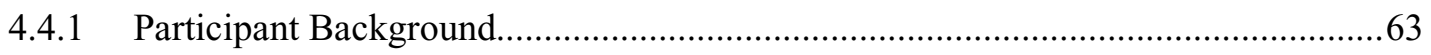

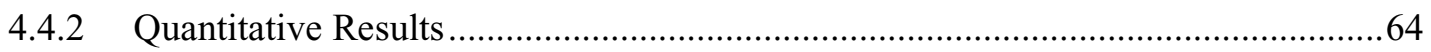

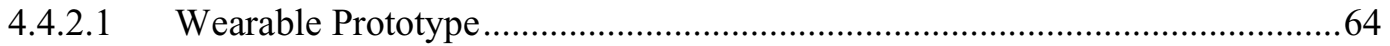

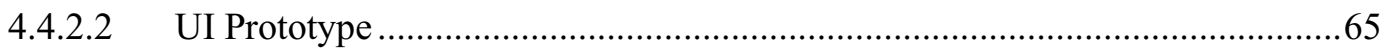

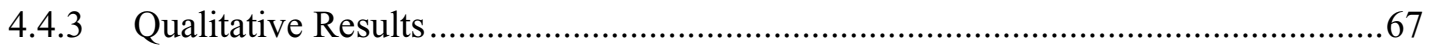

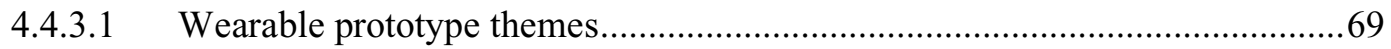

4.4.3.1.1 Ideas for further improvements........................................................... 72

4.4.3.1.2 Satisfaction with the wearable prototype..............................................73

4.4.3.1.3 Overall idea on wearable health track device for out-patients....................73

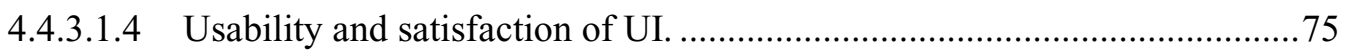

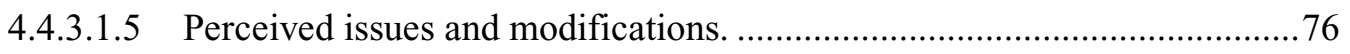

4.4.3.2 Overall opinion on the system UI and wearable prototype for out-patients....76

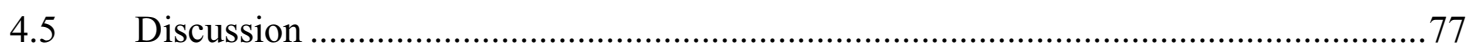

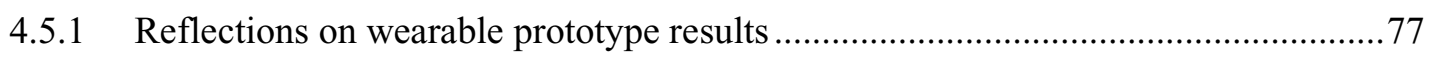

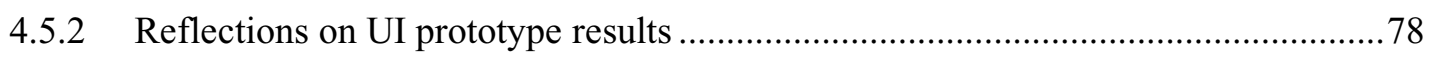

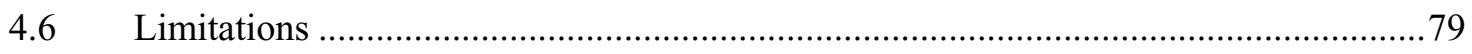

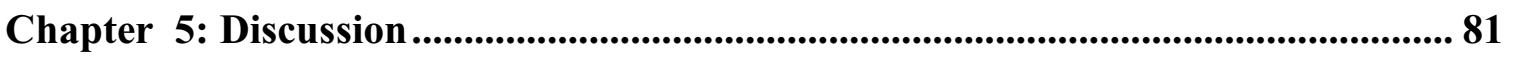

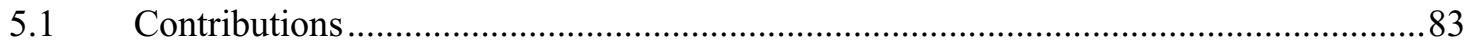

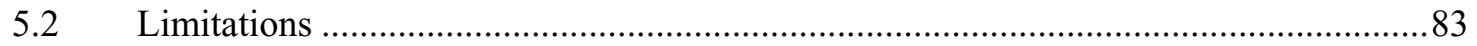

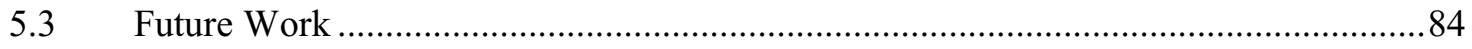

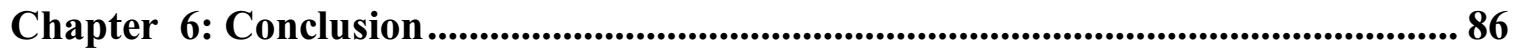

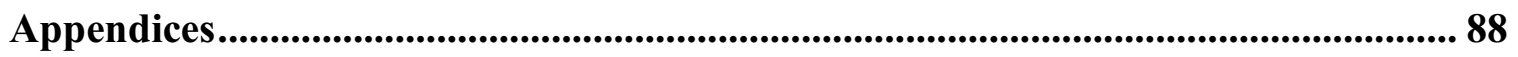

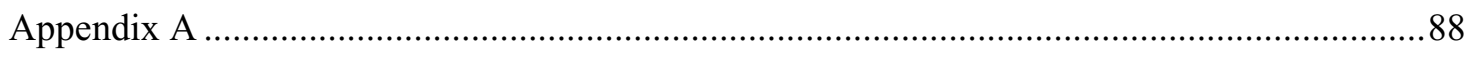

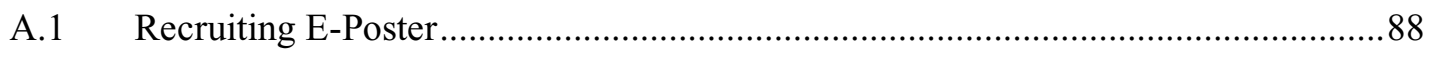




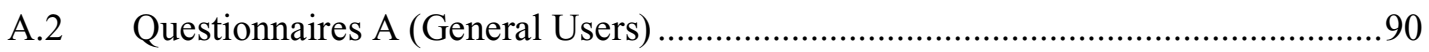

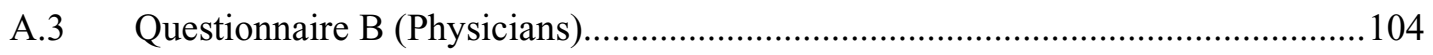

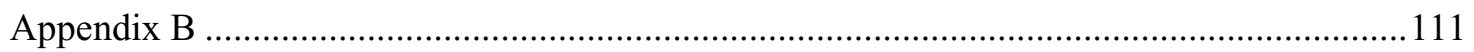

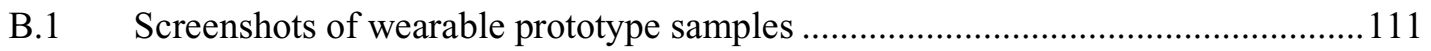

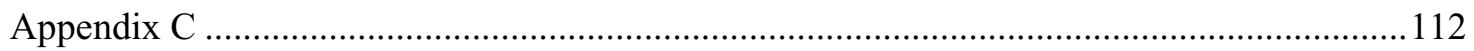

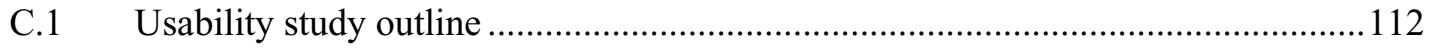

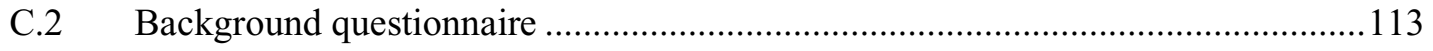

C.3 Wearable prototype usability and acceptability questionnaire ..............................115

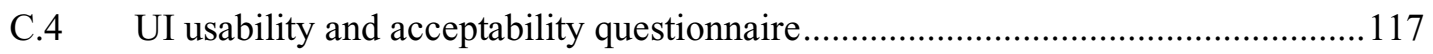

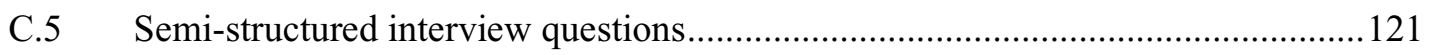

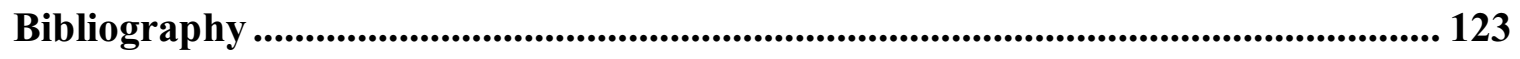




\section{List of Tables}

Table 1. Examples of common smart wearable devices................................................. 10

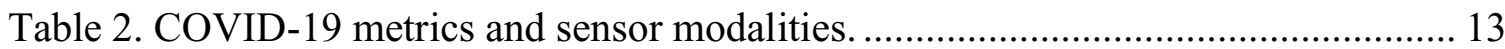

Table 3. Checkbox data results of the most important functionalities in a wearable healthcare device

Table 4. Checkbox data results of the most important design specifications in wearable

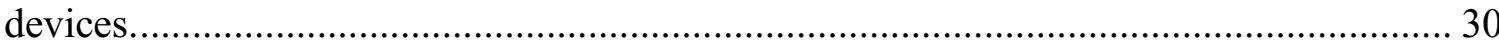

Table 5. Comparison of the participants' acceptance toward the positioning of wearable

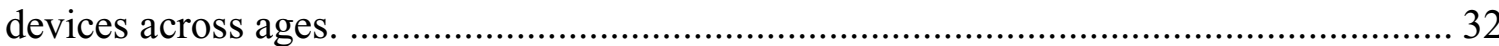

Table 6. Comparison of the participants' acceptance towards the positioning of wearable

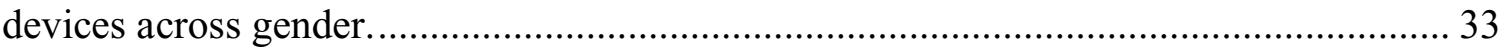

Table 7. Comparison of the perception of vital signs monitoring importance across

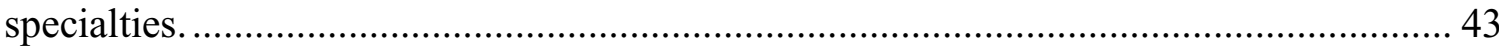

Table 8. Comparison of the perception of different aspects of monitoring importance

across specialties.

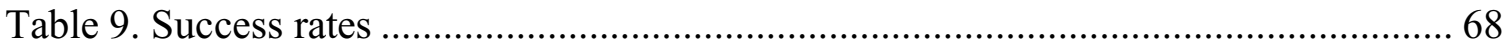

Table 10. Wearable device interview questions' codes ..................................................... 71

Table 11. Wearable device - interview questions' themes/categories ............................. 72

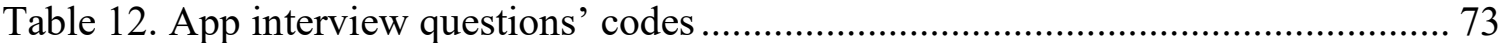

Table 13. App interview questions' themes/categories .................................................. 74 


\section{List of Figures}

Figure 1. Zeagler's body map on the social acceptance of wearable placement. 18

Figure 2. Difference between rigid and flexible circuits: A) One-layer design of a rigid

circuit [11]. B) Layers of a flexible circuit [71] 21

Figure 3 Body figure presented in the questionnaire forbody placement acceptability.... 25

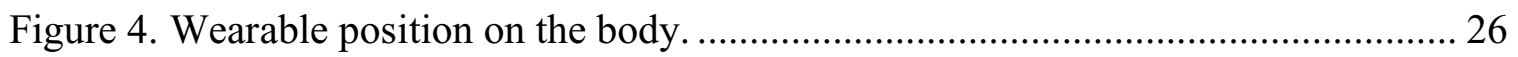

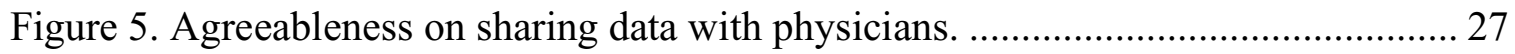

Figure 6. Importance of aesthetics in wearable devices. ........................................... 30

Figure 7. Important COVID-19 physiological parameters. ..................................... 40

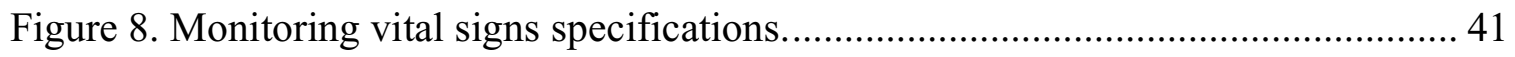

Figure 9. Preliminary sketch: a) option a, b)option b ............................................. 50

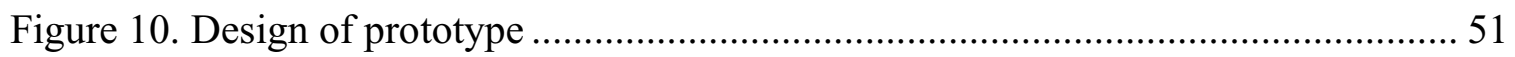

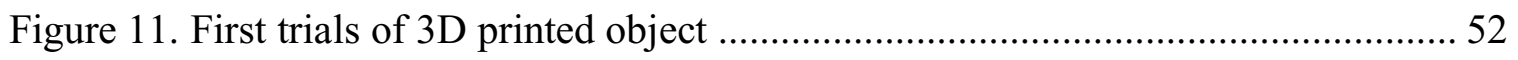

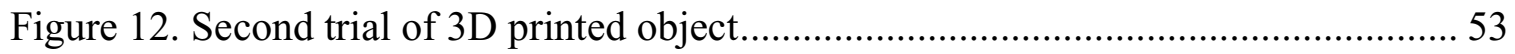

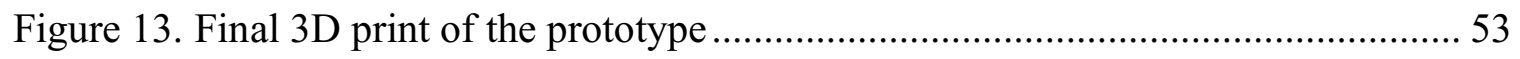

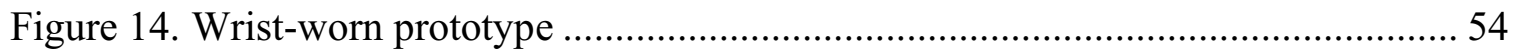

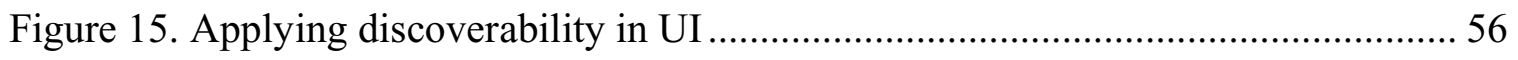

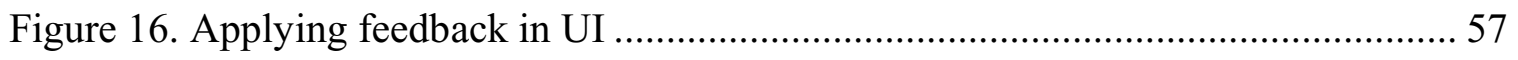

Figure 17. Applying conceptual models in UI ...................................................... 59

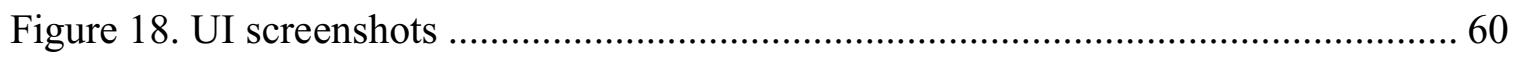

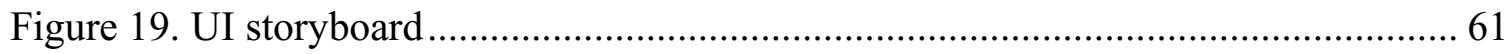

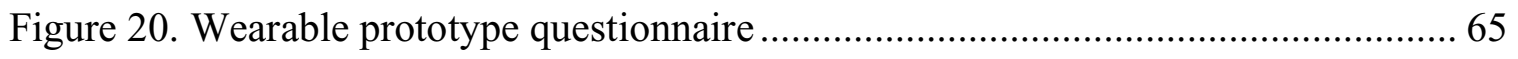

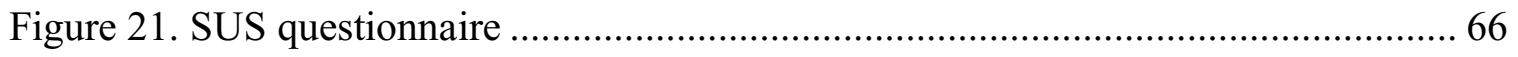


Figure 22. Heart rate vital sign readings... 


\section{Chapter 1: Introduction}

With the growth of information technology, portable devices have developed significantly and become important tools for connectivity [34]. These devices are divided into categories such as tablets, smartphones, and wearables. Wearables refer to any electronic device that a user can wear on an external part of the body either directly (e.g., as a wristband) or indirectly (e.g., embedded in clothes) [33]. Wristbands, rings, and chesttype wearables are usually used to track physiological and health-related parameters, where the use of wearable devices in healthcare can help in early diagnostics [29].

Moreover, wearable devices have the potential to transform healthcare toward a model of connected healthcare [65]. Wearable health devices provide continuous monitoring of physiological data such as electrocardiography, oxygen saturation, pulse, and respiratory rate during daily life [29, 27]. Furthermore, wearable devices are beneficial with regard to the existence of infectious diseases that are more likely to spread in hospital settings, such as COVID-19, because patients can be monitored without any direct contact with healthcare staff [64]. At present, we can see the growth of trendy off-the-shelf wearable devices (e.g., Fitbit, Whoop, Oura Ring), which are equipped with multiple sensors that continuously monitor heart rate and activity data. Today, some wearable devices are used to determine specific changes in physiological parameters (e.g., changes in heart rate) to predict the occurrence of an infectious disease. Radin et al. [48] conducted a retrospective study where they evaluated sensor data that was gathered from people who wore a Fitbit device during the years 2016-2018. They investigated the use of wearable sensor data, specifically sleep data and resting heart rate, and evaluated if sensor data could help predict the trends of seasonal infections such as influenza and increase the influenza 
surveillance in the United States. They found that resting heart rate (RHR) and sleep data derived from Fitbit had a significant effect on improving predictions regarding influenzalike illnesses.

COVID-19 is a disease that is caused by severe acute respiratory syndrome coronavirus 2 (SARS-CoV-2). The COVID-19 pandemic has engendered more than 150 million confirmed cases across the globe [14]. Many hospitals have reached full capacity and are struggling to find ways to manage ICU beds and hospital recourses [36, 17]. The clinical spectrum of the disease varies from mild, where physiological monitoring can be done remotely, to severe cases, which require physiological monitoring within a clinical environment [44]. For non-severe COVID-19 cases, some patients are being consciously monitored at their quarantine location (e.g., home) [44]. From the beginning of the pandemic, several researchers $[44,23,28]$ have studied the use of existing wearable devices and innovative ways to leverage the data in diagnosing and monitoring COVID-19. China was the first to encounter the disease and, thus, the first to search for solutions to accommodate the remote monitoring of patients [44]. They developed remote monitoring through the use of smart phones, by which patients can conduct remote telemedicine consultations and assign their symptoms through applications and websites; approximate monitoring of heart rate and tracking patient's location are also possible. Smarr et al. [23] utilized sensor data from 50 participants who used a wearable device called Oura Ring [7] — a fitness tracker that is worn on the finger to track some physiological parameters such as heart rate - to detect people's early body temperature before the manifestation of COVID-19 symptoms. They found that by using wearable devices to continuously monitor physiological changes, they were able to generate predictions of an illness. Similarly, 
Miller et al. [28] conducted a study using a wearable device called WHOOP [15]—a fitness tracker that is worn on the wrist and tracks a user's sleep, strain (a metric of cardiovascular load during exercise), and recovery - for the early detection of COVID-19. They found that the wearable device was able to determine changes in the respiratory rate, which is an early indication of COVID-19 infection. Despite all examples of utilizing off-the-shelf wearable devices and other telemedicine methods, it is not yet possible to offer all measurements of most vital signs (such as body temperature, respiration rate, or pulse oximetry) in one wearable device. These limitations can diminish the possibility of utilizing these devices for effectively monitoring, tracking, and predicting COVID-19 [42]. Moreover, many of these wearable health-tracking devices have not yet been cleared or approved by the United States' Food and Drug Administration (FDA) [1].

With home healthcare gaining more attention and more wearable healthcare devices being developed, patients have the option to receive care, such as continuous monitoring, from their home rather than a hospital bed. In addition, hospitals are preserving important resources for more critical patients [52]. Nevertheless, usability issues arise in many of these healthcare devices, further emphasizing the importance of usability studies and how they can reduce medical errors and costs and save patients' lives [61].

Mchome et al. [61] conducted a literature survey on usability in healthcare; they found that most usability studies were applied after system implementation to retrieve insights for re-engineering and that usability experts were not included from the beginning of the development process. Although post-implementation usability studies are important, we need to consider including stakeholder groups (e.g., end-users and medical 
professionals) in early design stages and perform usability testing throughout the system modeling process to better understand user needs and requirements.

\subsection{Research Goal}

The aforementioned text highlights the importance of usability studies in healthcare systems as well that of including stakeholders (e.g usability experts and end-users) in the early stages of system development. Usability testing is an evaluation of the usability of a device or system. Usability studies can be designed for internal validity (e.g., in a lab, controlled for variables) or external/ecological validity (e.g., usability studies in real-world settings). The tradeoff between the two is that internal validity affords greater control of variables, resulting in more robust findings. Meanwhile, external, or ecological validity presents researchers with the opportunity to evaluate the usability of a device or system in the situations where it is most likely to be used. In both types, the studies are usually done by inviting potential end-users to complete several tasks related to the system, service, or product being examined. During the usability test, the researcher prepares usability measures, such as questionnaires, interviews, and observations, to collect data that can later be analyzed to identify design flaws and problems during task performances. To this end, we propose a user-centered design approach, in which we include two stakeholders' groups (general users and physicians) in the design process to understand their requirements and levels of acceptance toward wearable health-tracking devices. We chose these two groups because general users are our primary end-users of the wearable device, and we chose physicians because they are important decision makers when it comes to dealing with COVID-19 patients. We designed a novice UI system model with a wearable prototype in which we included stakeholders at the early design stages and throughout the design 
process. Our study contributes to the human and computer interaction (HCI) community by exploring the usability and acceptability of using a wearable health-tracking device with its corresponding UI for COVID-19 out-patient monitoring.

The main objectives of this research were as follows:

1. To evaluate the acceptance of health-monitoring devices for out-patients.

2. To understand physicians' needs regarding COVID-19 out-patient monitoring.

3. To contribute to knowledge in $\mathrm{HCI}$ on the design of wearable devices to support COVID-19 out-patient monitoring.

To pursue these objectives, we conducted two studies. For the first study, our aim was to understand the needs for monitoring COVID-19 patients as well as users' needs in terms of using wearable health-tracking devices. To achieve these, we designed two questionnaires. The first questionnaire targeted local physicians from different specialties (e.g., emergency, medicine, intensive care unit, etc.) who worked with COVID-19 patients. The second questionnaire had a wider and more international audience, targeting general users who could potentially become COVID-19 out-patients. The main research questions were as follows:

A) Research questions related to our first study:

1. Research questions for the patients' questionnaire:

RQ1.1: Which are the most acceptable locations for patients when wearing a health-tracking device? 
RQ1.2: Is data control important for patients (to control which vital signs they are sharing with their healthcare provider)? Moreover, are they comfortable sharing some or all their data?

RQ1.3: Which design features do patients most value in a wearable healthtracking device?

2. Research questions for the physicians' questionnaire:

RQ2.1: What are the most important vital parameters for monitoring COVID19 patients?

RQ2.2: How frequently should vital signs be measured?

RQ2.3: What are the most important features for out-patient monitoring technologies (specifically related to COVID-19 out-patients)?

After completing the investigations, we analyzed our findings and started the second phase of our study, which was an iterative process of designing the UI and wearable health-tracking prototypes. Once this design phase had been completed, we proceeded to the second study. For this, we designed and conducted a usability test for both the wearable prototype and the UI system on five participants. The main research questions were as follows:

B) Research questions related to our second study:

RQ1: How do users perceive the usefulness and acceptability of the wearable device and health application?

RQ2: What are the most important features that must be included in a health application? 


\subsection{Thesis Outline}

This thesis is divided into six chapters. In chapter 1 , we introduce the idea of wearable devices and how it has been utilized in the field of medicine. We further share examples of using wearable devices, such as Fitbit and Oura Rings, during the COVID-19 pandemic. We also elaborate on the importance of co-design and usability studies when designing healthcare technologies. Finally, we conclude the chapter by stating our research goals and main objectives.

In chapter 2, we present a background overview and an examination of the existing literature and related work. We carry out a literature review on papers from several databases, most importantly the papers from the ACM Special Interest Group on Computer-Human Interaction (SIGCHI) conference on Human Factors in Computing Systems (CHI), which is considered one of the most important conferences in the field of HCI. In this chapter, we dig deep into multiple topics related to our study. We start by surveying wearable devices in the healthcare sector and the most common smart wearables that are used in the health sector. Afterward, we review the usage of wearable devices during the COVID-19 pandemic. We also review medical papers that discuss the physiological metrics for COVID-19 with its corresponding sensors, which are summarized in a table. Moreover, we analyze papers that discuss the significance of usability studies and co-design. We also review papers that explain the usage of lowfidelity prototyping. Finally, we talk about the evolution of sensors and wearable materials and how materials can affect the design and function of the wearable device.

In chapter 3, we present two questionnaires used to explore all stakeholders' requirements and needs with regard to a wearable health-tracking device for COVID-19 
out-patients. In the first questionnaire, which was filled out by 195 general users (potential COVID-19 patients), we enquired about user needs in terms of comfort, design, and privacy. In the other questionnaire, we asked physicians from different departments (e.g., emergency, ear, nose, and throat, intensive care unit etc.) to fill out the survey in order to learn more about the important vital signs to be monitored and features that must be added to the wearable device. The results from both questionnaires were used as a benchmark for our design process.

In chapter 4, we present the usability study as well as the design and implementation of both the UI and wearable prototypes. In the design and implementation section, we justify our design choices and present screenshots of both prototypes. We further explain our methodology and study design. Finally, we share our findings and reflect on the results.

Finally, in chapter 5, we summarize our study and recap what we learned and how this study contributes to the HCI community. Furthermore, we share the limitations that challenged us throughout this research project. We conclude by presenting some ideas and plans for our future work. 


\section{Chapter 2: Background and Related Work}

\subsection{Wearable Devices in Healthcare}

Wearable healthcare devices are defined as a new technology that can be worn on the user's body to track and monitor physiological data [29]. Recently, consumer-based wearable devices have been designed to provide users with capabilities to track their own health continuously, such as Fitbit or Apple Watch [46].

Most wearable devices contain similar sensors; for instance, they are almost all equipped with photoplethysmography (PPG), which can distinguish between the different features of circulation using light reflection from the skin surface [29]. By utilizing PPG, we can obtain the blood oxygen saturation ( $\mathrm{SpO} 2)$. In addition, we can derive other parameters, such as respiratory rate and pulse pressure [45]. Electrocardiography (ECG) is one of the most recent sensors that has been included in commercial-based wearable devices. From ECG readings, we can detect the variations of respiration with the heart rate to detect the respiratory rate [58]. Most big technology companies interested in enhancing their wearable devices have included ECG sensors in their devices - for example, Samsung Galaxy Watch Active 2, Withings Move and ScanWatch, Amazfit Verge 2, QardioCore, Hexoskin Smart, and Apple watch 5. The most popular wearable devices are presented in Table 1. 
Table 1. Examples of common smart wearable devices.

\begin{tabular}{|c|c|c|c|c|c|}
\hline Manufacturer & Model & Form Factor & Sensors & Cost & Ref. \\
\hline Whoop & Whoop wristband & Wristband & $\begin{array}{l}\text { Infrared photo- } \\
\text { plethysmography } \\
\text { sensor (PPG), } \\
\text { Accelerometer, } \\
\text { body temperature } \\
\text { sensor, gyroscope }\end{array}$ & $\$ 30$ per month* & [15] \\
\hline Fitbit & Charge & Wristband & $\begin{array}{c}\text { PPG, } \\
\text { Accelerometer, } \\
\text { gyroscope }\end{array}$ & $\$ 200.00$ & [38] \\
\hline Amazfit & Verge & Wristband & $\begin{array}{c}\text { PPG, } \\
\text { Accelerometer, } \\
\text { gyroscope }\end{array}$ & $\$ 115.00$ & [21] \\
\hline Garmin & Vivosmart & Wristband & $\begin{array}{c}\text { PPG, } \\
\text { Accelerometer, } \\
\text { gyroscope, Pulse } \\
\text { Ox2 sensor }\end{array}$ & $\$ 130.00$ & [40] \\
\hline Oura & Oura Ring & Ring & $\begin{array}{c}\text { PPG, } \\
\text { Accelerometer, } \\
\text { gyroscope, body } \\
\text { temperature } \\
\text { sensor }\end{array}$ & $\$ 299.00$ & [7] \\
\hline AVA & Ava Bracelet & Wristband & $\begin{array}{c}\text { PPG, } \\
\text { Electrodermal } \\
\text { Activity (EDA), } \\
\text { Accelerometer, } \\
\text { body temperature } \\
\text { sensor }\end{array}$ & $\$ 249.00$ & [56] \\
\hline Apple & Watch Series 5 & Watch & $\begin{array}{c}\text { PPG, } \\
\text { Accelerometer, } \\
\text { gyroscope, ECG, } \\
\text { BALT }\end{array}$ & $\$ 399.00$ & [69] \\
\hline
\end{tabular}

\subsection{Wearable Devices During COVID-19}

In December 2019, a virus called SARS-CoV-2, also known as COVID-19 was first detected in Wuhan, China. The symptoms of COVID-19 range from none to severe, such as loss of taste, loss of smell, and high temperature. Furthermore, some patients may 
be asymptomatic, making it harder to detect whether they carry the virus. In the wake of COVID-19, scientists and physicians have been leveraging wearable technologies to monitor physiological parameters such as heart rate, respiratory rate, and other relevant functions. The Robert Koch Institute has recently enrolled more than 10,000 volunteers to monitor their temperature, pulse, and sleep using a wearable smartwatch or a fitness tracker to learn how many of them are clinically symptomatic [6].

We found several press releases, online and in the news, that presented the ongoing clinical trials focused on diagnosing and monitoring COVID-19 via wearable sensors. One example is the TemPredict research study, which focused on the changes in the participant's body temperature and heart rate along with other relevant metrics to better understand and characterize COVID-19 [13]. They utilized a commercial wearable device, called Oura Ring, which is worn on the finger to track body temperature and heart rate. Similarly, Central Queensland University collaborated with the Cleveland Clinic and partnered with WHOOP, a wearable health-tracking device company, to investigate the relationship between COVID-19 and respiratory rate [3]. Furthermore, the Scripps Research Institute is currently conducting a research study called DETECT, utilizing a number of smartwatches and fitness tracker devices (such as Apple watch, Garmin, Fitbit, Amazfit, etc.) to identify COVID-19 in patients before the emergence of any symptoms [4]. Moreover, the Ava fertility health tracker is also being used as an early detector of COVID-19 [2]. This device continuously measures temperature and breathing, which can be used to detect COVID-19 early symptoms (such as elevation in body temperature). Mishra et al. [66] conducted a retrospective study to determine if wearable health-tracking devices can be utilized to detect COVID-19 prior to a person being symptomatic. More 
than 5000 participants who were infected with COVID-19 and were using a health-tracking wearable device were enrolled. The authors examined the changes in their physiological parameters close to the time of illness and their association with the symptoms. They were able to detect changes in the physiological parameters before - or during — the emergence of symptoms in more than $85 \%$ of the infected patients.

Catherine et al. [25] has elaborated on the role of mobile health (mHealth) technology, which is the practice of healthcare services on mobile devices, in mitigating the effects of COVID-19. mHealth technology is being used to monitor patients in selfquarantine, who are mostly asymptomatic or have mild symptoms and do not require hospitalization. More importantly, mHealth technologies such as wearable devices can observe the occurrence of exacerbation, wherein the patient experiences some severe symptoms, thus requiring appropriate intervention and hospitalization. Furthermore, wearable devices can detect disease progression, such as subtle physiological changes that are not yet visible in asymptomatic patients. For instance, a patient may have a low level of oxygen saturation, which may not be noticeable without a wearable sensor. Moreover, the authors mentioned that mHealth technologies can also be utilized for post-recovery monitoring, establishing a better understanding of the long-term consequences of COVID19 , and adopting suitable clinical interventions.

\subsection{Physiological Metrics for COVID-19}

There exist several different physiological signs that can be monitored in a human body to gain an understanding of the body's health. When it comes to vital signs related to COVID-19 patients, there are specific physiological signs that must be considered. From 
the literature, we found specific metrics, such as respiration rate (RR), heart rate (HR), resting heart rate ( $\left.\mathrm{HR}_{\text {rest }}\right)$, heart rate variability $(\mathrm{HRV})$, core body temperature (CBT), and arterial oxygen saturation ( $\mathrm{SpO} 2)$, which contain information that can help detect the existence of a COVID-19 infection [32].

Seshadri et al. [32] elucidated in their paper the clinical significance and technical overview of each COVID-19-related physiological metric. In Table 2, we have summarized the physiological metrics relevant to COVID-19 and their corresponding sensors, as mentioned in [32].

Table 2. COVID-19 metrics and sensor modalities.

\begin{tabular}{l|c|c}
\hline \multicolumn{2}{c|}{ Metrics } & Sensor \\
\hline \hline \multirow{2}{*}{ Cardiovascular } & HR & ECG, PPG \\
& HRV & ECG, PPG \\
& Heart Rhythm & ECG, PPG \\
& RHR & ECG, PPG \\
\hline Respiration & & ECG, PPG, Accelerometer \\
\hline SpO2 & & PPG \\
\hline Skin Temperature & & Temperature \\
\hline Core Temperature & ECG, PPG, Temperature \\
\hline \hline
\end{tabular}

\subsection{User-centered Design and Usability}

Bodker et al. [57] had a project called UTOPIA, where they designed a low-fidelity prototype using paper and pencil and provided an opportunity for workers to share their inputs on the workplace technology. Consequently, the participants expressed their 
satisfaction in sharing their design insights and ideas and were happy to see their requirements met in the final product. The user-centered design approach is applied to generate a design solution that is considered usable and fulfils user requirements. Khayal [43] explained the domain of stakeholder requirements, where the stakeholders' needs can be enquired and studied through customer feedback and market research.

Unfortunately, many healthcare technologies are being designed in isolation by technical engineers and healthcare community members with limited or no consideration regarding user requirements. Batalden et al. [51] introduced a co-production framework to healthcare, where professionals offer their expertise in medical science and patients share their perspectives, preferences, and values. This process transforms patients from passive users to active agents. On a specific note, Jayatilaka et al. [16] emphasized the need for more research focused on the acceptance of wearable devices. Furthermore, the authors stated that a well-designed technology can be unsuccessful due to failing to satisfy endusers. In their study, their main objective was to understand users' acceptance and perception of their battery-less wearable device and then come up with a new, updated design according to the user feedback. They found that by providing users with the experience to evaluate the device, they were more confident and trustful in the technology and were able to come up with a design that suited the user needs.

Furthermore, usability in general is a very important topic that should be addressed, and its role is even more crucial when it comes to the usability of technologies in healthcare domains. Philips Electronics [8] stated that in their survey in 2012, 11\% of the participants said that without access to health information from websites or applications, they would have been incapacitated or even dead. Moreover, 27\% of the participants preferred 
interacting with health applications when compared to doctors. Correspondingly, this suggests more need to focus on the usability of such technologies and ensure that the electronic services provided to patients are of high quality as well as functionality and delivers a great user experience. Experts and end-users along with a number of usability measurements can help find design flaws and potential issues [49]. Many studies have revealed that including end-users in the evaluation phase greatly facilitates understanding real design problems [39].

\subsection{Personal Health Information Privacy}

When it comes to accessing patient's health information such as vital parameters and other personal information (e.g., age. gender, etc.), data privacy is a critical issue that is often discussed. Abdelhamid et al. [19] conducted a survey-based study on more than 1600 participants to investigate the reasons which influence individuals in sharing personal health information with their health providers. They found that when it comes to sharing personal information individuals were mainly influenced due to privacy concerns. The authors introduce two main predictors which accordingly show individuals' interest in sharing their personal health information. The first predictor was patient activation which was defined by the individual's health lifestyle and the degree to which the individual wants to be engaged in preventive health. The second predictor was issue involvement which is how important a certain health problem is to that individual. In the context of COVID-19 we can hypothesize that due to the criticality of the virus and the fatality percentage individuals will be more willing and accepting on sharing their personal health information. Further, Whiddett et al. [68] conducted a study on 200 participants where they 
measured the willingness of individuals to share various categories of their information with different type of recipients. They found that participants' willingness in sharing their data depended on the identity of recipient, wherein participants were more willing to share their data with health professionals and less accepting on sharing it with other stakeholders (e.g., researchers). They also found that their willingness depended on the type of information they are sharing where they were less accepting on sharing data that had a more personal nature. Moreover, they articulated the importance of designing adjustable access control policies for future systems to satisfy patient's preferences.

\subsection{Low-Fidelity Prototyping}

A low-fidelity porotype is a common solution used in the early stages of usability studies. It has certain features, such as being cheap, quick to design, adjustable, disposable, and sharable [22]. Many different tools have been used in HCI for fabrications, such as laser-cutting [63] and 3D printing [62]. In 3D printing, a 3D printer uses plastic through a hot nozzle and builds a 3D object layer by layer [62]. Further, a common methodology that is usually applied in usability tests when using a low-fidelity prototype is "Wizard of Oz" [30]. Wizard of $\mathrm{Oz}$ is a method used by usability researchers when testing a product (e.g., system) that is not yet complete or functioning, where the researcher pretends to be the system and simulates how the system operates.

\subsection{Designing Wearable Devices}

Many guidelines exist for designing a wearable device. Gemperle et al. [37] discussed in their paper design guideline categories that communicate the essential 
principles for designing wearable devices. The list below is the suggested guidelines for wearability, which is sorted from simple to more complex:

1. Placement: Where should it be placed on the body.

2. Form language: Deciding on the shape by understanding the human form to ensure comfort and stability.

3. Human movement: Considering human movement and how it introduces constraints and resources.

4. Proxemics: Considering the perception of space. For instance, an extremely thick and bulky wearable device can affect comfort and perception.

5. Sizing: Considering the diversity of body sizes.

6. Attachment: Attaching and wrapping devices around the body.

7. Containment: Considering the inner components of the wearable device (e.g., sensors and other technologies that affect the structure of the device).

8. Weight: Considering the appropriate weight according to the wearable placement on body (i.e., heavier when it is closer to center of gravity, such as the waist, and lighter when spreading to the edges, such as the wrists).

9. Accessibility: Considering the necessary accessibility of the device.

10. Sensory interaction: Sensitive to interactions with the wearable device.

11. Thermal: Considering the three thermal aspects—-functional, biological, and perceptual (i.e., ensuring that the body breathes and not trapping heat while wearing the device).

12. Aesthetics: Aesthetics is an important aspect of the form and function. Culture and context must be considered when thinking about aesthetics. 
13. Long-term use: Testing the device over a long period and understanding its long-term effects.

Zeagler [26] explained the importance of considering social acceptability when designing a wearable device. As an example, he pointed out the time Google Glass faced issues with social acceptance, as the public did not accept having a camera visible on the wearer's face. As shown in Figure 1, Zeagler has developed a body map that helps locate the acceptable placements of a wearable technology.

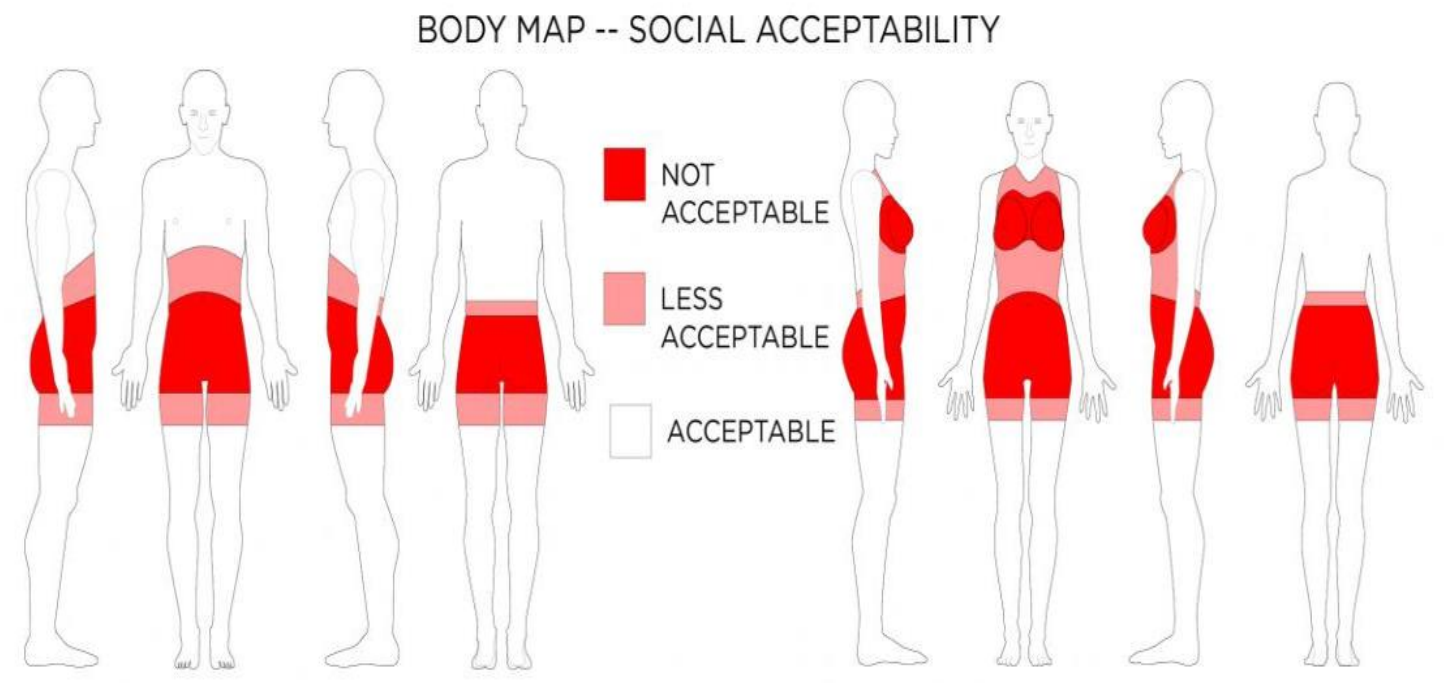

Figure 1. Zeagler's body map on the social acceptance of wearable placement.

In this study, we focus on "placement" as a considerable part of user acceptability depends on the placement of the wearable device. We will also consider "human movement" and investigate the users' comfort when moving and wearing the device. We will also focus on "proxemics" and "weight" as they are important factors in making the device feel comfortable and natural to the user. Correspondingly, we focus on "containment," where we contain all sensors and still focus on the proxemics and weight of the device. Moreover, since this is a device that is expected to be worn by diverse users, "sizing" must be considered. Although the other factors are also important, we will not 
consider them because this study aims to design an initial prototype and test its usability. However, we will investigate other factors in the design process in future works.

\subsection{Sensor Placement on the Body}

The placement of sensors on a human body is based on several factors: accessibility, acceptability, comfort, and-most importantly-the ability to convey data

effectively [24]. Özdemir [18] conducted 2520 tests to examine the best sensor location on the body for a fall-detection sensor for the elderly. The participants placed the sensors in six different locations: right wrist, right thigh, right ankle, head, chest, and waist. Using machine learning, it was found that the most effective placement of the sensor was on the waist, with a $99.96 \%$ sensitivity to fall detection as compared to placing it on the wrist (which is a very common sensor placement in wearable devices). The placement of sensors depends on what we are trying to monitor. For example, to monitor the heart rate, a PPG or a pulse oximeter is usually placed in areas where blood vessels are near the skin surface (e.g. wrist, finger) $[54,67]$. Taking the aforementioned passage and Zeagler's placement acceptability recommendations to mind combined to knowledge that sometimes health sensors have to be positioned in specific areas (e.g., placing an ECG sensor in the chest area for monitoring accuracy) influenced our investigations in the acceptability of sensor placement. Wherein our study we focus on understanding the acceptability of placing COVID-19 related sensors on the patient's body, and whether the context of health and specifically COVID-19 might affect the acceptability rates of sensor placements. The study design is reported in details chapter 3. 


\subsection{Wearable Materials and Device Architecture}

Regardless of the advancement in wearable healthcare technology, it mostly uses bulky components (such CPU, large batteries, etc.), which are heavy to wear continuously and on a daily basis [41]. In the coming decade, it is expected that over $\$ 100$ billion will be invested in wearable materials and device architecture to further pursue the advancement in wearable devices [47]. Consequently, these advances in wearable materials (such as sensors) open new doors for improving wearable design, reliability, size/weight, cost, and usability. One example of advances in wearable material is in [70], a battery-less nano sensor that uses sweat to generate energy. Although this is a solution for developing a small, wearable device that is not reliant on a bulky battery, because it is dependent on body sweat, it can only be used for athletic wearable devices where the user is most likely to sweat. In terms of healthcare devices, this will likely not be as effective and reliable.

During our literature review, we have found that sensors can be integrated in a rigid printed circuit board $(\mathrm{PCB})$ or a flexible $\mathrm{PCB}$. In a rigid $\mathrm{PCB}$, all of the components are connected on the board using rigid and non-bendable materials, as shown in Figure 2-a. (e.g., computer motherboard). On the other hand, a flexible PCB is when the circuit is printed layer by layer and connected vertically, such as the "island-bridge" technique, where the islands are the rigid components (e.g., sensors), and the bridges are the flexible connectors built on a multilayer system, as shown in Figure 2-b.

Flexible PCBs can be utilized in many healthcare-related applications and create opportunities for more flexible wearable devices [71]. Flexible PCB is a good option because most commercial wearable sensors are bulky and not comfortable for users. Moreover, most off-the-shelf devices, such as Fitbit and WHOOP, are worn on one part of 
the body (e.g., wrist), so not all vital signs are monitored effectively from the same body position. One method is to use more than one sensor to monitor multiple parameters accurately. Nevertheless, we believe that by using soft sensors and connecting via one cloud, we can make a more effective, acceptable, and user-friendly wearable healthtracking device that can be used during this pandemic, future epidemics, or for chronic illnesses. Although the scope of this research doesn't cover developing or utilizing real miniatured sensors, we thought it is important to understand the materials, components, and architecture of these sensors to be able to better design and mimic the look and feel of real sensors when developing the wearable prototype.

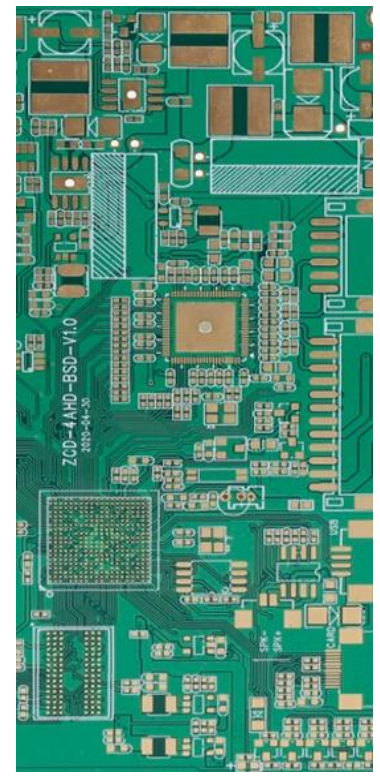

(A)

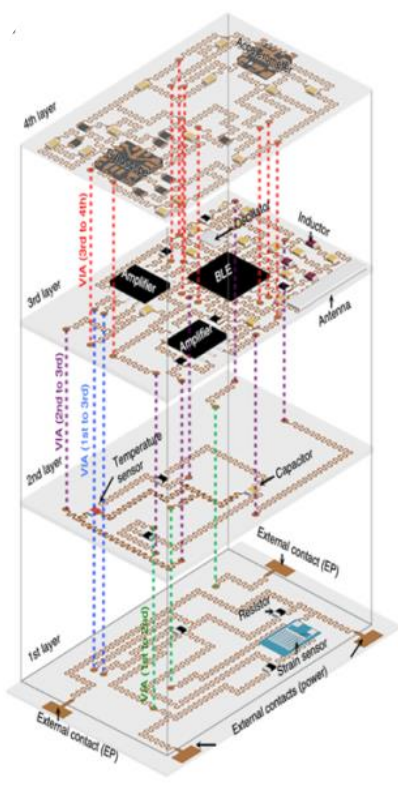

(B)

Figure 2. Difference between rigid and flexible circuits: A) One-layer design of a rigid circuit [11]. B) Layers of a flexible circuit [71]. 


\section{Chapter 3: Online Survey Study}

In this chapter, we will present the first phase of our research study, which was an online survey. We designed two different questionnaires: i) for general users and ii) for physicians. Each questionnaire helped us garner knowledge toward user acceptance and monitoring requirements.

\subsection{A: General User Survey}

\subsubsection{Research Questions}

As mentioned earlier, for this study, we had three main research questions:

RQ1: Which are the most acceptable locations for patients when wearing a health-tracking device?

RQ2: Is data control important for patients (to control which vital signs they are sharing with their healthcare provider)? Moreover, are they comfortable sharing some or all their data?

RQ3: Which design features do patients most value in a wearable health-tracking device?

\subsubsection{Methodology}

We designed a questionnaire using Google Forms, which consisted of 16 questions. The survey was conducted with a general population to determine mainly the following:

1. Rates of acceptance on the quantity and position of the wearable device.

2. Rates of importance on physiological data control.

3. User preferences in the design and functionality of wearable devices. 
In addition, there were four questions for gathering demographic information, such as age group, gender, level of education, and technology experience. This research has been granted clearance (Project \# 115372) by the Carleton University Research Ethics Board-B (CUREB-B).

\subsubsection{Participants}

Our participants were general users who spoke English, were older than 18 years, and have experience with any sort of technologies (e.g., smartphone, fitness tracker, smartwatch, etc.). We chose general users because potential COVID-19 out-patients do not comprise a specialized group with provided skills or specific knowledge base; thus, we believed that the general population would be a good fit for a user-centered design study.

We used virtual snowball sampling method via social networks as a channel for recruiting participants. We posted electronic posters on Facebook groups and other social network platforms, such as WhatsApp. The e-poster explained the study clearly and included a link to the questionnaire, as shown in Appendix A.1. Those who wished to participate in the study could access the attached link, sign the consent form (included in the questionnaire link), and fill out the questionnaire; both the questionnaire and consent form can be found in Appendix A.2. Our sample included 195 participants who fit the aforementioned inclusion criteria (over 18 years old, understands English, and a user of one or more of the following technologies: smartphone, fitness tracker, smart watch, etc).

\subsubsection{Results}

In this section, we present the results obtained from Questionnaire A. 


\subsubsection{Demographics}

The majority $(75.8 \%)$ of the participants were female, and the rest $(24.2 \%)$ were male. Their ages ranged from 18 to 75 years; however, $67 \%$ of the participants were in the age range of 18 to 35 years. More than half of the participants (57.4\%) had completed their bachelor's degree, and some (21\%) had graduate and post-doctoral education. Others $(13.3 \%)$ had only graduated from high school. Further, more than half $(59.4 \%)$ of the participants considered themselves tech savvy, some (36\%) rated themselves as neutral, and others $(4.5 \%)$ considered themselves novice users.

\subsubsection{Acceptance}

In this section, we present the acceptability rates on wearable placement and the number of wearable devices that are thought to be tolerable and acceptable by the user. Users rated the acceptance of wearable positioning according to the body figure presented in the questionnaire, as shown in Figure 3. 


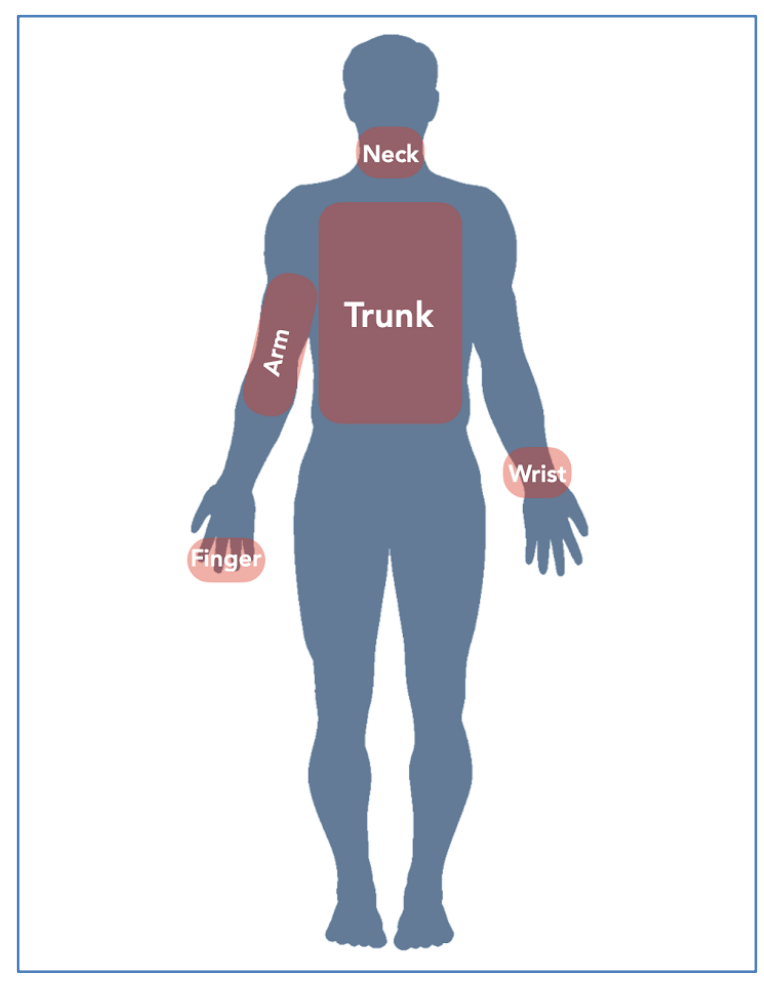

Figure 3 Body figure presented in the questionnaire forbody placement acceptability

As shown in Figure 4, the participants reacted to a five-point Likert scale (where 1 is "not acceptable" and 5 is "very acceptable") to the following positions: i) finger, ii) wrist, iii) arm, iv) trunk, and v) neck. From the graph, we can see that 137 participants rated wearing a wearable device on a wrist as acceptable or very acceptable, only 22 participants rated it as less acceptable or not acceptable at all, and only 32 participants rated it as neutral. This indicates that the wrist is a wearable position that is considered most acceptable as compared to the trunk or neck, which are negatively skewed. More than 100 participants rated wearing a wearable device on trunk or neck as unacceptable. Meanwhile, the data related to the arm and finger was normally distributed. 


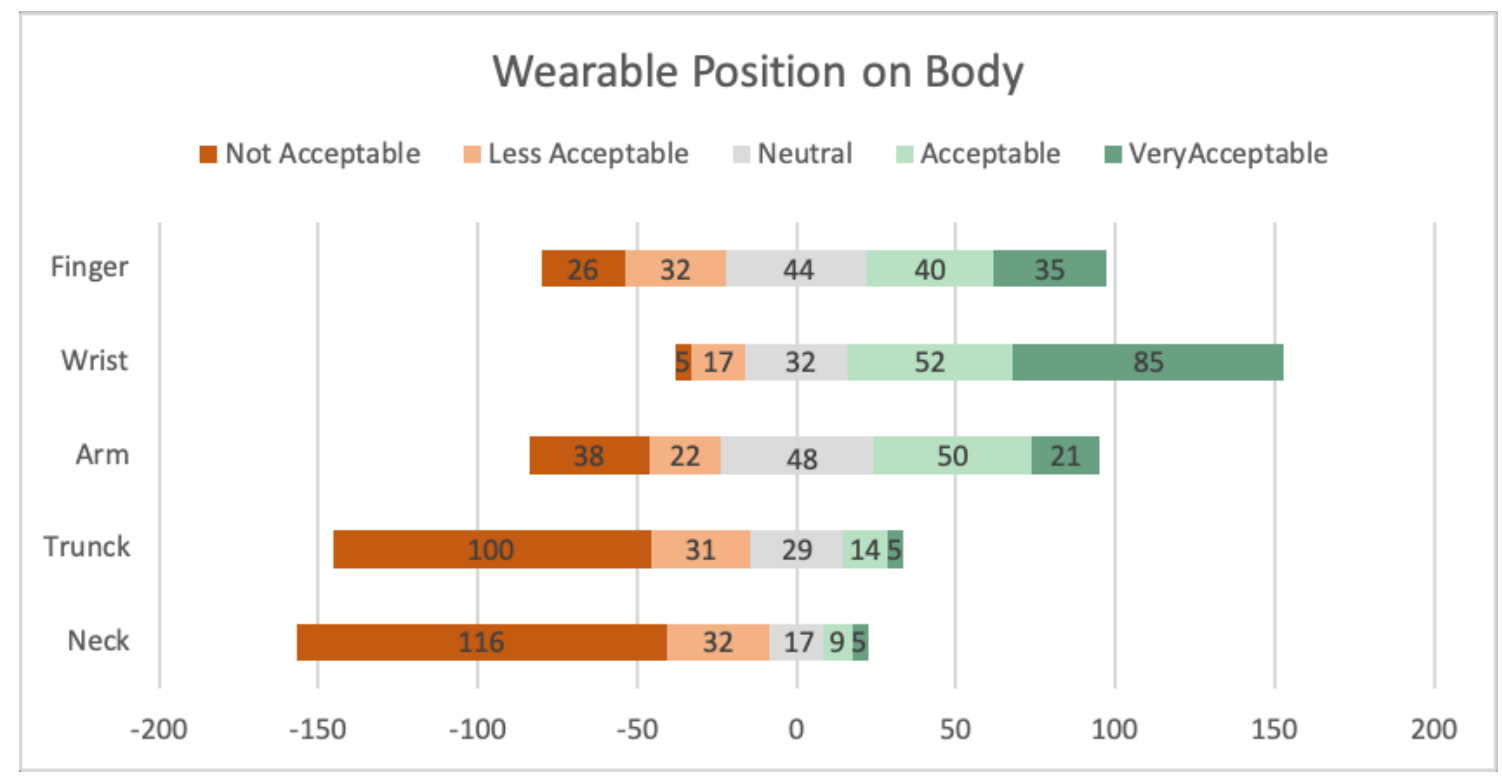

Figure 4. Wearable position on the body.

Moreover, the results show that $21.8 \%$ of the participants accepted wearing more than one device to track their health (e.g., wearing a ring to track the level of oxygen, a neck monitor to track cough patterns, and a chest monitor to track the heart rate). However, $37.6 \%$ of the participants did not accept wearing more than one device, and $36.5 \%$ of the participants responded with "maybe". Furthermore, one participant agreed to use more than one device only if it was deemed necessary, and another responded that it was acceptable only if it was comfortable to wear.

\subsubsection{Privacy and Control}

Using the questionnaire, we asked the participants if it is important to control sharing their vital signs with their physician (e.g., control sharing their pulse rate with their physician). In answer, $60.9 \%$ of the participants responded with "yes", while $10.2 \%$ responded with "no"; $27.9 \%$ of the participants responded with "maybe". 
Furthermore, as shown in Figure 5, most participants (more than 154) agreed or strongly agreed on sharing their body mass index (BMI), age, and vital signs with their physicians. However, regarding sharing the global positioning system (GPS), 86 participants did not agree on sharing their GPS locations to their healthcare physicians, 53 participants agreed on sharing, and 53 participants rated it neutrally.

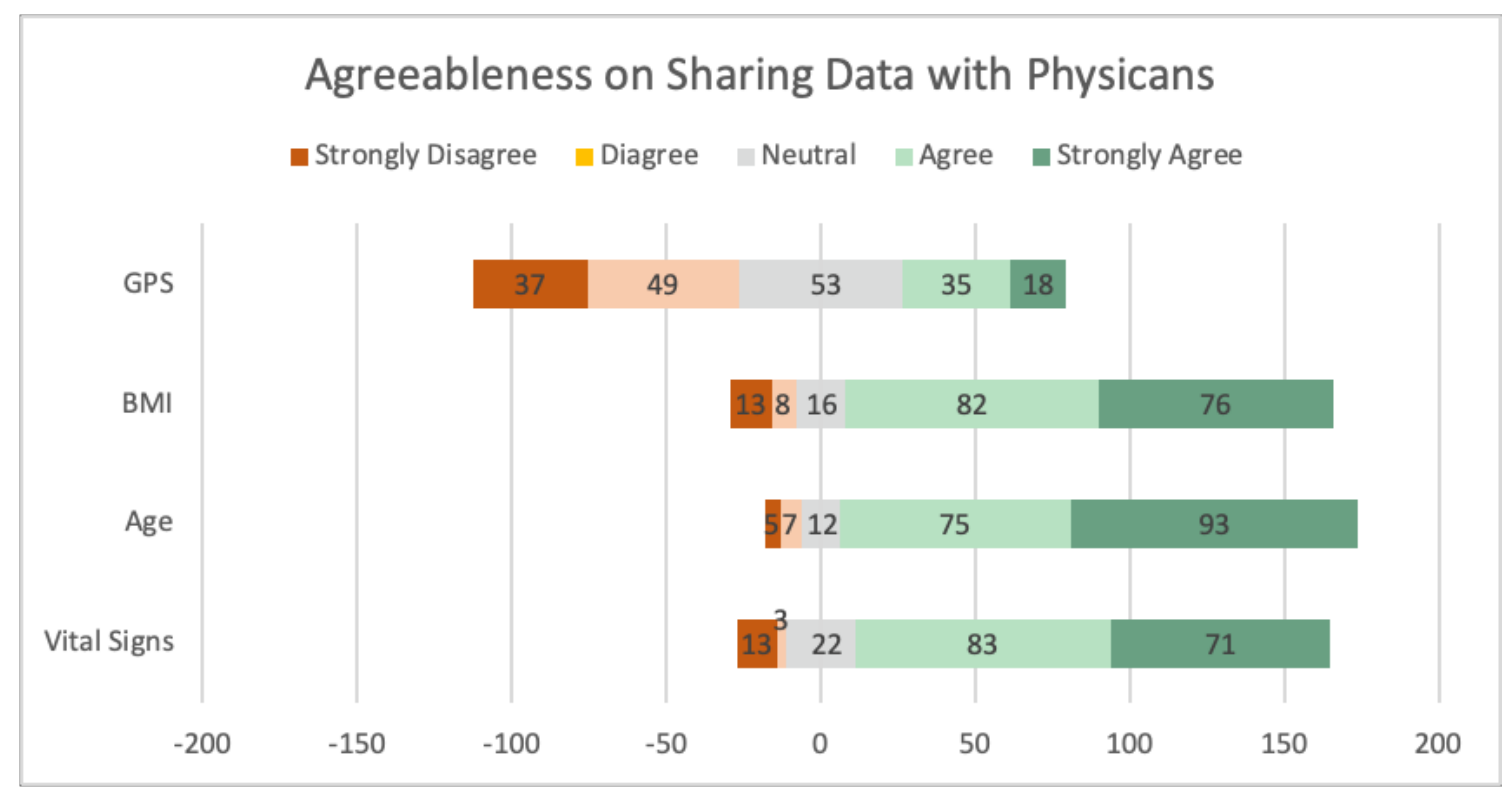

Figure 5. Agreeableness on sharing data with physicians.

\subsubsection{Wearable Features and Functionalities}

One of the functionalities of wearable devices is to be able to access the data from the wearable device itself, through an application embedded in a mobile device or accessible from both. In response to the questionnaire, $54.6 \%$ of the participants responded that it was important to view the data from both the wearable device and a mobile application, $30.6 \%$ responded that it was important to access the data from a mobile application, $7.1 \%$ responded that it was important to access the data directly from the wearable device, and $6.6 \%$ were not sure. We asked the participants if using an active 
wearable device through which they could interact with their data affected their selfawareness in terms of health. In answer, $58.2 \%$ of the participants responded with "yes", 19.4\% responded with "no", and 22.4\% responded with "maybe". Furthermore, one of the wearable functionalities we enquired about was the ability to receive alert messages on the wearable device. In answer, $77.4 \%$ of the participants responded with "yes", stating that it was important to receive alert messages on the device. Meanwhile, $5.1 \%$ responded with "no", and $17.4 \%$ responded with "maybe". Additionally, the participants rated the most important functionality specifications of a wearable device. As summarized in Table 3, $80.5 \%$ of the participants rated having a long battery life as being an important feature, $66.7 \%$ rated the importance of having daily activity monitoring, $36.9 \%$ rated the importance of having automated fall detection, $46.2 \%$ rated the importance of supporting multiple languages, and $47.70 \%$ rated the importance of having a $24 / 7$ access to technical support.

Table 3. Checkbox data results of the most important functionalities in a wearable healthcare device.

Wearable Functionalities

Long Battery Life

Daily Activity Monitoring

Automated Fall Detection

Accepts Multiple Languages

24/7 Access to Technical Support
Participants

$80.50 \%$

$66.70 \%$

$36.90 \%$

$46.20 \%$

$47.70 \%$

\subsubsection{Price}


According to the questionnaire, $50.3 \%$ of the participants responded that prices ranging from 101 USD to 400 USD was the most acceptable for a wearable device. However, $31.3 \%$ responded that an acceptable price range was less than $100 \$, 8.7 \%$ responded that $400 \$$ to $600 \$$ was an acceptable price range, and only $1.5 \%$ accepted a price range between $601 \$$ and $1000 \$$. Some $(3.6 \%)$ participants responded that any price was acceptable, while a few (1\%) responded that it depended on the quality and performance.

\subsubsection{Design and Material}

We asked the participants to rate the level of importance on wearable aesthetics and design. As shown in Figure 6, most (134) participants rated aesthetics as important or very important in a wearable device, some (51) rated it neutrally, and only a few (5) rated it as not important.

Furthermore, the participants had to choose the most important design specification required in a wearable device. As summarized in Table 4, most (83.7\%) participants chose water resistance and light weight, while some (61.2\%) participants stated that smash resistance was an important design feature. Others (45.9\%) voted for the importance of being made of a durable material. Furthermore, a number (40.8\%) of participants stated that it was important for the device to be aesthetically pleasing, and one participant specified the importance of supporting different sizes. 


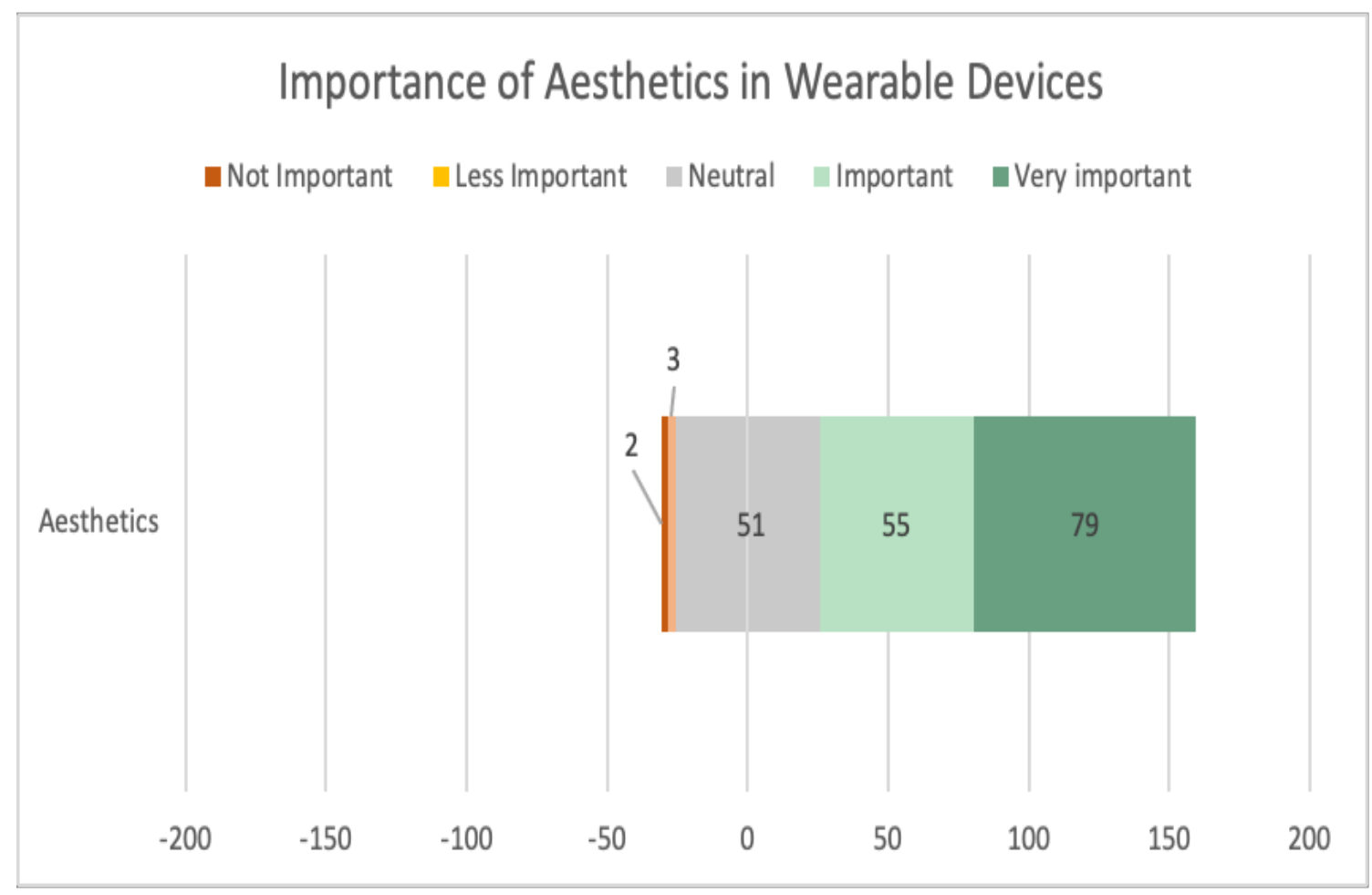

Figure 6. Importance of aesthetics in wearable devices.

Table 4. Checkbox data results of the most important design specifications in wearable devices.

Design Specification

Participants

\begin{tabular}{lc}
\hline \hline Water Resistance & $83.70 \%$ \\
Light Weight & $83.70 \%$ \\
Smash Resistance & $61.20 \%$ \\
Durable Material & $45.90 \%$ \\
Aesthetically Pleasing & $40.80 \%$ \\
\hline \hline
\end{tabular}

\subsubsection{Statistical Analysis}

To look for any association between our variables, we used chi-square test of independence which is a non-parametric test. Before we started the statistical analysis, we 
had to manipulate the datasets in order to conduct a statistical analysis. There was one participant in the age group 66-75, so we combined them with the age group 56-65 and named this group 56 and older. Table 5 demonstrates the comparison of the participants' acceptance toward the positioning of wearable devices across ages. A significant difference in the acceptance of wearing wrist monitoring devices was seen across age groups $(\mathrm{p}<$ $0.001)$, wherein the age group with the highest acceptance rate was the $18-25$ one. The age group with the lowest acceptance rate was the 56 and older group. No significant difference was seen across age groups regarding the acceptance of wearing a tracking device on the neck, trunk, arm, and finger. It is worth mentioning that overall, the position with the highest rate of acceptance was wrist $(71.4 \%)$, while neck and trunk positioning were notable highly not accepted (92.6\% and $91 \%$, respectively). It should be noted that device acceptance was re-defined to make the comparison possible; the definition of "no acceptance" included those who chose "not accepted", "less accepted", and "neutral", while the definition of "acceptance" included those who chose "acceptable" and "very acceptable".

Table 6 illustrates the comparison of the participants' acceptance toward the positioning of wearable device across gender. No significant difference in the acceptance of positioning the monitoring device was observed across gender. 
Table 5. Comparison of the participants' acceptance toward the positioning of wearable devices across ages.

\begin{tabular}{|c|c|c|c|c|c|c|c|}
\hline \multirow[b]{2}{*}{$\begin{array}{c}\text { Position of } \\
\text { Wearable Device }\end{array}$} & \multicolumn{5}{|c|}{ Age } & \multirow[b]{2}{*}{ Total } & \multirow[b]{2}{*}{$\begin{array}{c}\mathrm{P}- \\
\text { Value }\end{array}$} \\
\hline & $\begin{array}{l}18-25 \\
\text { years }\end{array}$ & $\begin{array}{c}26-35 \\
\text { years }\end{array}$ & $\begin{array}{l}36-45 \\
\text { years }\end{array}$ & $\begin{array}{l}46-55 \\
\text { years }\end{array}$ & $\begin{array}{c}56 \\
\text { years } \\
\text { and } \\
\text { older } \\
\end{array}$ & & \\
\hline \multicolumn{8}{|l|}{ Neck } \\
\hline Not accepted & $\begin{array}{c}62 \\
(93.9 \%)\end{array}$ & $\begin{array}{c}51 \\
(85 \%)\end{array}$ & $\begin{array}{c}37 \\
(97.4 \%)\end{array}$ & $\begin{array}{c}16 \\
(100 \%)\end{array}$ & $\begin{array}{c}9 \\
(100 \%)\end{array}$ & $\begin{array}{c}175 \\
(92.6 \%)\end{array}$ & \multirow[t]{2}{*}{0.075} \\
\hline Accepted & $4(6.1 \%)$ & $9(15 \%)$ & $\begin{array}{c}1 \\
(2.6 \%)\end{array}$ & $0(0 \%)$ & $0(0 \%)$ & $\begin{array}{c}14 \\
(7.4 \%)\end{array}$ & \\
\hline \multicolumn{8}{|l|}{ Trunk } \\
\hline Not accepted & $\begin{array}{c}59 \\
(89.4 \%)\end{array}$ & $\begin{array}{c}53 \\
(88.3 \%)\end{array}$ & $\begin{array}{c}35 \\
(92.1 \%)\end{array}$ & $\begin{array}{c}16 \\
(100 \%)\end{array}$ & $\begin{array}{c}9 \\
(100 \%)\end{array}$ & $\begin{array}{c}172 \\
(91 \%)\end{array}$ & \multirow{2}{*}{0.515} \\
\hline Accepted & $7(10.6 \%)$ & $\begin{array}{c}7 \\
(11.7 \%)\end{array}$ & $\begin{array}{c}3 \\
(7.9 \%)\end{array}$ & $0(0 \%)$ & $0(0 \%)$ & $17(9 \%)$ & \\
\hline \multicolumn{8}{|l|}{ Arm } \\
\hline Not accepted & $\begin{array}{c}36 \\
(54.5 \%)\end{array}$ & $\begin{array}{c}34 \\
(56.7 \%)\end{array}$ & $\begin{array}{c}27 \\
(71.1 \%)\end{array}$ & $\begin{array}{c}12 \\
(75 \%)\end{array}$ & $\begin{array}{c}8 \\
(88.9 \%)\end{array}$ & $\begin{array}{c}117 \\
(61.9 \%)\end{array}$ & \multirow{2}{*}{0.112} \\
\hline Accepted & $\begin{array}{c}30 \\
(45.5 \%)\end{array}$ & $\begin{array}{c}26 \\
(43.3 \%)\end{array}$ & $\begin{array}{c}11 \\
(28.9 \%)\end{array}$ & $4(25 \%)$ & $\begin{array}{c}1 \\
(11.1 \%)\end{array}$ & $\begin{array}{c}72 \\
(38.1 \%)\end{array}$ & \\
\hline \multicolumn{8}{|l|}{ Wrist } \\
\hline Not accepted & $\begin{array}{c}15 \\
(22.7 \%)\end{array}$ & $\begin{array}{c}11 \\
(18.3 \%)\end{array}$ & $\begin{array}{c}13 \\
(34.2 \%)\end{array}$ & $\begin{array}{c}7 \\
(43.8 \%)\end{array}$ & $\begin{array}{c}8 \\
(88.9 \%)\end{array}$ & $\begin{array}{c}54 \\
(28.6 \%)\end{array}$ & \multirow{2}{*}{$\begin{array}{c}< \\
0.001 *\end{array}$} \\
\hline Accepted & $\begin{array}{c}51 \\
(77.3 \%)\end{array}$ & $\begin{array}{c}49 \\
(81.7 \%)\end{array}$ & $\begin{array}{c}25 \\
(65.8 \%)\end{array}$ & $\begin{array}{c}9 \\
(56.3 \%)\end{array}$ & $\begin{array}{c}1 \\
(11.1 \%)\end{array}$ & $\begin{array}{c}135 \\
(71.4 \%)\end{array}$ & \\
\hline \multicolumn{8}{|l|}{ Finger } \\
\hline Not accepted & $\begin{array}{c}36 \\
(54.5 \%)\end{array}$ & $\begin{array}{c}34 \\
(56.7 \%)\end{array}$ & $\begin{array}{c}22 \\
(57.9 \%)\end{array}$ & $\begin{array}{c}11 \\
(68.8 \%)\end{array}$ & $\begin{array}{c}8 \\
(88.9 \%)\end{array}$ & $\begin{array}{c}111 \\
(58.7 \%)\end{array}$ & \multirow{2}{*}{0.237} \\
\hline Accepted & $\begin{array}{c}30 \\
(45.5 \%)\end{array}$ & $\begin{array}{c}26 \\
(43.3 \%)\end{array}$ & $\begin{array}{c}16 \\
(42.1 \%)\end{array}$ & $\begin{array}{c}5 \\
(31.3 \%)\end{array}$ & $\begin{array}{c}1 \\
(11.1 \%)\end{array}$ & $\begin{array}{c}78 \\
(41.3 \%)\end{array}$ & \\
\hline Total & $\begin{array}{c}66 \\
(34.9 \%)\end{array}$ & $\begin{array}{c}60 \\
(31.7 \%)\end{array}$ & $\begin{array}{c}38 \\
(20.1 \%)\end{array}$ & $\begin{array}{c}16 \\
(8.5 \%)\end{array}$ & $\begin{array}{c}9 \\
(4.8 \%)\end{array}$ & $\begin{array}{c}189 \\
(100 \%)\end{array}$ & - \\
\hline
\end{tabular}

* Significant at level 0.05 
Table 6. Comparison of the participants' acceptance towards the positioning of wearable devices across gender.

\begin{tabular}{|c|c|c|c|c|}
\hline \multirow{2}{*}{ Position of Wearable Device } & \multicolumn{2}{|c|}{ Gender } & \multirow{2}{*}{ Total } & \multirow{2}{*}{ P-Value } \\
\hline & Male & Female & & \\
\hline \multicolumn{5}{|l|}{ Neck } \\
\hline Not accepted & $\begin{array}{c}43 \\
(95.6 \%)\end{array}$ & $132(91.7 \%)$ & $\begin{array}{c}175 \\
(92.6 \%)\end{array}$ & 0.385 \\
\hline Accepted & $2(4.4 \%)$ & $12(8.3 \%)$ & $14(7.4 \%)$ & \\
\hline \multicolumn{5}{|l|}{ Trunk } \\
\hline Not accepted & $\begin{array}{c}40 \\
(88.9 \%)\end{array}$ & $132(91.7 \%)$ & $\begin{array}{c}172 \\
(91 \%)\end{array}$ & 0.570 \\
\hline Accepted & $5(11.1 \%)$ & $12(8.3 \%)$ & $17(9 \%)$ & \\
\hline \multicolumn{5}{|l|}{ Arm } \\
\hline Not accepted & $27(60 \%)$ & $90(62.5 \%)$ & $\begin{array}{c}117 \\
(61.9 \%)\end{array}$ & 0.763 \\
\hline Accepted & $18(40 \%)$ & $54(37.5 \%)$ & $\begin{array}{c}72 \\
(38.1 \%) \\
\end{array}$ & \\
\hline \multicolumn{5}{|l|}{ Wrist } \\
\hline Not accepted & $\begin{array}{c}14 \\
(31.1 \%)\end{array}$ & $40(27.8 \%)$ & $\begin{array}{c}54 \\
(28.6 \%)\end{array}$ & 0.666 \\
\hline Accepted & $\begin{array}{c}31 \\
(68.9 \%) \\
\end{array}$ & $104(72.2 \%)$ & $\begin{array}{c}135 \\
(71.4 \%) \\
\end{array}$ & \\
\hline \multicolumn{5}{|l|}{ Finger } \\
\hline Not accepted & $27(60 \%)$ & $84(58.3 \%)$ & $\begin{array}{c}111 \\
(58.7 \%)\end{array}$ & 0.843 \\
\hline Accepted & $18(40 \%)$ & $60(41.7 \%)$ & $\begin{array}{c}78 \\
(41.3 \%)\end{array}$ & \\
\hline Total & $\begin{array}{c}45 \\
(23.8 \%)\end{array}$ & $144(76.2 \%)$ & $\begin{array}{c}189 \\
(100 \%)\end{array}$ & - \\
\hline
\end{tabular}

*Significant at level 0.05 


\subsubsection{Discussion}

From our results, we identified user acceptability and requirements about the use and design of wearable health-tracking devices. These results can help us in the design process and provide design recommendations for healthcare wearable designers and developers.

From previous literature, we expected that the most acceptable wearable placement on a patient's body was on the wrist, and we noticed that it was especially important to young adults. This may be because many young adults are used to wearing commercial wearables that are worn on the wrist (e.g., Apple watch, Fitbit, etc.); consequently, the participants were more familiar with it and, therefore, more accepting toward it. However, when it comes to functionality, the position of a sensor on the body can drastically affect the accuracy of data. For instance, to accurately monitor oxygen saturation, a pulse oximetry (which is a non-invasive monitor that reads oxygen saturation in the blood using two wavelengths of light) is best placed on a finger [50]. Moreover, until recently, tracking electrical signals in your heart (i.e., ECG) could only be done in a doctor's office or a clinic, where they attach up to 12 sensors (electrodes) to the patient's chest and limbs for accurate analysis. Hence, even though user acceptance in sensor positioning is important, it is even more crucial for the wearable to be accurate and reliable. Thus, a balance must be struck between user preferences and data accuracy. We can explore many methods to achieve data accuracy; one of them may involve using multiple wearable sensors that are connected via one network, such as using the internet of things (IoT), where data from all sensors can be combined and provide full and accurate analysis of physiological data. This may be a solution in terms of accuracy, but according to our results, $37.6 \%$ of the participants did 
not agree on wearing multiple devices to track their health parameters, and only $21.8 \%$ agreed on it, while the rest were indifferent. This creates a challenge in terms of designing acceptable and functional wearable devices. Fortunately, with the advancement of sensors, monitoring health parameters have become much simpler. One example of sensor advancement can be seen in the new generation of Apple Watch [12], which is equipped with an ECG sensor and is more user-friendly; they have also made it much easier for a normal consumer to monitor their cardiac rhythm. Hence, we can argue that the design improvement of wearable healthcare devices is much affected by the evolution of sensor technology.

Regarding privacy concerns, it was interesting to see that most of the participants were open to sharing their personal data, such as physiological information and age, with their physicians. However, it was not clear if participants agreed on sharing their personal information continuously or only during specific time intervals (e.g., sharing it for only 6 hours a day). When it came to GPS, we understood that this is considered highly privileged information and we anticipated that our participants would likely not be agreeable on sharing it; however, in the context of the COVID-19 pandemic, it may be important to monitor this data as controlling the spread of the virus during the contagious period is a matter of public health, as was shown in the China study [44]. As predicted, participants were less agreeable about sharing their GPS location. In general, participants were very eager about controlling their own data, in terms of controlling what they wanted to share with their physicians and what they wished to keep private. For example, if the GPS information is not mainly required from a patient, then they are able to control this function and keep it private; likewise, if patients are required to share their age and vital signs, then 
patients can accept and share them with their physicians. Design and aesthetics are very important for users. Although the aim of the wearable health tracking device is mainly for COVID-19 out-patients, it was interesting to see the high importance of aesthetics and design for users. In addition to the feel and look of a wearable device, the participants believed that the device must be practical and durable. They strongly stressed the importance of a water-resistant and light-weight wearable device. This is important and should be considered in the design process and when choosing materials and fabrication technologies.

\subsubsection{Limitations}

In our study we have encountered a small number of limitations that could potentially have affected the accuracy of our findings. Firstly, the phrasing or lack of clarifying details of some of our survey questions might have introduced ambiguity in participants' responses. One example can be found when participants have agreed on sharing some data with physicians (i.e., BMI, age, etc.) their answers lacked details on moment specificity, which made us unable to differentiate whether they agreed on sharing these data generally, at a specific time or under specific conditions. Although our recruitment and consent materials indicated that the focus of this this study was wearables for COVID-19 out-patients, this context was absent from some of our survey questions. In other words, it is possible that some of our participants answered some questions more generally about wearables and not specifically about a wearable device that would only be worn to monitor their at-home recovery from COVID-19. As a result, our findings can only guide us to better understand general user preferences for health monitoring. In addition, 
as with all survey-based research, we must also consider the limitations of self-reported data and how participants may have interpreted the questions provided to them. For example, recognizing that on a Likert scale, participants' individual interpretations of the weight of the values can have an impact on results. Lastly, we used snowballing method for our recruitment, which can result in a more biased or homogenous sample. Participants might have come from similar backgrounds (e.g., same socio-cultural, socio-economic, or other background). Hence, we must be aware of these limitations and the quality of the results when interpreting our findings. As for future direction, we intend to look more closely at survey design guiding similar research on COVID-19 outpatient monitoring research.

\subsection{B: Physicians Survey}

\subsubsection{Research Questions}

As previously mentioned, we have three main research questions:

RQ1: What are the most important vital parameters for COVID-19 patients?

RQ2: How frequently should vital signs be measured?

RQ3: What are the most important features for out-patient monitoring technologies (specifically related to COVID-19 out-patients)?

\subsubsection{Methodology}

We designed a questionnaire using Google Forms; it consisted of seven questions. The survey was conducted with working staff (physicians) to determine mainly the following:

1. Vital parameters for COVID-19 patients. 
2. Measurement frequency of vital signs.

3. Features related to monitoring vital signs.

In addition, there was a question for gathering demographic information (i.e., physician's specialty).

\subsubsection{Participants}

For this questionnaire, we included working physicians from four main departments: i) internal medicine (including infectious diseases and pulmonology), ii) intensive care unit, iii) emergency medicine, and iv) family medicine. These four specialties are the most likely to care for COVID-19 patients due to the nature of the disease; hence, these physicians will have more experience and knowledge of the healthcare and monitoring needs when treating these patients. Physicians from other departments who had some experience with COVID-19, such as ophthalmology and earnose-and-throat specialists, were also invited to participate in the study.

We used virtual snowball sampling via social networks as a channel for recruiting participants. We posted electronic posters on medical groups in social network platforms, such as WhatsApp. The e-poster explained the study clearly and included a link to the questionnaire, as shown in Appendix A.1. Those who wished to participate in the study could access the attached link, sign the consent form (included in the questionnaire link), and fill out the questionnaire; both the questionnaire and consent form can be found in Appendix A.3. Our sample included 53 participants who fit our inclusion criteria (attending staff who are working with COVID-19 patients and who are able to communicate in English). 


\subsubsection{Results}

In this section, we present the results from Questionnaire B (Physicians): 36.7\% of the participants were from the emergency department, $32.7 \%$ were from the intensive care unit department, and the rest were from ear, nose, and throat (6.1\%), ophthalmology (4.1\%), surgery $(6.1 \%)$, and other specialties $(10.1 \%)$.

We asked the participants to rate the most important COVID-19 physiological data that needed to be monitored. As shown in Figure 7, 35 participants rated it as important or very important to monitor body temperature, 8 rated it as neutral, and 6 rated that it is not important or less important. Regarding blood pressure, 19 participants rated it as important or very important, 14 rated it as neutral, and 14 rated it as not important or less important. As for the oxygen saturation, 39 participants rated it as very important or important, 4 rated it as neutral, and 4 rated it as not important or less important. Moreover, 31 participants rated monitoring the pulse rate as important or very important, 10 rated it as neutral, and 6 rated it as not important or less important. Regarding the respiration rate, 34 participants rated it as important or very important, 6 rated it as neutral, and 5 rated it as not important or less important. Only 16 participants rated monitoring cough patterns as important or very important; 16 rated it as neutral, and 15 rated it as not important or less important. 


\section{Important Covid-19 Physiological Parameters}

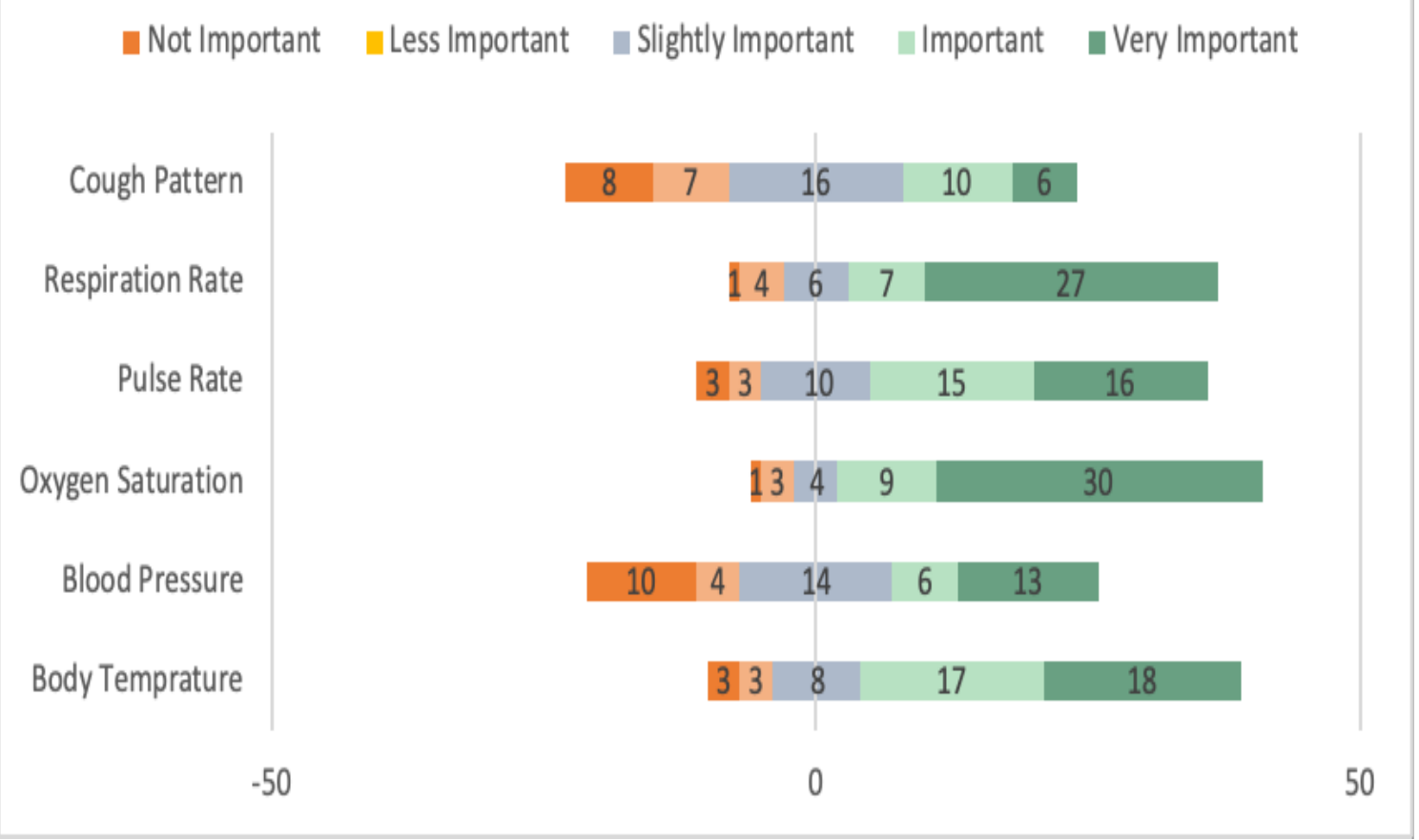

Figure 7. Important COVID-19 physiological parameters.

Furthermore, we asked the participants about the frequency of monitoring physiological parameters for COVID-19 out-patients. In answer, $40.8 \%$ of the participants recommended that patients should be monitored every 6 hours, $20.4 \%$ recommended every 4 hours, $18.4 \%$ recommended every 24 hours, $8.2 \%$ recommended every 8 hours, $4.1 \%$ recommended every 12 hours, and $4.1 \%$ recommended every 2 hours.

In the questionnaire, we inquired about the specifications regarding monitoring the vital signs of COVID-19 out-patients. As illustrated in Figure 8, 44 participants rated that it was important or very important to send alerts and messages to patients, 2 participants rated it as neutral, and 3 rated it being less important. The GPS positioning of out-patients was considered important or very important by 28 participants, while 11 participants rated 
it as neutral and 10 rated it as not important or less important. Regarding the time-stamped measurements (i.e., where there exists a time stamp for each piece of recorded data), 31 participants rated it as very important or important, 14 participants rated it as neutral, and 4 rated it as not important or less important. Moreover, 33 participants rated remote access to out-patients' data as important or very important, 6 rated it as neutral, and 10 rated it as not important or less important. As for sleep monitoring, 25 participants rated it as important or very important, 4 rated it as neutral, and 20 rated it as not important or less important.

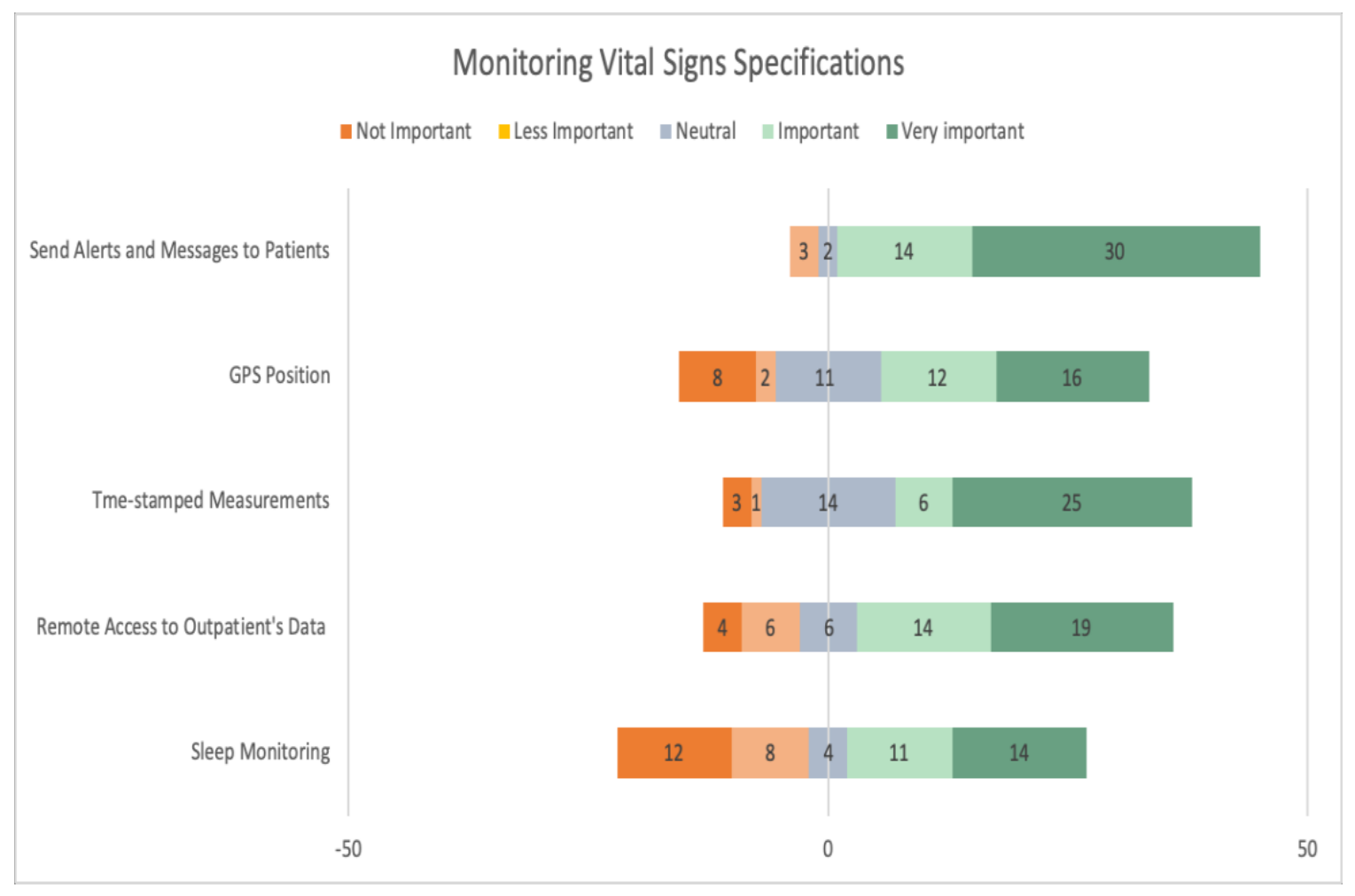

Figure 8. Monitoring vital signs specifications.

\subsubsection{Statistical Analysis}

Similarly, we used a chi-square test of independence for the statistical analysis. During our analysis, we created a new group called "other specialties" that included family 
medicine, surgery, ophthalmology, radiology, and otorhinolaryngology; we combined them into one group because each specialty had a very small number (2-5) of participants, which would make the comparison inaccurate.

Table 7 displays the comparison of the perception of visual signs monitoring importance across specialties. A significant difference in the perception of blood pressure monitoring importance was seen across specialties $(\mathrm{p}=0.001)$; the specialty with the highest rate of high importance perception was ICU (63.2\%), followed by emergency medicine (42.1\%). Meanwhile, none of the other specialties perceived blood pressure as an important vital sign to be monitored. A significant variation in the perception of peripheral capillary oxygen saturation monitoring importance was seen across specialties $(\mathrm{p}=0.037)$; the specialty with the highest rate of high importance perception was emergency medicine (100\%), followed by ICU (73.7\%) and then the other specialties (69.2\%). The perception of cough pattern monitoring importance was significantly different across specialties $(\mathrm{p}=$ $0.001)$; the specialty with the lowest rate of high importance perception was ICU $(10.5 \%)$, followed by emergency medicine (31.6\%) and then the other specialties (76.9\%). No significant difference in the perception of monitoring importance of body temperature, pulse rate, and respiration rate was observed across specialties.

Table 8 shows the comparison of the perception of different aspects of monitoring importance across specialties. No significant different was seen in the perception of different aspects of monitoring across specialties. It should be noted that "low perception of importance" means those who chose "not important", "slightly important", and "moderately important". Meanwhile, "high perception of importance" means those who 
chose "important" and "highly important". We re-arranged the answers to be only in these two groups to make the comparison possible.

Table 7. Comparison of the perception of vital signs monitoring importance across specialties.

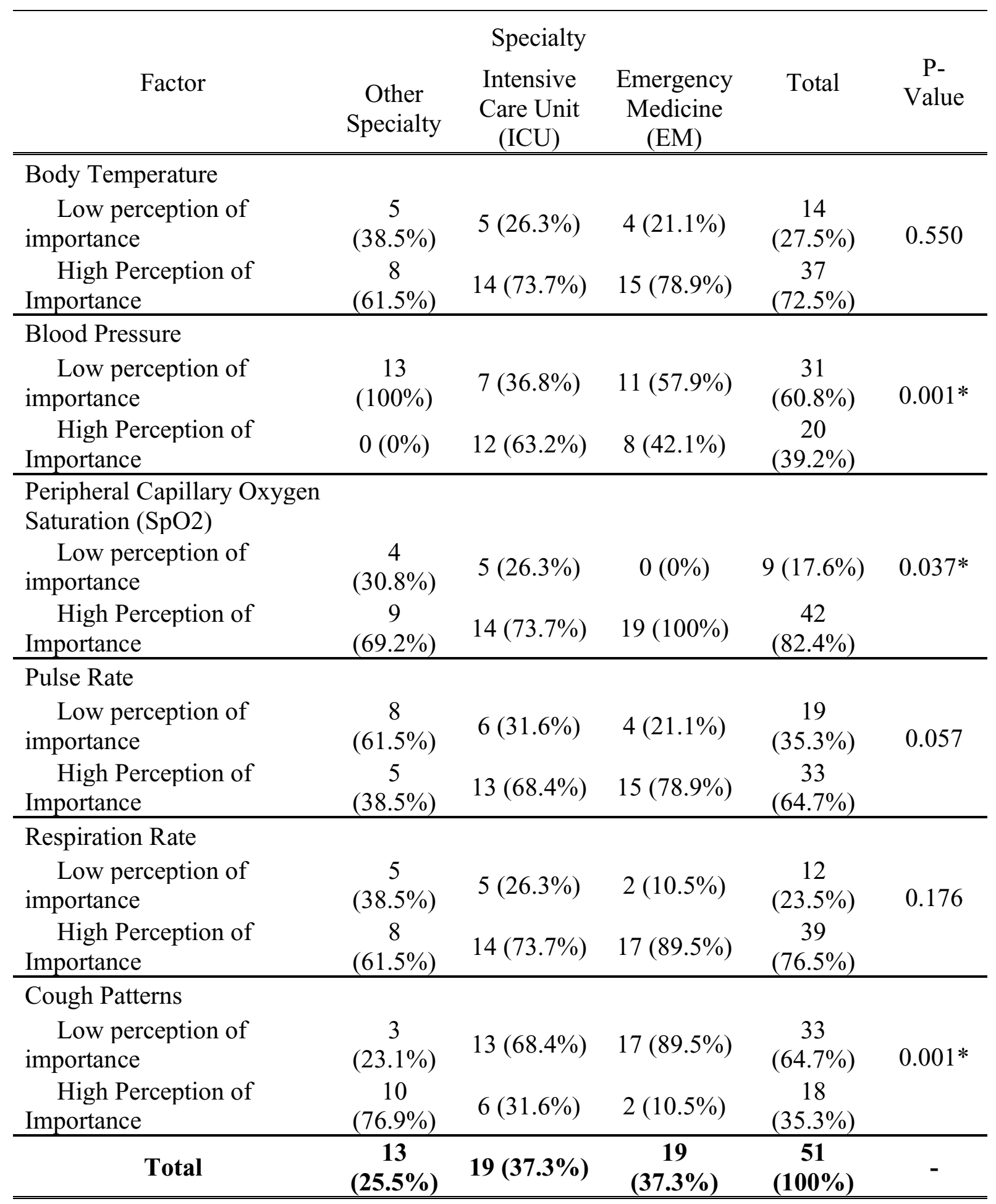

*Significant at level 0.05 
Table 8. Comparison of the perception of different aspects of monitoring importance across specialties.

\begin{tabular}{|c|c|c|c|c|c|}
\hline \multirow[b]{2}{*}{ Factor } & \multicolumn{3}{|c|}{ Specialty } & \multirow[b]{2}{*}{ Total } & \multirow[b]{2}{*}{$\begin{array}{c}\text { P- } \\
\text { Value }\end{array}$} \\
\hline & $\begin{array}{c}\text { Other } \\
\text { Specialty }\end{array}$ & $\begin{array}{c}\text { Intensive } \\
\text { Care } \\
\text { Unit } \\
\text { (ICU) } \\
\end{array}$ & $\begin{array}{c}\text { Emergency } \\
\text { Medicine } \\
\text { (EM) }\end{array}$ & & \\
\hline \multicolumn{6}{|l|}{$\begin{array}{l}\text { Monitoring Covid-19 out-patients } \\
\text { during sleep }\end{array}$} \\
\hline Low perception of importance & $\begin{array}{c}7 \\
(53.8 \%)\end{array}$ & $\begin{array}{c}8 \\
(42.1 \%)\end{array}$ & $12(63.2 \%)$ & $\begin{array}{c}27 \\
(52.9 \%)\end{array}$ & 0.428 \\
\hline High Perception of Importance & $\begin{array}{c}6 \\
(46.2 \%) \\
\end{array}$ & $\begin{array}{c}11 \\
(57.9 \%)\end{array}$ & $7(36.8 \%)$ & $\begin{array}{c}24 \\
(47.1 \%) \\
\end{array}$ & \\
\hline \multicolumn{6}{|l|}{$\begin{array}{l}\text { Being able to remotely access out- } \\
\text { patient's data at anytime }\end{array}$} \\
\hline Low perception of importance & $\begin{array}{c}4 \\
(30.8 \%)\end{array}$ & $\begin{array}{c}7 \\
(36.8 \%)\end{array}$ & $7(36.8 \%)$ & $\begin{array}{c}18 \\
(35.3 \%)\end{array}$ & 0.925 \\
\hline High Perception of Importance & $\begin{array}{c}9 \\
(69.2 \%) \\
\end{array}$ & $\begin{array}{c}12 \\
(63.2 \%) \\
\end{array}$ & $12(63.2 \%)$ & $\begin{array}{c}33 \\
(64.7 \%) \\
\end{array}$ & \\
\hline \multicolumn{6}{|l|}{$\begin{array}{l}\text { Having time-stamped } \\
\text { measurements }\end{array}$} \\
\hline Low perception of importance & $\begin{array}{c}7 \\
(53.8 \%)\end{array}$ & $\begin{array}{c}5 \\
(26.3 \%)\end{array}$ & $8(42.1 \%)$ & $\begin{array}{c}20 \\
(39.2 \%)\end{array}$ & 0.278 \\
\hline High Perception of Importance & $\begin{array}{c}6 \\
(46.2 \%) \\
\end{array}$ & $\begin{array}{c}14 \\
(73.7 \%) \\
\end{array}$ & $11(57.9 \%)$ & $\begin{array}{c}31 \\
(60.8 \%) \\
\end{array}$ & \\
\hline \multicolumn{6}{|c|}{$\begin{array}{l}\text { Locating Covid-19 out-patient position by } \\
\text { GPS }\end{array}$} \\
\hline Low perception of importance & $\begin{array}{c}6 \\
(46.2 \%)\end{array}$ & $\begin{array}{c}9 \\
(47.4 \%)\end{array}$ & $8(42.1 \%)$ & $\begin{array}{c}23 \\
(45.1 \%)\end{array}$ & 0.945 \\
\hline High Perception of Importance & $\begin{array}{c}7 \\
(53.8 \%)\end{array}$ & $\begin{array}{c}10 \\
(52.6 \%)\end{array}$ & $11(57.9 \%)$ & $\begin{array}{c}28 \\
(54.9 \%)\end{array}$ & \\
\hline \multicolumn{6}{|c|}{$\begin{array}{l}\text { Being able to send alerts and messages to } \\
\text { patients }\end{array}$} \\
\hline Low perception of importance & $\begin{array}{c}2 \\
(15.4 \%)\end{array}$ & $\begin{array}{c}2 \\
(10.5 \%)\end{array}$ & $2(10.5 \%)$ & $\begin{array}{c}6 \\
(11.8 \%)\end{array}$ & 0.896 \\
\hline High Perception of Importance & $\begin{array}{c}11 \\
(84.6 \%) \\
\end{array}$ & $\begin{array}{c}17 \\
(89.5 \%) \\
\end{array}$ & $17(89.5 \%)$ & $\begin{array}{c}45 \\
(88.2 \%) \\
\end{array}$ & \\
\hline Total & $\begin{array}{c}13 \\
(25.5 \%)\end{array}$ & $\begin{array}{c}19 \\
(37.3 \%)\end{array}$ & $19(37.3 \%)$ & $\begin{array}{c}51 \\
(100 \%)\end{array}$ & - \\
\hline
\end{tabular}

*Significant at level 0.05 


\subsubsection{Discussion}

Reflecting on our results, we can observe that the most crucial vital signs required to monitor COVID-19 patients are: i) respiration rate, heart rate, oxygen saturation, and body temperature. According to our previous literature survey, our findings are in line with the current list of vital signs critical to COVID-19 tracking. Although our participants reported some variance in the required frequency of monitoring vital signs, the majority have suggested tracking patients every 6 hours is best. Results revealed that physicians believe that sending alerts and being able to contact patients is an important feature of these devices. Similar to a real emergency room setting, with these devices, doctors and nurses can always remain in close contact with the patient and provide comments or suggest actions according to the patient's health status. GPS positioning is a critical subject in terms of privacy, even though most physicians agreed that it is somewhat important to share patient's GPS; however, it must be remembered that patient's control on their privacy is crucial. By providing control to the patient, the choice to share their location or not lies with them.

\subsubsection{Limitations}

Similar to our first survey limitations, the phrasing or lack of clarifying details of some of our survey questions might have introduced ambiguity in participants' responses that might have affected the quality of our findings. For instance, participants agreed on the importance of sending alerts and messages to patients, although our intended question was regarding automated alert messages, we did not explicitly clarify the type of alert in 
our question. Another limitation in our survey design was that some questions did not have follow-up questions for clarification. For example, we asked participants to rate the importance of sharing patient's GPS location and most agreed that it was important; however, because participants were not prompted for additional details, we still can't fully understand the reason behind their rating. These findings can only guide us to better understand physician's requirements for monitoring COVID-19 out-patients, but we must consider these limitations and also consider the general limitations of self-reported data and how participants interpreted the questions provided to them. Finally, it would have been interesting to compare ratings with years of experience within and between specialties. For example, would physicians with more years of experience provide different response than junior colleagues? Given the ever-evolving nature of medical research specific to the treatment of COVID-19, it would also be interesting to collect snapshots of physician responses at different stages of the pandemic (reflecting changes to treatment protocols, etc.). Finally, including other stakeholder groups (e.g., nurses and software engineers) would have made our results richer and more diverse. 


\section{Chapter 4: Usability Study}

In this chapter, we discuss the design and implementation of our two low-fidelity prototypes: i) wearable device and ii) health application UI. We highlight the design decisions that were considered for both prototypes in term of usability and acceptability. Further, the study's methodology is presented, and study outcomes are discussed.

\subsection{Design and Implementation}

During our design phase, we primarily focused on our audience, who they are and what are their requirements. We wanted to design a simple and straightforward service for out-patients, which patients with any background, levels of education, and skill set can find usable and acceptable. In Chapter 3, we empathized with our users and gained insight from our surveys regarding their needs and requirements for wearable health-tracking devices. We also learned the most important vital signs that need to be monitored and what other features need to be included in the device. From our surveys and literature, we were able to gain a better understanding of how to design the wearable device and the health application.

\subsubsection{Body Placement of Wearable Prototype}

When it came to the placement of the wearable device prototype, we had to consider two main aspects: i) user acceptance of body placement and ii) effectiveness of sensor placement. We considered several body locations which could capture the vital signs effectively and were perceived as acceptable by users. Drawing from prior studies on 
wearable placements [37], [24] and our findings from the two questionnaires described in Chapter 3, we chose to design and evaluate the usability of a wrist-worn wearable device.

\subsubsection{Wearable Device}

Our primary goal was to build a wearable device from miniature sensors which can monitor all vital signs and still feel light and almost invisible. As mentioned earlier, the use of these sensors is still evolving, and they are not found easily off-the-shelf. Therefore, we wanted this design to feel close enough to a device that uses miniature sensors and is extremely light weight. Unlike other smart watches, this device had a singular goal: monitoring vital signs. Hence, patient's direct interaction with the device was not important, but it was more significant that they could check the corresponding application to view and interact with the system. More importantly, our main goal was to make it as invisible as possible, so the patient can wear it all the time (e.g., while sleeping) without experiencing any discomfort. Therefore, in our 3D prototype, we made sure that the prototype was flexible, thin, and light.

We first created preliminary sketches of the prototype of the wearable device and how it will appear on the user's wrist. As seen in Figure 9, we had two initial design options. The first alternative was meant to contain miniature sensors embedded in an adhesive square strip which would stick on the user's arm, preferably an area with no or minimum hair, to avoid irritation, as shown in Figure 9-a. The other option was to embed the same type of sensors (miniature sensors) to an elastic band which does not stick on the user's wrist and can be worn as a bracelet or a wristwatch, as shown in Figure 9-b. 
The first option required using a sticky elastic band, which could have caused annoyance and pain for people with hairy wrists. Hence, we chose to proceed with the second option as it was more suitable for this prototype study. Once we chose this design, we used software called Rhino [10] to create a 3D sketch of the prototype and ensured that we mimicked the size of the miniature sensors, as shown in Figure 10. 


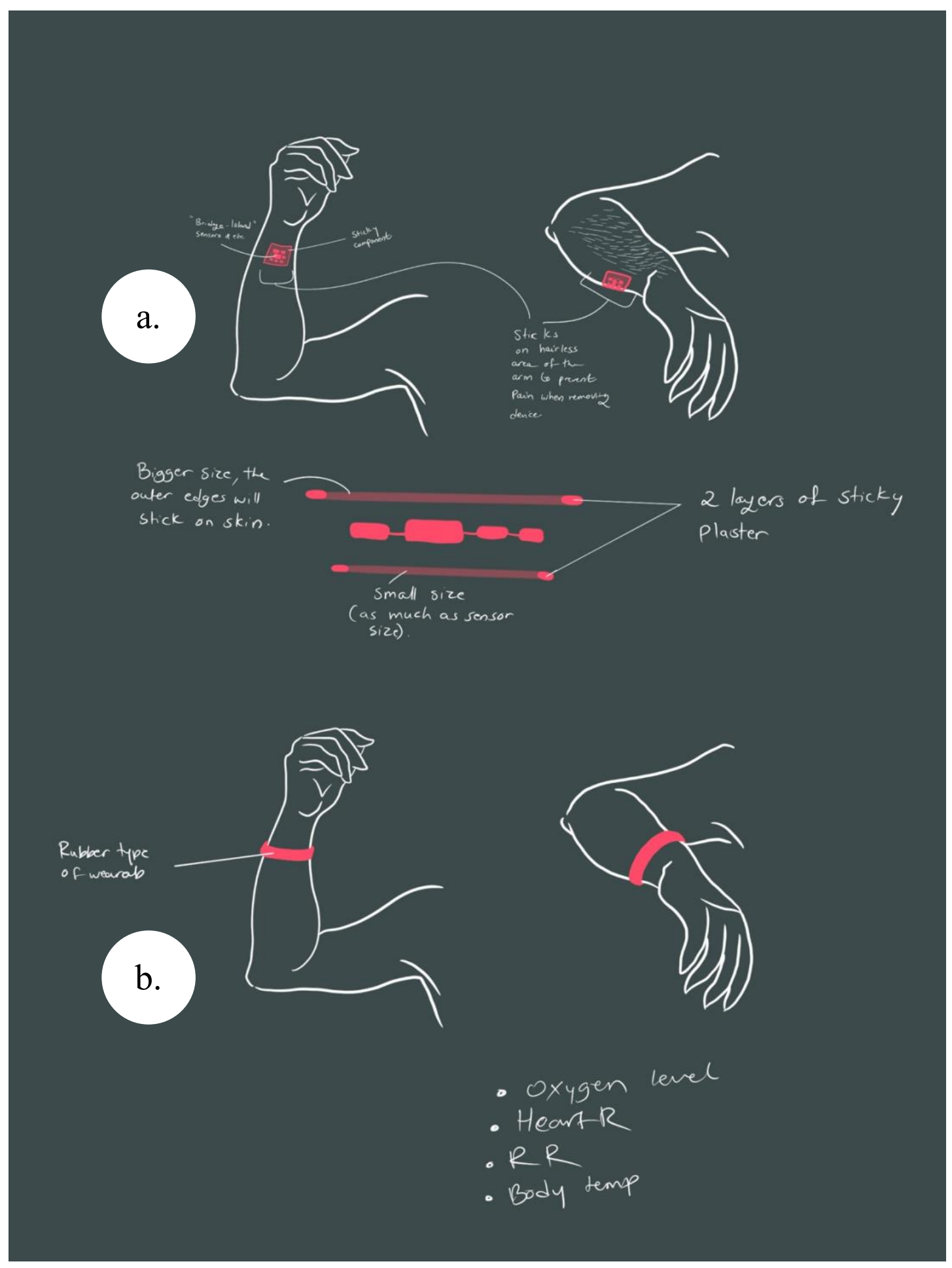

Figure 9. Preliminary sketch: a) option a, b) option b 


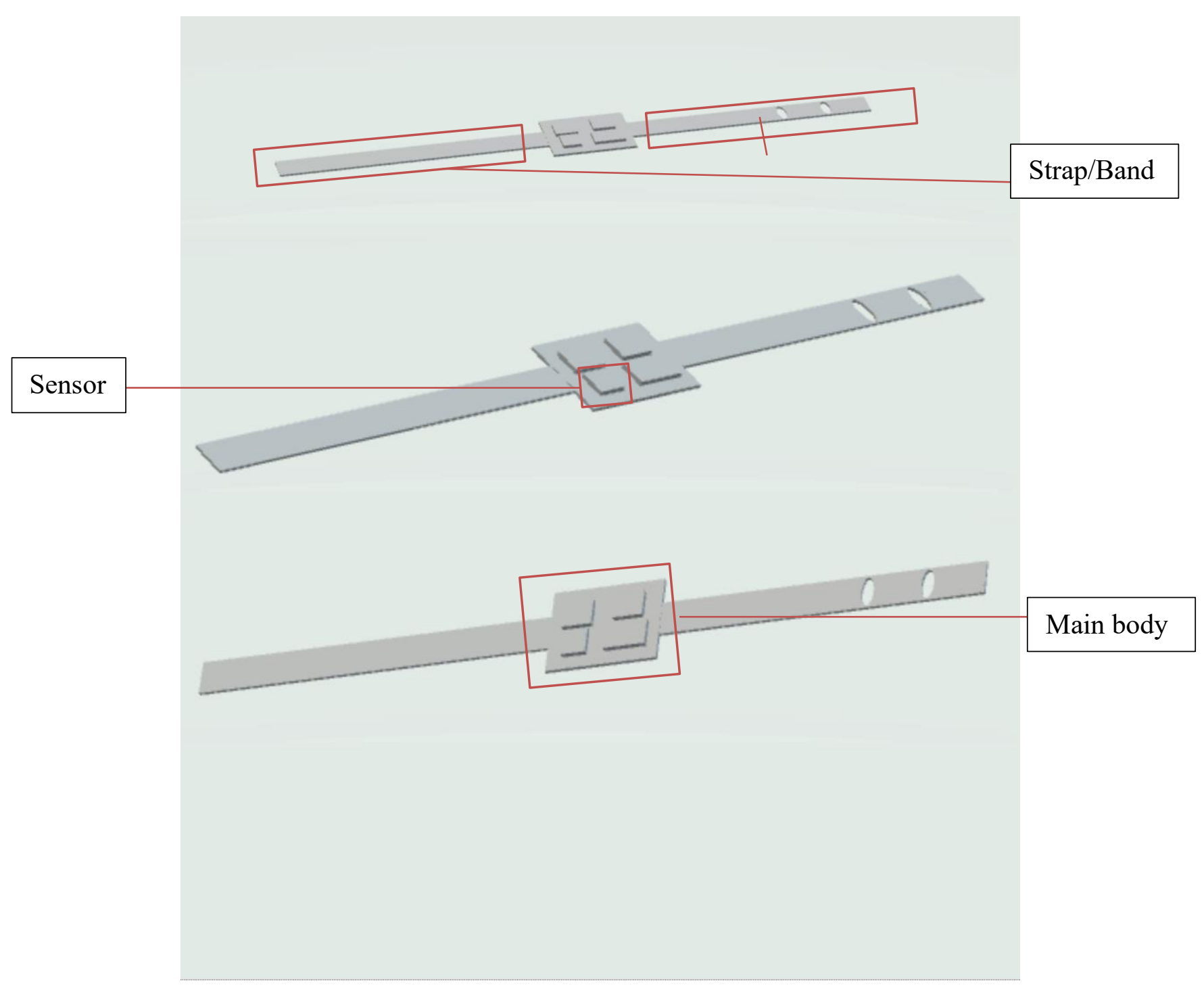

Figure 10. Design of prototype

Based on the software design, we created a low-fidelity prototype using a 3D printer called Prusa [60] where we used a black and white PLA filament (i.e., a material similar to plastic). The process of 3D printing was not precise from the first trial. Because our prototype is meant to demonstrate a health tracking wearable device which is equipped with miniature sensors and components that are meant to be thin and light weight; hence, our aim was to design a similar look and feel. We went through several iterations till we 
reached the final prototype. The first few 3D-print trials were a failure due to its large size and material of the 3D printed object. In the first trial, it was too big (i.e., $9 \mathrm{~cm}$ wide) and not flexible enough (i.e., we used a non-flexible filament called PLA), as shown in Figure 11. We altered the size to be more fitting on the wrist and adjustable to different wrist sizes and used another similar filament which is a more flexible compared to the previous material but still not sufficiently flexible, as shown in Figure 12. Finally, we used a Flex filament which is very flexible, and the resultant $3 \mathrm{D}$ printed object became our chosen prototype, as shown in Figure 13. The prototype was highly flexible, light (i.e., weighted less than $0.01 \mathrm{~kg}$ ), was $20 \mathrm{~cm}$ long which can be wrapped around the wrist and adjusted according to the user, and around $1 \mathrm{~mm}$ thick but it was $1 \mathrm{~mm}$ thicker for the 4 squares (which acts as sensor components) in the center of the wearable prototype.

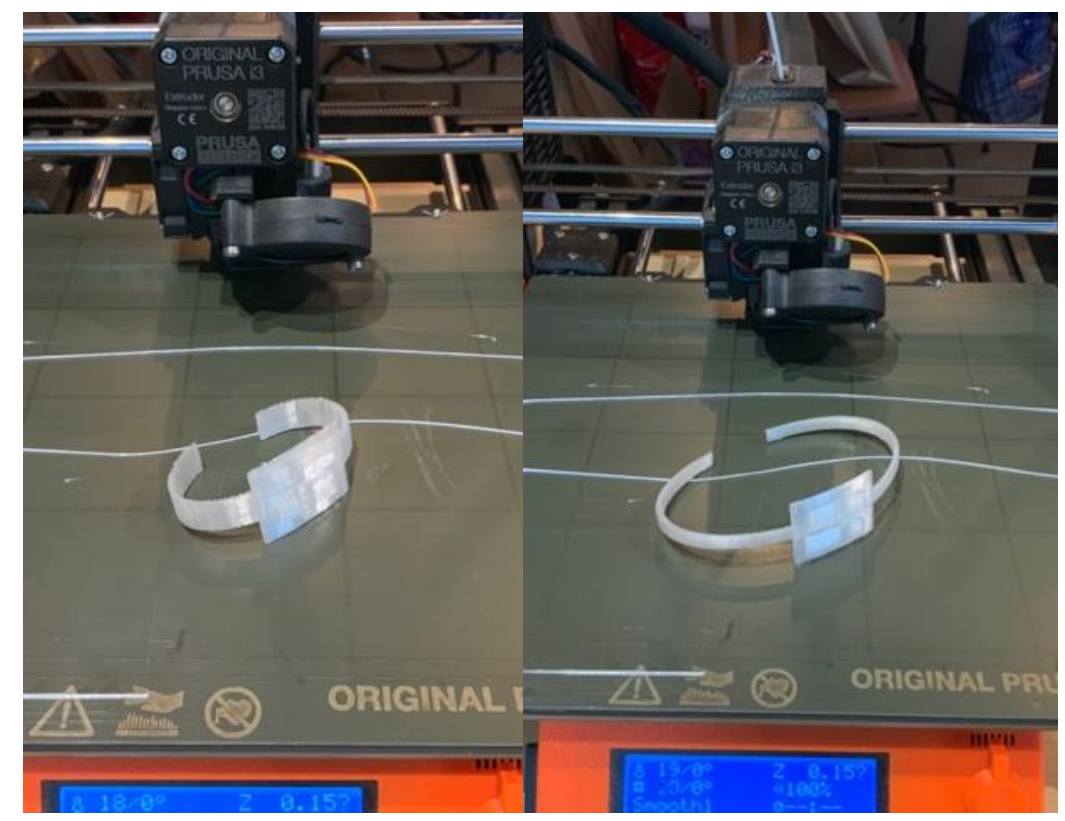

Figure 11. First trials of 3D printed object 


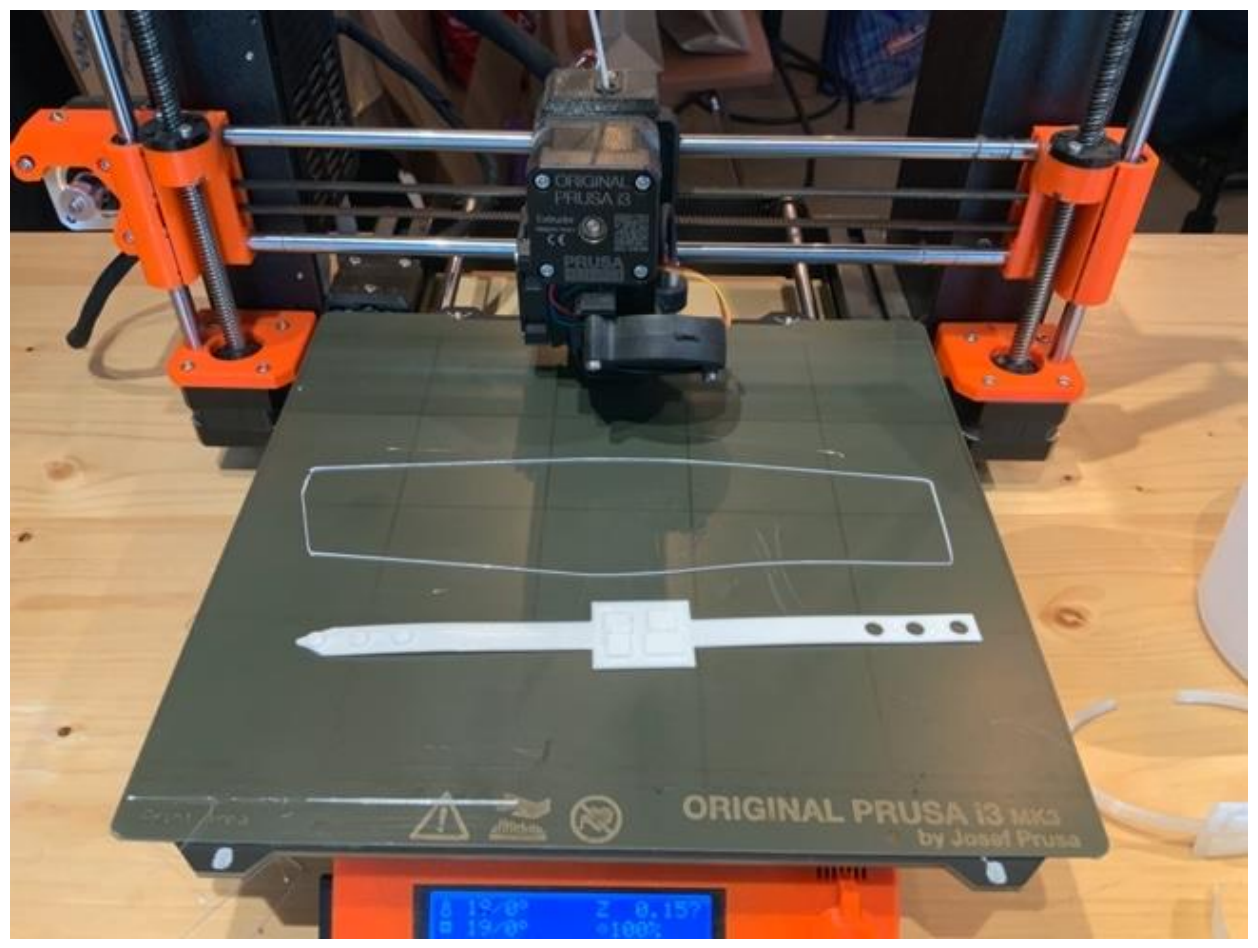

Figure 12. Second trial of 3D printed object

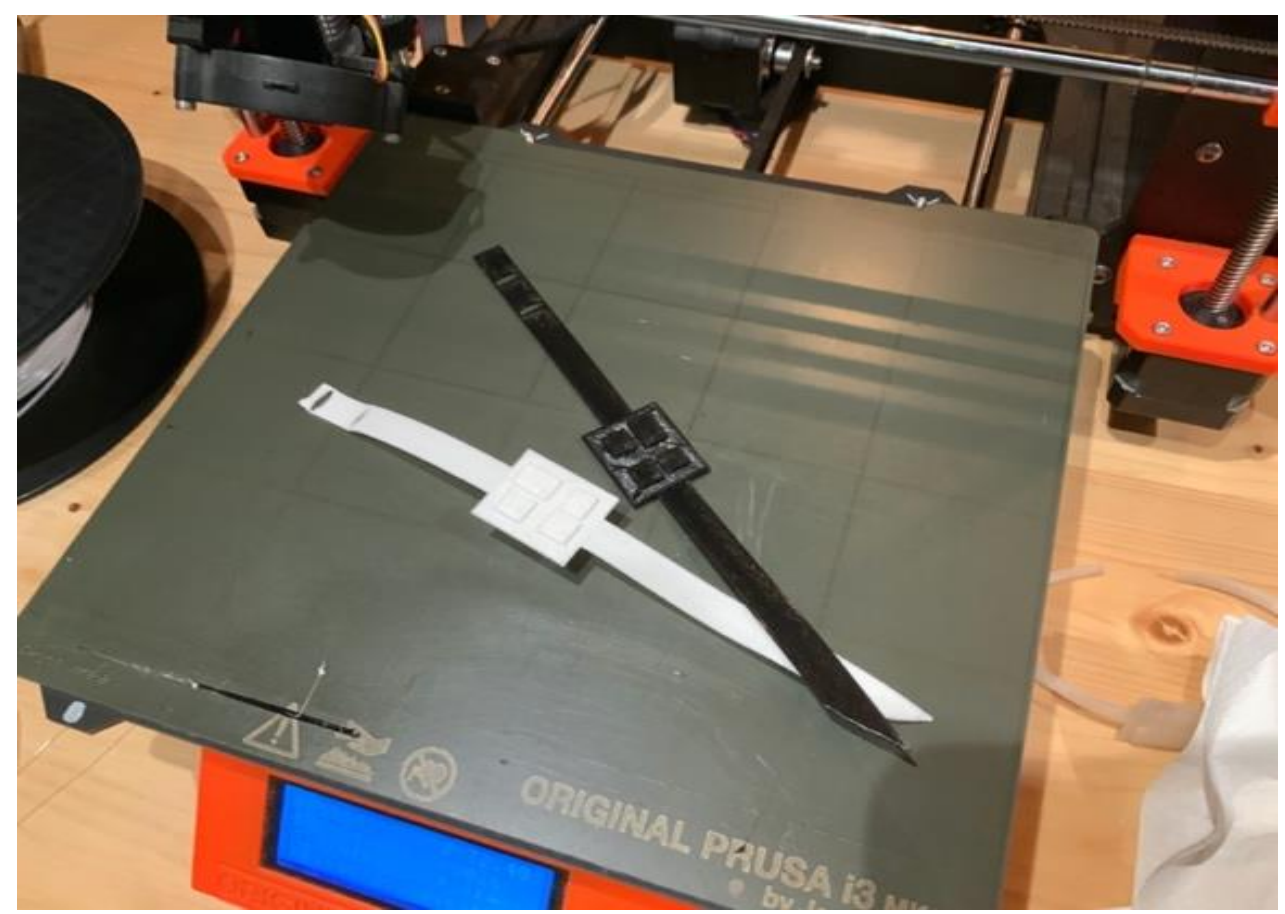

Figure 13. Final 3D print of the prototype 
Furthermore, the device is worn on the participant's wrist like a wristwatch, as shown in Figure 14. Participants used this prototype, and it was tested in terms of usability and acceptability. We have presented all prototype samples in Appendix B.

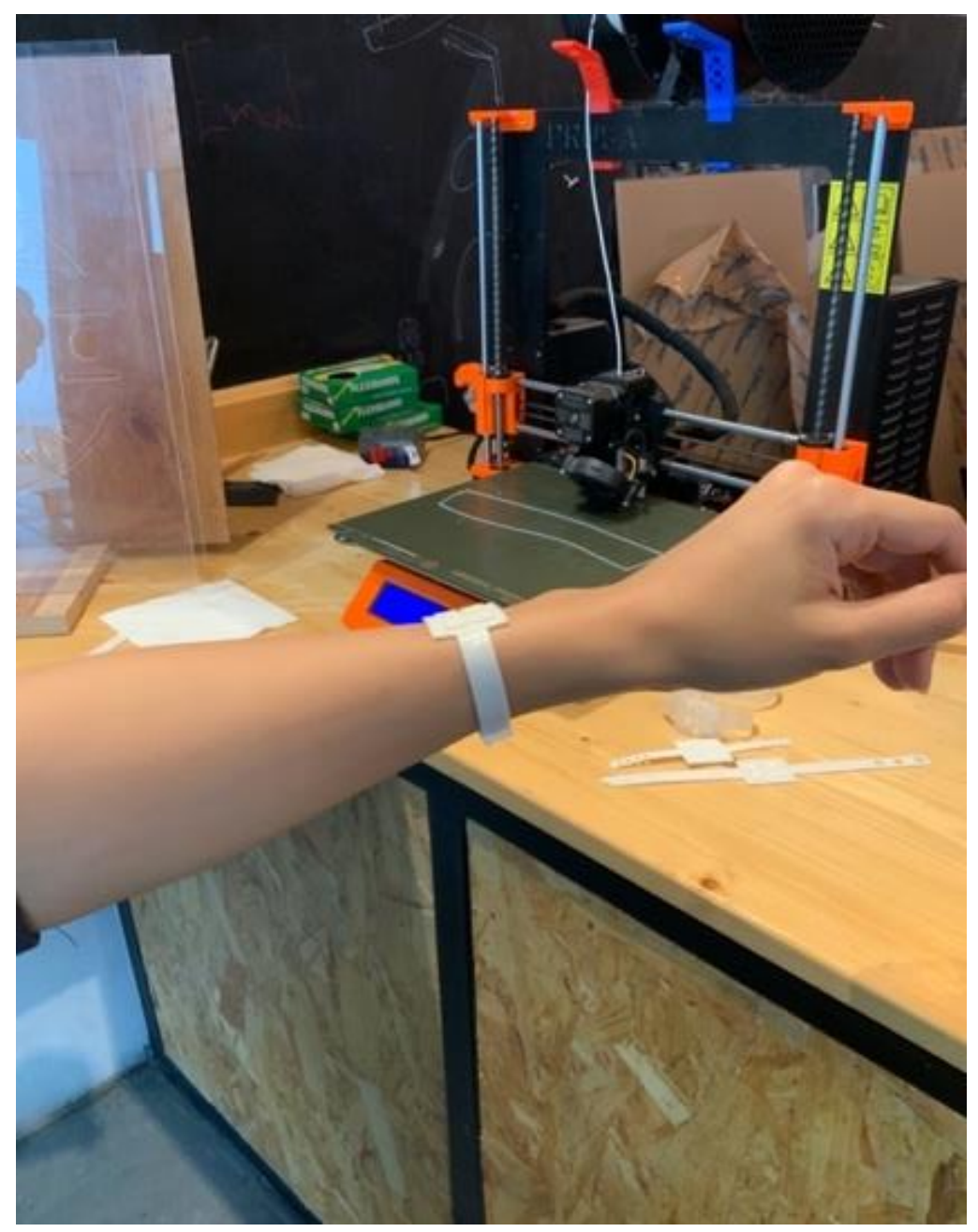

Figure 14. Wrist-worn prototype

\subsubsection{Health Application UI}

Most wearable devices are usually connected to a mobile application and most interaction takes place through it, and there exists many health applications examples that are user friendly and provide the user with an intuitive interaction experience. During the 
design process of the health application, we considered the existing health application such as google fit app which had a very sophisticated and minimal design and only showing most vital physiological parameters. Further, we made sure to utilize UI components and paradigms that are common to both popular apps and commercial-off-the-shelf health trackers (e.g., using the familiar share icon that is used in many user interfaces) to avoid the learning curve and minimize the user's cognitive overload when using the UI components. We also surveyed multiple design sites such as Dribbble [35] and Pinterest [59] for design inspiration. Furthermore, although our UI design was voluntarily and involuntarily influenced by prior health applications, our main design inspirations came from our $1^{\text {st }}$ study, wherein this application, apart from other existing health apps, is purely catered for COVID-19 home monitoring services. Despite that, we have also considered some of Don Norman's design principles [31], which have been listed below:

\section{- Discoverability}

- Norman [31] explained good discoverability in a device as a user being able to determine possible actions easily. We attempted to make all components visible and easily understandable by the user. For example, we used back buttons to increase navigation throughout the application, as shown in Figure 15. 


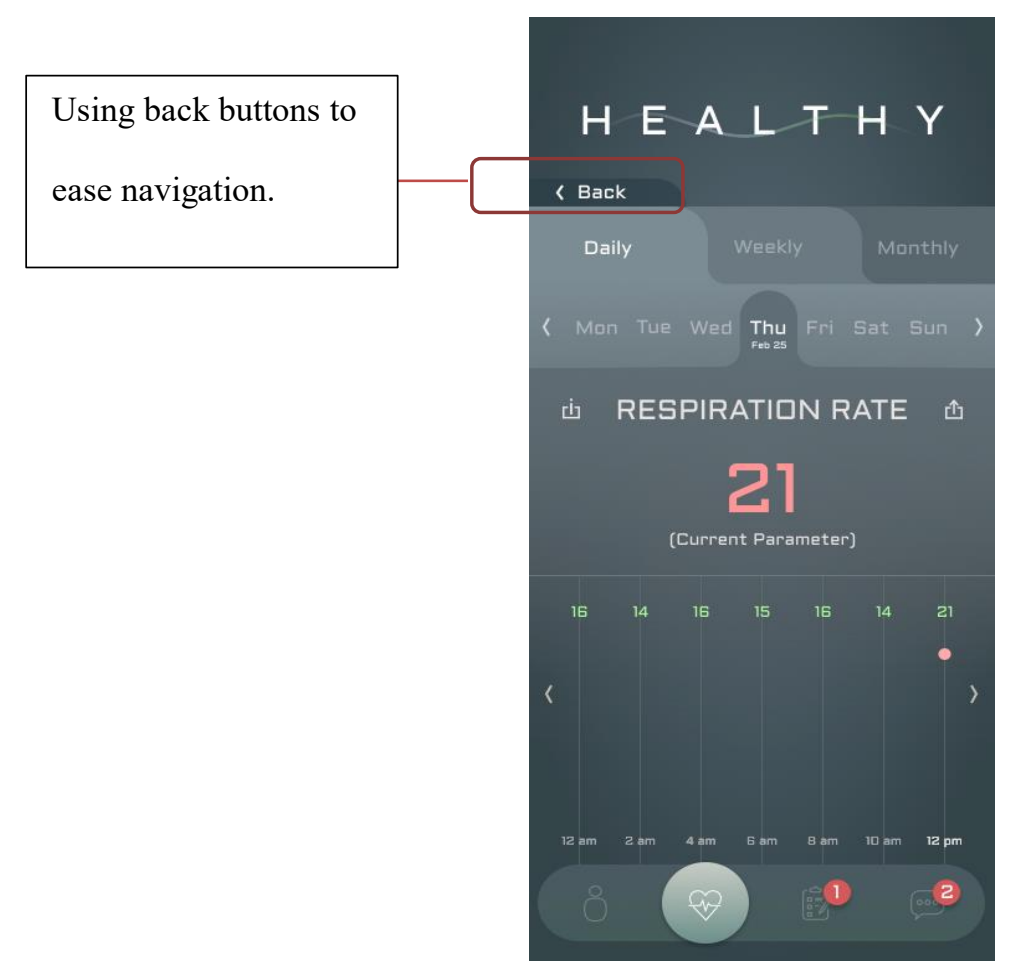

Figure 15. Applying discoverability in UI

- Feedback

- When a user interacts with the UI, we made sure they receive action feedback which responds to the user's action, allowing them to know that the system is in action and responsive. We applied feedback through several functions, such as changing colors and showing pop-up messages, as shown in Figure 16. 


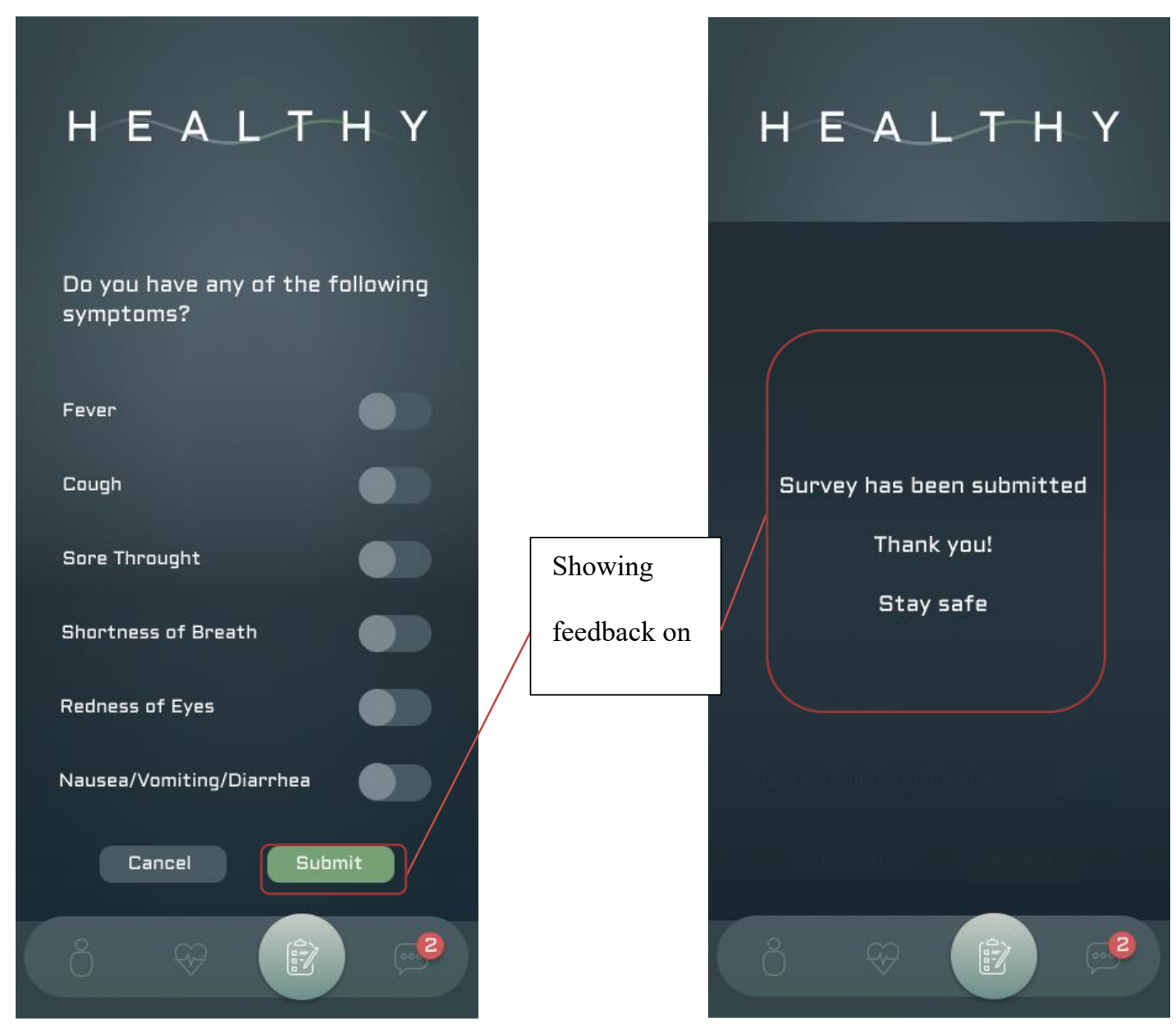

Figure 16. Applying feedback in UI

\section{- Conceptual models}

- We used simple and clear icons to represent our four main components: i) profile, ii) vital signs, iii) daily survey and iv) chat box, as shown in Figure 17.

- Further, some functions can be found in most applications (for e.g., share function), and users are familiar with their representative icons. Hence, it is better to recycle those icons and use them instead of creating new 
representations which can confuse the user and would demand more cognitive load.

\section{- Signifiers}

- We made sure that all buttons were meaningfully labeled to inform the user of the action they are about to perform and prevent them from making errors.

For the design of the health application, we used a UI design tool called Figma [5] and principle [9]. The UI contains four main pages: i) personal, ii) health parameters, iii) daily health questionnaire, and iv) chat box. The home page presents an overall analysis of the current vital signs tracked by the wearable device. With regard to the design of the UI, we selected cold tones for the background, san serif fonts, and minimal design to reflect a minimal and simple design that can be used and easily comprehended by the majority of users from different backgrounds and of different age groups. In Figure 18, we present screenshots of the application UI. To better present the workflow of the UI, we presented a storyboard in Figure 19 -it shows the flow of a user when completing the tasks provided during the usability study. 


\section{HEALTH Y}

< Back

Daily

Weekly

Monthly

\section{Using}

meaningful icon
〈Mon Tue Wed Thu Fri Sat Sun > Feb 2:

ఉ RESPIRATION RATE ثิ

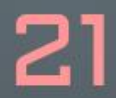

(Current Parameter)

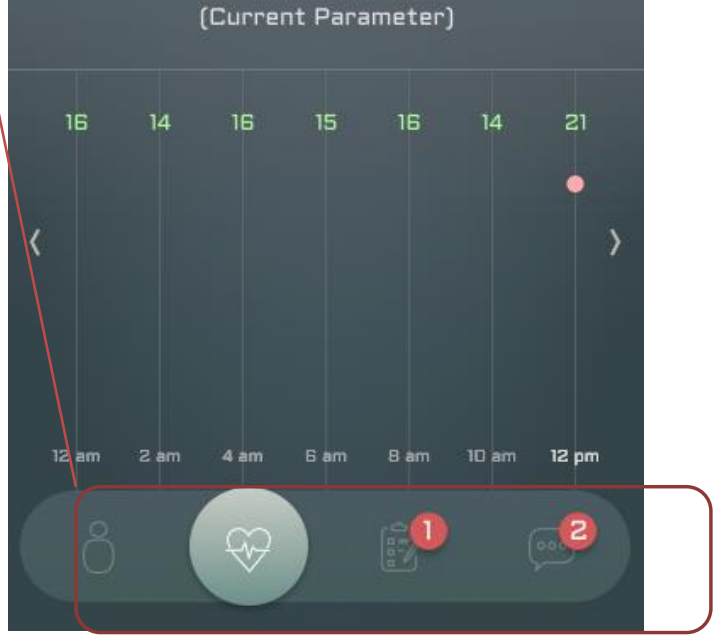

Figure 17. Applying conceptual models in UI 

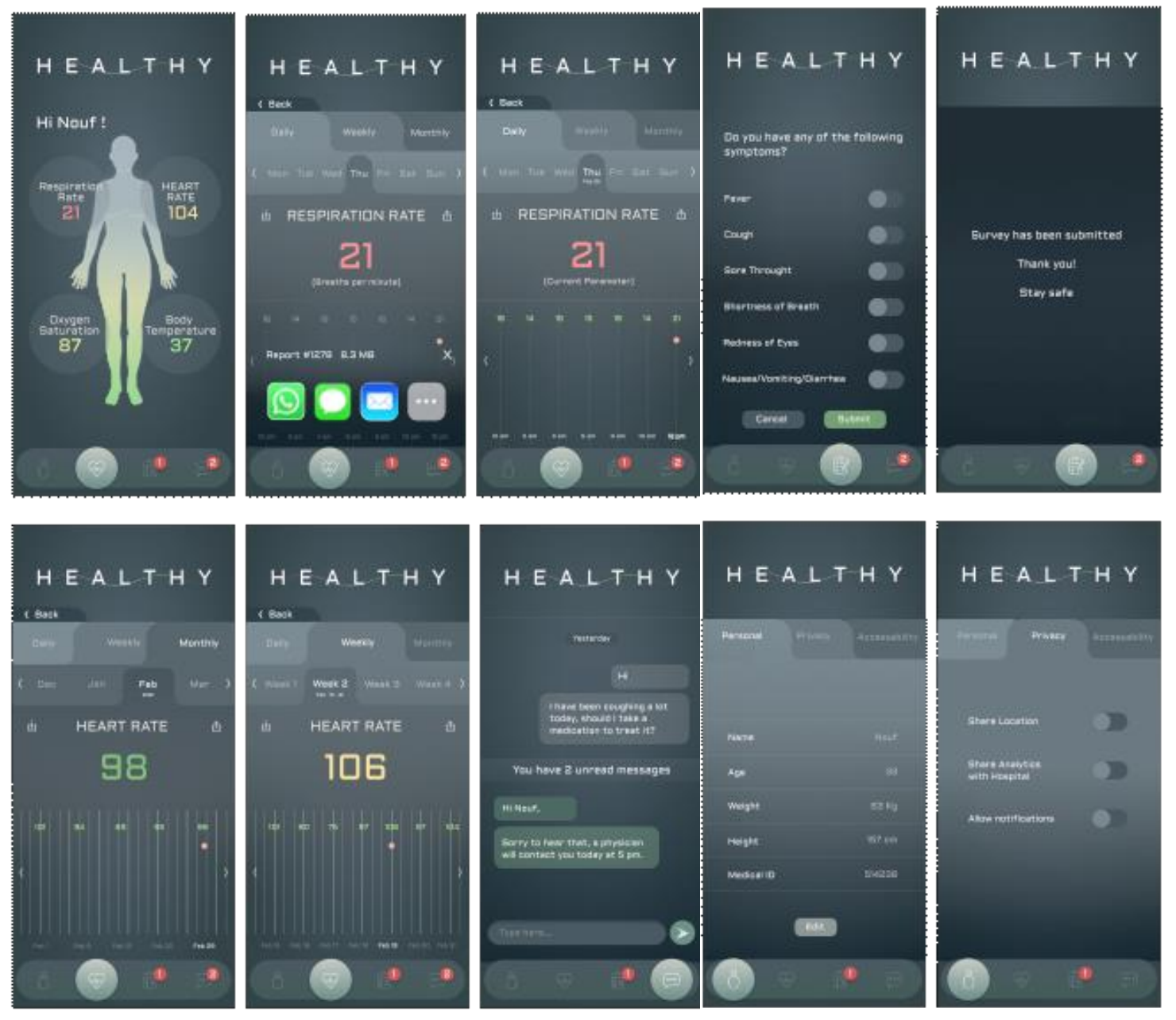

Figure 18. UI screenshots 


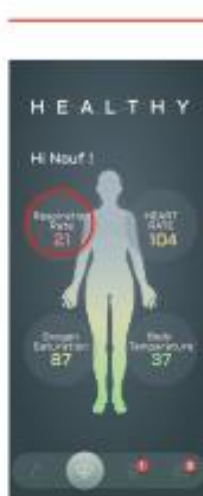

Home page, clicks on Respiration rate to

show more information.

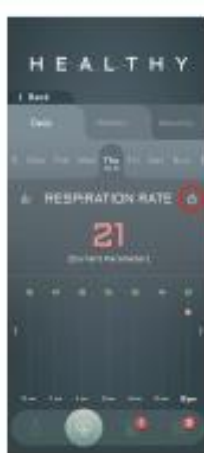

Clicks on share icon to preview options.

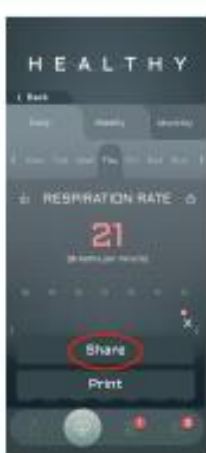

Clicks on Shere and choose which application to share to.

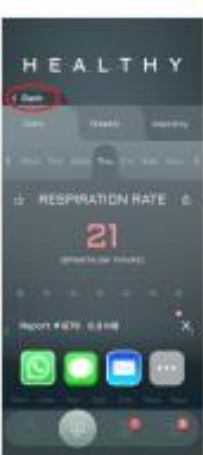

Clicks on back

button to go back to

home page.

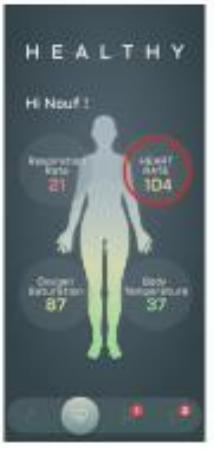

Clicks on Hoart rate to show more infomation.

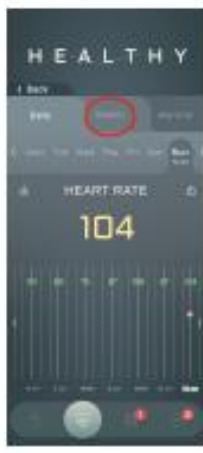

Click on any day to show more info on specifio day. Also, click on weekly tab to shaw more info in a weekty basis.

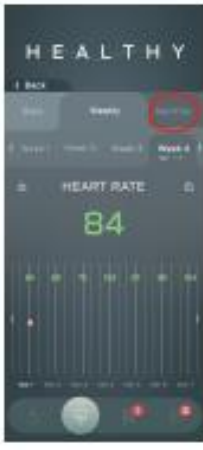

Click on any woek to show more info on specifio week. Aso, click on monthly tab to show more info in a monthly basis.

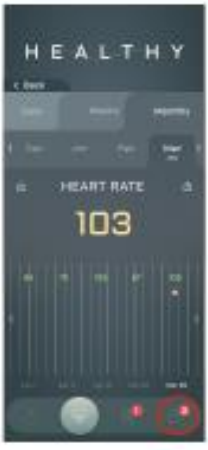

Cicks on messages ioon to move to see unread messages in messaging pago.

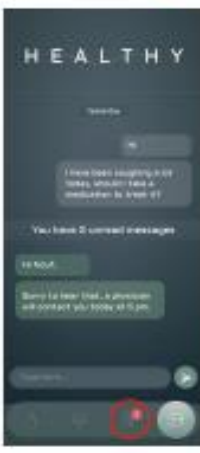

Clicks on sunvey icon to fill out the daily heath questionnsire.

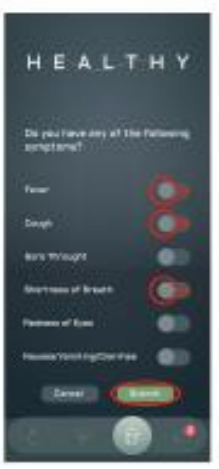

Side the symptorre that you feel (Fever, Cough and shortnese of breath Next, click on submit.

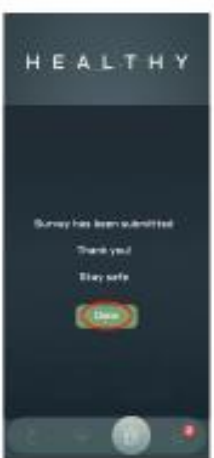

Clicks done to exit pøge.

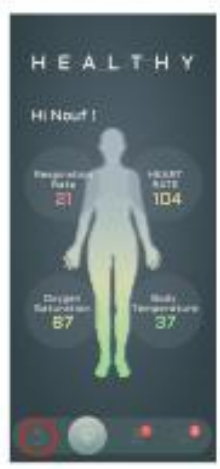

Clicks on the profle ioon to move to the profile page.

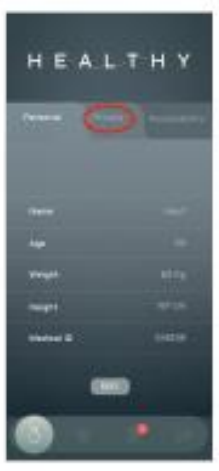

Clicks on privacy tab.

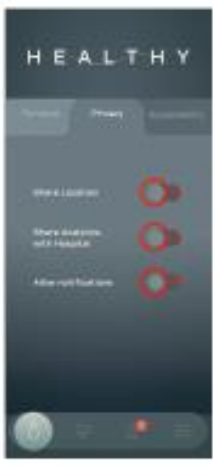

Turn an all privacy settings.

Figure 19. UI storyboard 


\subsection{Research Questions}

As stated earlier, we had two primary research questions in our study:

RQ1: In the context of COVID-19, what do people think of using a wearable device and app provided by the hospital to monitor their health from home, and how acceptable and usable are these to end-users?

RQ2: How do users perceive the usefulness of the application prototype and what important features must be included in a health application for COVID-19 home monitoring?

\subsection{Methodology}

We divided our study into three phases. First, we asked each participant to wear the low-fidelity prototype for 24 hours. Next, in a semi-lab environment, we asked each participant to complete six tasks on the UI prototype on an iPhone X. Subsequently, each participant was required to fill our three questionnaires which were design using Google Forms: i) background, ii) usability of wearable prototype, and iii) usability of UI. Finally, we conducted a semi-structured interview with each participant, noting that there were no additional COVID-19 protocols since participants are family members. Interview questions are found in Appendix C.1.

In phase 2, participants completed few tasks to test the usability of most primary functions within the application, the tasks were as follows:

1. Check respiration rate and share with a friend.

2. Check heart rate (daily, weekly, monthly).

3. Read unread messages. 
4. Fill out daily questionnaire (e.g., have fever, cough, and sore throat symptoms).

5. Change privacy settings to all $\mathrm{ON}$.

We asked participants to use the think aloud protocol where they express their thought while using the application. Moreover, we observed each participant and wrote notes during the session. Then participants filled out a usability questionnaire, see Appendix C.2. The application is only a prototype which means that no real data was monitored, and we only used fake data to present the application. This research has been granted clearance (Project \# 113333) by the Carleton University Research Ethics Board-B (CUREB-B).

\subsubsection{Participants}

Due to COVID-19 restrictions, we only recruited family members who were non COVID-19 patients and shared the same household with us. The household members were 8 in total, but since this is a pilot study, we asked only 5 participants to join our study. All participants included in the study were over 18 years old.

\subsection{Results}

\subsubsection{Participant Background}

We recruited three male and two female participants with age ranging between 25 to 84 years old. A total of four of our participants responded with "maybe" to the question “Are you familiar with wearing a health-tracking device?" while only one was unfamiliar with health-tracking wearable devices. 


\subsubsection{Quantitative Results}

In this section, we have presented the quantitative results from the standardized tests such as system usability scale (SUS) and our surveys. To simplify the presentation of results, this section has been divided into two sub-sections: results related to the wearable prototype and results related to the UI prototype.

\subsubsection{Wearable Prototype}

In this survey, we asked participants to rate seven statements using a Likert scale where 1 corresponds to "strongly disagree" and 5 to "strongly agree". The statements were related to the usability and acceptability of wearing the prototype and have been presented below:

1. I liked wearing the wearable device.

2. The wearable device helped me think about my health during the day.

3. I would recommend a wearable device to out-patients.

4. I would wear this device daily.

5. I feel the device was light weight.

6. I felt comfortable wearing the device.

7. I like how the device looked.

As shown in Figure 20,60\% of the participants liked wearing the wearable device, $80 \%$ would recommend it to out-patients, and all participants agreed to wearing it on a daily basis. However, when it came to whether it made them more aware of their health, $80 \%$ of the participants did not agree to that statement, meaning that they believed the prototype did not help them think more about their health during the day. Regarding 
comfort and aesthetics, all participants found the prototype light weight, $80 \%$ felt comfortable wearing it, and $40 \%$ found the prototype aesthetically pleasing.

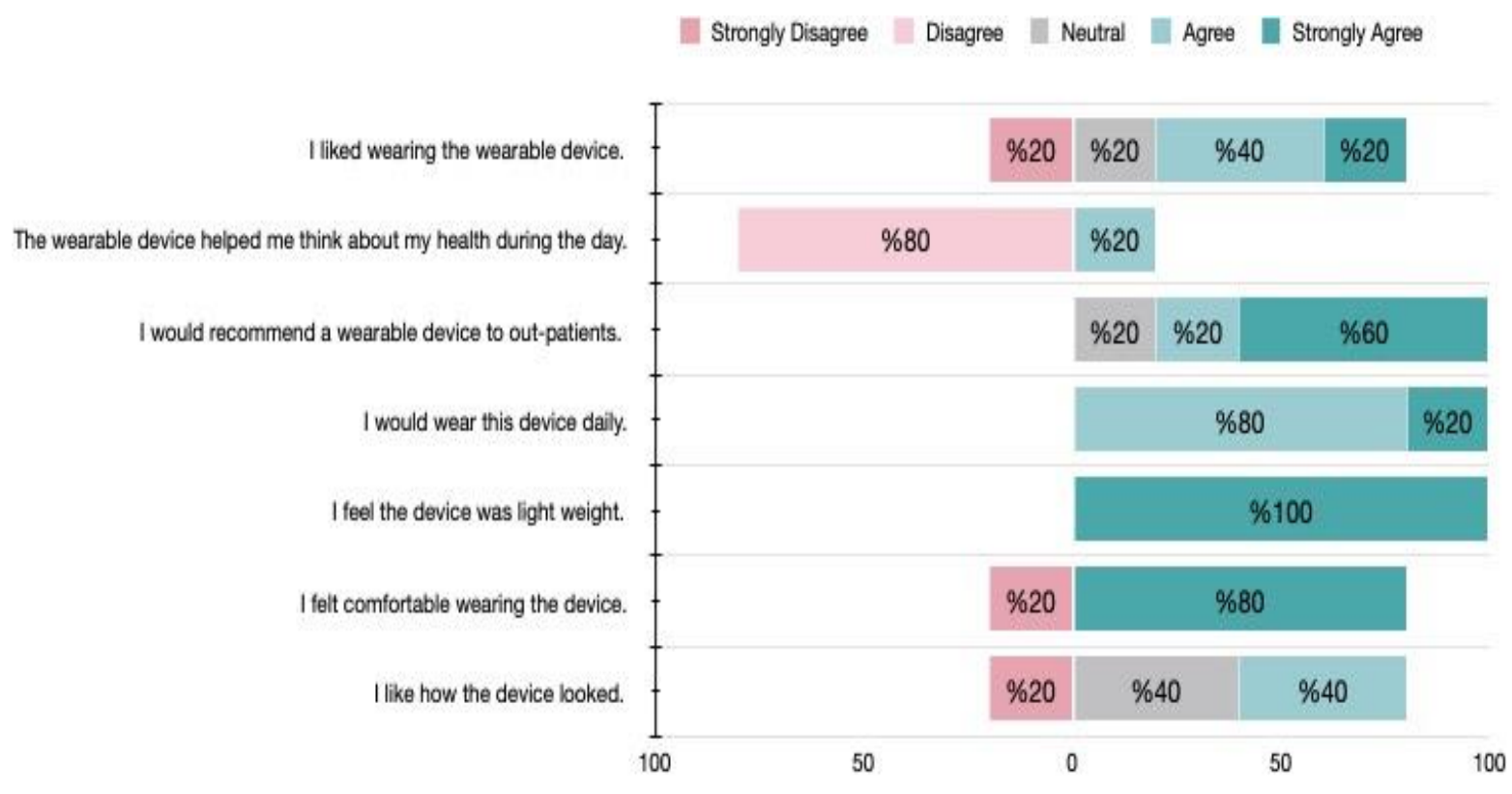

Figure 20. Wearable prototype questionnaire

\subsubsection{UI Prototype}

For the UI prototype, we chose the SUS standardized questionnaire to evaluate the usability of the system, which consists of 10 statements that the user can rate from 1 to 5 (i.e., where 1 is strongly disagree and 5 is strongly agree) as shown below:

1. I think that I would like to use this feature frequently.

2. I found the feature unnecessarily complex.

3. I thought the feature was easy to use.

4. I think that I would need the support of a technical person to be able to use this feature.

5. I found the various functions in this feature were well integrated.

6. I thought there was too much inconsistency in this feature. 
7. I would imagine that most people would learn to use this feature very quickly.

8. I found the feature very cumbersome to use.

9. I felt very confident using the feature.

10. I needed to learn a lot of things before I could get going with this feature.

. The SUS questionnaire is commonly employed in usability studies to attain a general score of how usable the system is. In our study, the average SUS score was found to be 92 which is considered a high score and indicates that the system is perceived to be usable. In Figure 21, we have presented the SUS scores for each question.

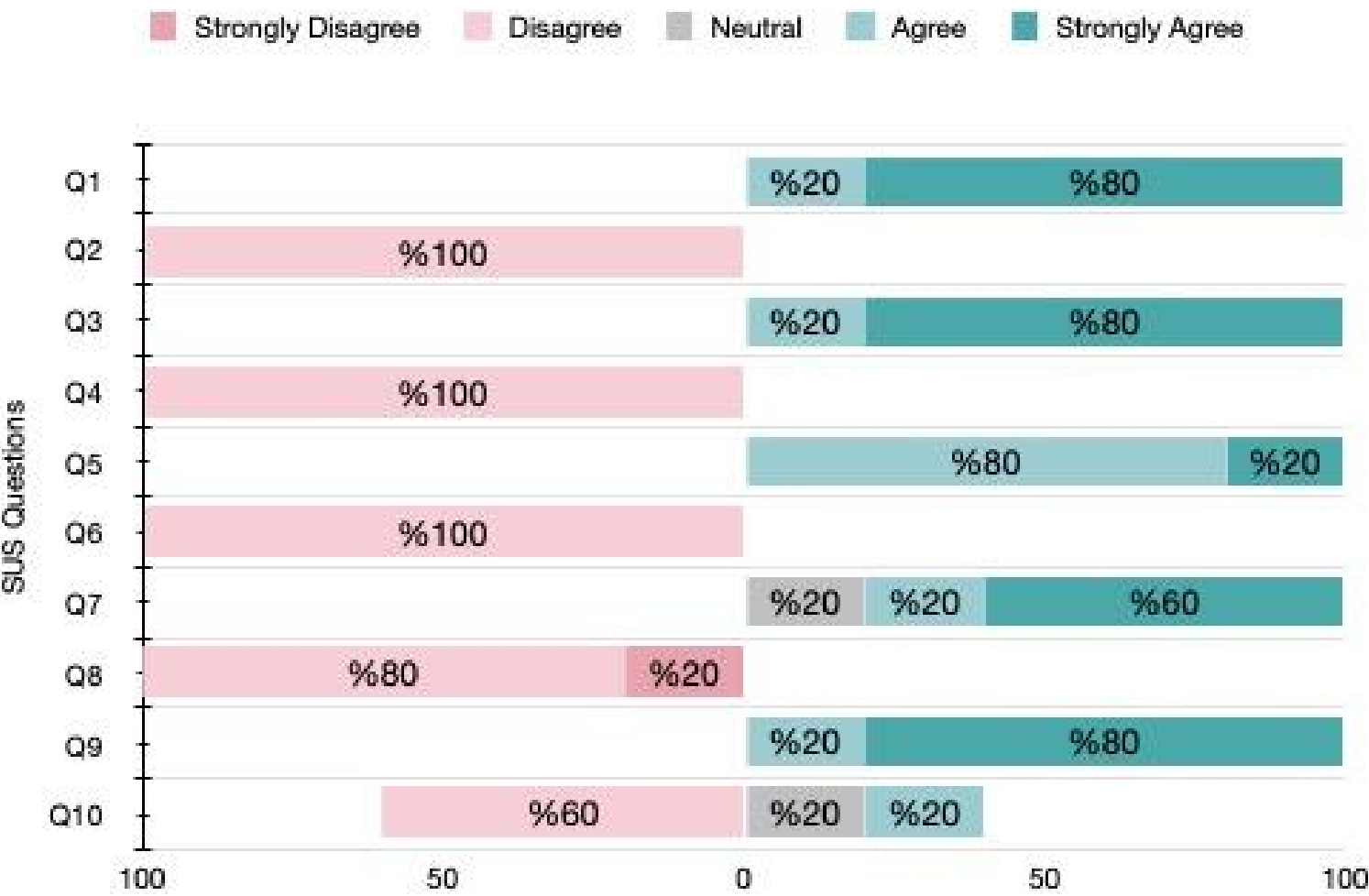

Figure 21. SUS questionnaire

It can be noted that all participants agreed to using the system frequently, believed the system was easy to use, found various functions in the system well integrated, and felt 
confident using the system. Moreover, $80 \%$ of the participants believed that most users would learn to use it quickly. All participants disagreed with the statements that the system was unnecessarily complex, there was a need for technical support to use the system, the system was too inconsistent and cumbersome. A total of $60 \%$ of the participants disagreed that users need to learn a lot before using the system.

\subsubsection{Qualitative Results}

As for our qualitative data, we obtained them from both interview questions and observations. For the UI usability test, we found that not all participants completed each task successfully. In Table 9, we can see the success rate of each task and that most participants completed tasks successfully; however, one participant was not able to complete task one (sharing vital signs with a friend) as they were not familiar with the share icon. The share button icon is a universal icon which indicates the share feature; however, this participant was over 40 years old and possessed low experience in technology in general. Furthermore, in task 5, a participant was unable to reach the questionnaire page, as they did not find the survey icon to be intuitive. Like the other participant, this participant was over 70 years old and had low to medium experience with technology.

Moreover, through the think aloud methodology, we were able to determine specific user concerns and points of confusion. One example: two participants were confused about whether the vital sign rate (as shown in Figure 21) represented the current reading or the average. Furthermore, one participant was confused about which day was represented by "today" as the days were presented in terms of day name and number (e.g., 
Sunday, 10), which did not appear sufficiently clear to the participant. Additionally, we found that most participants were unable to read the graph timeslots and found the font extremely small and unreadable. This was observed for both younger and older participants. Younger participants were more articulate when it came to sharing their feedback. We noticed that younger participants explored the application more, while the older participants focused on completing the task as fast as possible.

With regard to the interview questions, they contained answers related to the wearable prototype and the UI prototype. We reviewed results from the recorded interview sessions and transcribed them applying the thematic coding method [20]. We first divided answers into wearable related and UI related, then grouped similar segments of text into key themes and divided them into categories. During the data analysis for questions related to the application UI, we combined some questions (Q2, dislikes on the app, and Q3, what they would do to change it) because in the interviews, most participants had already answered Q3 while answering Q2; hence, when we posed Q3, most participants did not offer new insights. Moreover, we removed question 4, "What were the issues you faced when wearing this device and using the app?", because most participants did not provide an answer or had already answered this in previous questions. Therefore, we decided to remove this question.

Table 9. Success rates 


\begin{tabular}{|c|c|c|c|c|c|c|}
\hline Participants & Task 1 & Task 2 & Task 3 & Task 4 & Task 5 & Task 6 \\
\hline $\mathbf{1}$ & 1 & 1 & 1 & 1 & 1 & 1 \\
\hline $\mathbf{2}$ & 0 & 1 & 1 & 1 & 1 & 1 \\
\hline $\mathbf{3}$ & 1 & 1 & 1 & 1 & 1 & 1 \\
\hline $\mathbf{4}$ & 1 & 1 & 1 & 1 & 1 & 1 \\
\hline $\mathbf{5}$ & 1 & 1 & 1 & 1 & 0 & 1 \\
\hline Success & 4 & 5 & 5 & 5 & 4 & 5 \\
\hline $\begin{array}{c}\text { Completion } \\
\text { Rates }\end{array}$ & $\mathbf{9 0 \%}$ & $\mathbf{1 0 0 \%}$ & $\mathbf{1 0 0 \%}$ & $\mathbf{1 0 0 \%}$ & $\mathbf{9 0 \%}$ & $\mathbf{1 0 0 \%}$ \\
\hline
\end{tabular}

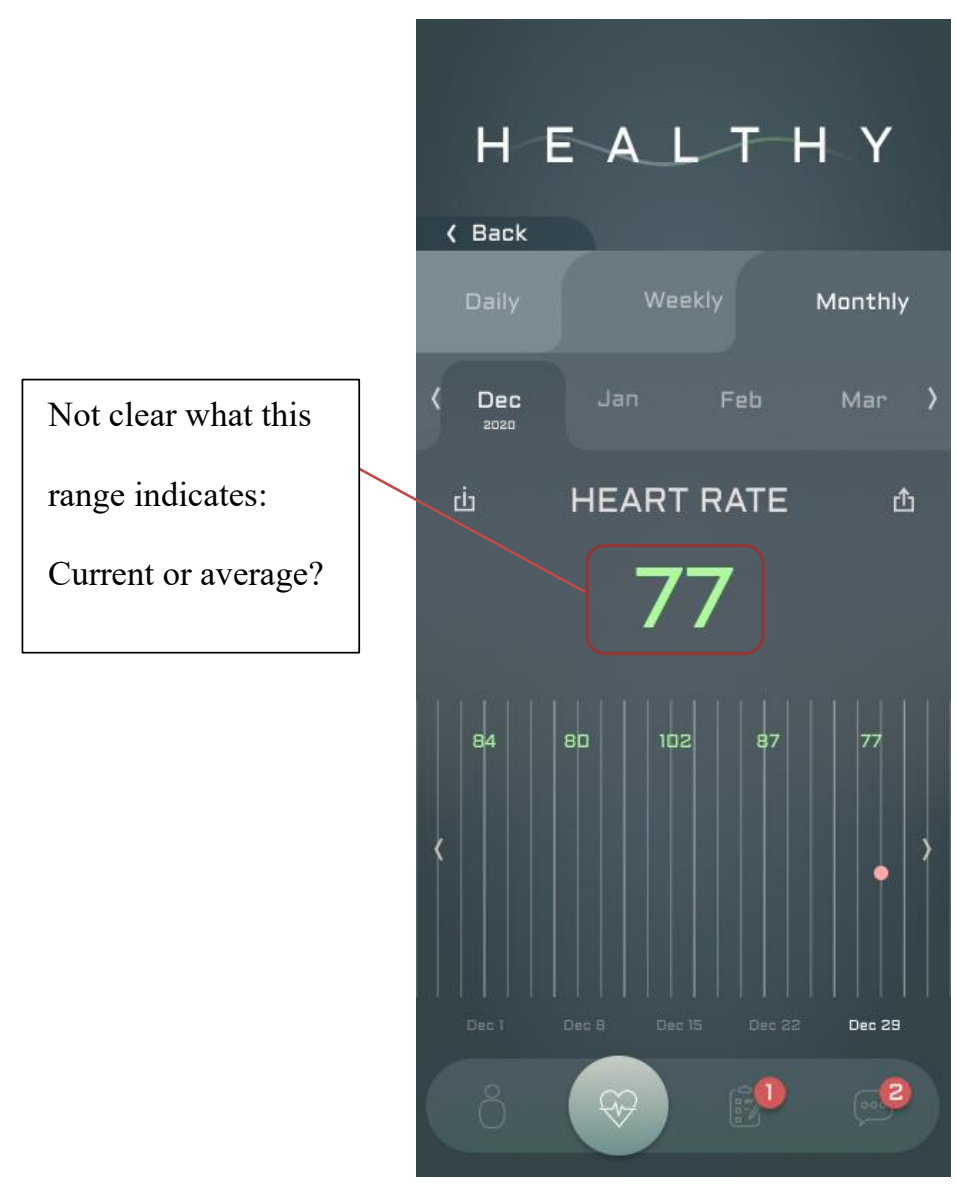

Figure 22. Heart rate vital sign readings

\subsubsection{Wearable prototype themes}


As shown in Table 10, we applied open coding on the data derived from interview sessions with participants, then combined related codes into main categories, as depicted in Table 11.

We classified the analyzed data into two main themes:

1. Ideas for further improvements.

2. Satisfaction with the wearable prototype. 
Table 10. Wearable device interview questions' codes

\begin{tabular}{|c|c|c|c|c|c|c|c|c|}
\hline & Q 1 & Code & Q 2 & Code & Q 3 & Code & Q 4 & Code \\
\hline Qs & $\begin{array}{l}\text { Tell us what you } \\
\text { liked about the } \\
\text { wearable device? }\end{array}$ & & $\begin{array}{l}\text { Tell us what you } \\
\text { disliked about } \\
\text { the wearable } \\
\text { device? }\end{array}$ & & $\begin{array}{l}\text { How would } \\
\text { you change } \\
\text { the design of } \\
\text { the device to } \\
\text { make it more } \\
\text { usable and } \\
\text { acceptable? }\end{array}$ & & $\begin{array}{l}\text { What are your } \\
\text { thoughts about } \\
\text { using a } \\
\text { wearable } \\
\text { device to } \\
\text { monitor out- } \\
\text { patients? }\end{array}$ & \\
\hline P1 & $\begin{array}{l}\text { Light, like it's } \\
\text { not there, I wear } \\
\text { watches so I } \\
\text { replaced that } \\
\text { with it. }\end{array}$ & $\begin{array}{c}\text { LIGHT } \\
\text { WEIGHT }\end{array}$ & $\begin{array}{l}\text { Closing it, the } \\
\text { clip. }\end{array}$ & LOOSE CLIPPER & $\begin{array}{l}\text { Change the } \\
\text { wrap. The } \\
\text { position was } \\
\text { good. }\end{array}$ & $\begin{array}{l}\text { CHANGE } \\
\text { WRAP }\end{array}$ & $\begin{array}{l}\text { I think it is } \\
\text { very } \\
\text { applicable. No } \\
\text { need for direct } \\
\text { interaction, } \\
\text { the most } \\
\text { important is } \\
\text { the access of } \\
\text { DOCTOR. }\end{array}$ & APPLICABLE \\
\hline $\mathbf{P 2}$ & $\begin{array}{l}\text { The watch was } \\
\text { very light. }\end{array}$ & $\begin{array}{c}\text { LIGHT } \\
\text { WEIGHT }\end{array}$ & $\begin{array}{l}\text { Wearable needs } \\
\text { some } \\
\text { modifications } \\
\text { and } \\
\text { improvements. }\end{array}$ & $\begin{array}{l}\text { NEEDS DESIGN } \\
\text { MODIFICATIONS }\end{array}$ & Nothing. & NOTHING & $\begin{array}{l}\text { I strongly } \\
\text { recommend } \\
\text { them to use it. }\end{array}$ & $\begin{array}{c}\text { RECOMMEND } \\
\text { IT }\end{array}$ \\
\hline P3 & $\begin{array}{l}\text { I liked the idea } \\
\text { that I don't have } \\
\text { to go to the } \\
\text { hospital every } \\
\text { day for daily } \\
\text { checkups. I liked } \\
\text { that I don't have } \\
\text { to use many } \\
\text { medical devices } \\
\text { to monitor my } \\
\text { vital signs. I feel } \\
\text { it is very } \\
\text { convenient that I } \\
\text { can stay at home } \\
\text { during this time } \\
\text { and be } \\
\text { monitored. It is } \\
\text { very light weight } \\
\text { and wearable for } \\
\text { both left and } \\
\text { right-handed. }\end{array}$ & $\begin{array}{c}\text { SECURE AT } \\
\text { HOME } \\
\text { CONVENIENT } \\
\text { LIGHT } \\
\text { WEIGHT }\end{array}$ & $\begin{array}{l}\text { The wearable fell } \\
\text { couple of times } \\
\text { during exercising } \\
\text { and during } \\
\text { sleeping. If it } \\
\text { was not going to } \\
\text { affect the space } \\
\text { with my watch, it } \\
\text { would be better } \\
\text { to wear it on the } \\
\text { same arm. }\end{array}$ & $\begin{array}{l}\text { LOOSE CLIPPER } \\
\text { NEEDS DESIGN } \\
\text { MODIFICATION }\end{array}$ & $\begin{array}{l}\text { Design it in a } \\
\text { way so as to } \\
\text { be able to } \\
\text { assure it is } \\
\text { not falling } \\
\text { and can be } \\
\text { worn on both } \\
\text { sides. }\end{array}$ & $\begin{array}{c}\text { NOT } \\
\text { FALLING, } \\
\text { WORN BOTH } \\
\text { SIDES }\end{array}$ & $\begin{array}{l}\text { I think it is a } \\
\text { good idea, it } \\
\text { makes the } \\
\text { patient more } \\
\text { comfortable } \\
\text { that they are } \\
\text { being } \\
\text { monitored } \\
\text { without being } \\
\text { in the hospital, } \\
\text { because } \\
\text { usually I don't } \\
\text { like going to a } \\
\text { hospital but } \\
\text { when I am } \\
\text { home or } \\
\text { wherever I can } \\
\text { be in a } \\
\text { getaway } \\
\text { location and } \\
\text { still be } \\
\text { monitored. }\end{array}$ & GOOD IDEA, \\
\hline P4 & $\begin{array}{l}\text { I liked that it was } \\
\text { very light, I liked } \\
\text { that you can } \\
\text { wear it on your } \\
\text { hand. }\end{array}$ & $\begin{array}{c}\text { LIGHT } \\
\text { WEIGHT } \\
\text { LIKED BEING } \\
\text { WRIST- } \\
\text { WORN }\end{array}$ & $\begin{array}{l}\text { I did not like that } \\
\text { it looked like a } \\
\text { watch, I would } \\
\text { like it to look } \\
\text { more like a } \\
\text { bracelet for } \\
\text { fashion reasons. }\end{array}$ & $\begin{array}{l}\text { NEEDS DESIGN } \\
\text { MODIFICATION }\end{array}$ & $\begin{array}{l}\text { Have it } \\
\text { thinner and } \\
\text { looking like a } \\
\text { bracelet. I } \\
\text { would add an } \\
\text { emergency } \\
\text { button which } \\
\text { sends my } \\
\text { location. }\end{array}$ & $\begin{array}{l}\text { THINNER, } \\
\text { LOOKS LIKE } \\
\text { BRACLET } \\
\text { EMERGENCY } \\
\text { BUTTON }\end{array}$ & $\begin{array}{l}\text { It is a nice } \\
\text { idea, because } \\
\text { it will be with } \\
\text { you all the } \\
\text { time and track } \\
\text { your health } 24 \\
\text { hours. }\end{array}$ & $\begin{array}{l}\text { NICE IDEA, } \\
\text { WITH YOU } \\
\text { ALL TIME }\end{array}$ \\
\hline P5 & $\begin{array}{l}\text { I felt that I was } \\
\text { secure while } \\
\text { wearing this } \\
\text { device. Because I } \\
\text { can check my } \\
\text { health at any } \\
\text { time. }\end{array}$ & FELT SECURE & Nothing. & NOTHING & $\begin{array}{l}\text { I would } \\
\text { change the } \\
\text { color and } \\
\text { make it more } \\
\text { fashionable } \\
\text { and less } \\
\text { patient } \\
\text { looking. }\end{array}$ & $\begin{array}{c}\text { CHANGE } \\
\text { COLOR, } \\
\text { FASHIONABLE }\end{array}$ & Very useful. & USEFUL \\
\hline
\end{tabular}


Table 11. Wearable device - interview questions' themes/categories

\begin{tabular}{|c|r|r|}
\hline WEIGH & Code & CATEGORY \\
\hline 1 & MAKE IT COLORFUL & \\
\hline 2 & CHANGE LOOSE CLIPPER & \\
\hline 2 & CHANGE THE DESIGN & \\
\hline 1 & ADD EMERGENCY BUTTON & \\
\hline 4 & SIGHT WEIGHT & \\
\hline 1 & CONVENIENT & \\
\hline 1 & LIKED BEING WRIST-WORN & \\
\hline 1 & SECURE AT HOME & \\
\hline 1 & FELT SECURE & \multirow{2}{*}{ OVERALL IDEA on wearable health track for out-patients } \\
\hline 1 & APPLICABLE & \\
\hline 1 & RECOMMEND IT & \\
\hline 1 & GOOD IDEA & \\
\hline 1 & NICE IDEA & \\
\hline 1 & USEFUL & \\
\hline
\end{tabular}

\subsection{Ideas for further improvements.}

Under this theme, participants shared comments to improve the prototype in terms of aesthetics, practicality, and function. In terms of aesthetics, two participants suggested that the wearable prototype could look more fashionable and colorful, one suggested that it should look more like a bracelet rather than a watch, so she can wear it with her own watch. Similarly, another participant said "I would change the color and make it more fashionable and less patient looking" [P5]. Furthermore, another participant expressed that he wears a watch on his left arm and prefers wearing nothing on his right arm, so when he wore the wearable prototype, it was hard to wear it on his left arm with his own watch, because the prototype looked more like a watch and took more wrist space. So, he also suggested that the wearable prototype have a thinner design and look less like a watch, "If it was not going to affect the space with my watch it would be better to wear it on the same arm" [P3]. 
Regarding practicality, three participants mentioned that the prototype clipper was somehow loose, which led the prototype to fall from their wrists: "The wearable fell couple of times from me during exercising and during sleeping" [P3]. Hence, they suggested finding another mechanism for the clipper which can make it more secure. Finally, in terms of functionality, one participant articulated that there should be an emergency button on the device which she can press in case of an emergency.

\subsection{Satisfaction with the wearable prototype.}

With regard to satisfaction, four participants expressed how light the prototype was. One participant mentioned that the idea of the prototype was extremely convenient "I feel it is very convenient that I can stay at home during this time and be monitored" [P3]. Another participant was satisfied with the fact that it was wrist worn and could be worn on both arms. Moreover, it was interesting to find that a participant expressed the feeling of security while wearing the prototype "I felt that I was secure while wearing this device. Because I can check my health at any time" [P5].

\subsection{Overall idea on wearable health track device for out-patients.}

As shown in Table 12, we applied open coding on the data derived from interview sessions with participants, then combined related codes into main categories, as shown in Table 13. We identified two main themes from the analyzed data:

1. Usability and satisfaction of UI.

2. Perceived issues and modifications. 


\begin{tabular}{|c|c|c|c|c|c|c|}
\hline & Q 1 & Code & Q 2 & Code & Q 3 & Code \\
\hline Qs & $\begin{array}{l}\text { Tell us what you liked } \\
\text { about the app? }\end{array}$ & & $\begin{array}{l}\text { Q2: Tell us what you } \\
\text { disliked about the } \\
\text { app? } \\
\text { Q3: How would you } \\
\text { change the design of } \\
\text { the device to make it } \\
\text { more usable and } \\
\text { acceptable? }\end{array}$ & & $\begin{array}{l}\text { What are your } \\
\text { thoughts about using } \\
\text { a wearable device to } \\
\text { monitor out-patients? }\end{array}$ & \\
\hline P1 & $\begin{array}{l}\text { Well-structured, easy } \\
\text { to use. Natural to use } \\
\text { similar to using other } \\
\text { established } \\
\text { applications. }\end{array}$ & $\begin{array}{l}\text { EASE OF USE } \\
\text { INTUITIVE }\end{array}$ & Nothing. & NOTHING & $\begin{array}{l}\text { I think it is very } \\
\text { applicable. No need } \\
\text { for direct interaction, } \\
\text { the most important is } \\
\text { the access of } \\
\text { DOCTOR. }\end{array}$ & APPLICABLE \\
\hline $\mathbf{P 2}$ & $\begin{array}{l}\text { Easy application, } \\
\text { means that people will } \\
\text { learn it very quickly } \\
\text { and will be helpful. }\end{array}$ & $\begin{array}{l}\text { EASE OF USE } \\
\text { INTUITIVE }\end{array}$ & Nothing. & NOTHING & $\begin{array}{l}\text { I strongly recommend } \\
\text { them to use it. }\end{array}$ & $\begin{array}{c}\text { RECOMMEND } \\
\text { IT }\end{array}$ \\
\hline $\mathbf{P 3}$ & $\begin{array}{l}\text { I liked the application } \\
\text { and how simple and } \\
\text { comfortable it is to the } \\
\text { eye; it is not } \\
\text { complicated for } \\
\text { someone who does } \\
\text { not know anything } \\
\text { about the medical } \\
\text { stuff. Color coding } \\
\text { was really nice and } \\
\text { important for me. }\end{array}$ & $\begin{array}{c}\text { SIMPLE } \\
\text { AESTHETICALLY } \\
\text { PLEASING } \\
\text { INTUITIVE } \\
\text { COLOR ORIENTED }\end{array}$ & $\begin{array}{l}\text { Regarding the } \\
\text { questionnaire, it would } \\
\text { be good if I can add } \\
\text { other symptoms. And I } \\
\text { would like to have like } \\
\text { a drop-down menu to } \\
\text { add the degree or from } \\
1-10 \text { how bad it is, a } \\
\text { scale to show the } \\
\text { severity of my } \\
\text { symptom. } \\
\text { For the messages, it is } \\
\text { better to change the } \\
\text { color of the sender to } \\
\text { green as this is the } \\
\text { color we are used to } \\
\text { for sender in many } \\
\text { social network apps. }\end{array}$ & $\begin{array}{c}\text { NO SYMPTOM SEVERITY } \\
\text { CHOOSE UNIVERSAL } \\
\text { COLOR CODING }\end{array}$ & $\begin{array}{l}\text { I think it is a good } \\
\text { idea; it makes the } \\
\text { patient more } \\
\text { comfortable that they } \\
\text { are being monitored } \\
\text { without being in the } \\
\text { hospital, because } \\
\text { usually I don't like } \\
\text { going to a hospital but } \\
\text { when I am home or } \\
\text { wherever I can be in a } \\
\text { getaway location and } \\
\text { still be monitored. }\end{array}$ & GOOD IDEA \\
\hline P4 & $\begin{array}{l}\text { I really liked it; it was } \\
\text { very easy simple and } \\
\text { straight to the point. I } \\
\text { liked the colors, and } \\
\text { that it greeted m,e it } \\
\text { felt personal. }\end{array}$ & $\begin{array}{c}\text { EASE OF USE } \\
\text { SIMPLE } \\
\text { AESTHETICALLY } \\
\text { PLEASING } \\
\text { FELT PERSONAL }\end{array}$ & $\begin{array}{l}\text { I want to know the } \\
\text { range of my data for } \\
\text { the month. }\end{array}$ & MONTH RANGE & $\begin{array}{l}\text { It is a nice idea, } \\
\text { because it will be with } \\
\text { you all the time and } \\
\text { track your health } 24 \\
\text { hours. }\end{array}$ & NICE IDEA \\
\hline P5 & It is easy to use. & EASE OF USE & Nothing. & NOTHING & Very useful. & USEFUL \\
\hline
\end{tabular}

Table 13. App interview questions' themes/categories 


\begin{tabular}{|c|c|c|}
\hline WEIGH & Code & CATEGORY \\
\hline 4 & EASE OF USE & \multirow{6}{*}{ Usability and satisfaction of UI } \\
\hline 3 & INTUITIVE & \\
\hline 2 & SIMPLE & \\
\hline 2 & $\begin{array}{l}\text { AESTHETICALLY } \\
\text { PLEASING }\end{array}$ & \\
\hline 1 & COLOR ORIENTED & \\
\hline 1 & FELT PERSONAL & \\
\hline 1 & $\begin{array}{l}\text { NO SYMPTOM } \\
\text { SEVERITY }\end{array}$ & \multirow[t]{3}{*}{ Perceived issues and modifications } \\
\hline 1 & $\begin{array}{c}\text { CHOOSE } \\
\text { UNIVERSAL COLOR } \\
\text { CODING }\end{array}$ & \\
\hline 1 & MONTH RANGE & \\
\hline 1 & APPLICABLE & \multirow[t]{5}{*}{ OVERALL IDEA on the system for out-patients } \\
\hline 1 & RECOMMEND IT & \\
\hline 1 & GOOD IDEA & \\
\hline 1 & NICE IDEA & \\
\hline 1 & USEFUL & \\
\hline
\end{tabular}

\subsection{Usability and satisfaction of UI.}

As for usability and satisfaction, four participants mentioned that the UI was extremely easy to use, three participants expressed how intuitive it was, and two mentioned the simplicity of using the UI for a normal user "I liked the application and how simple and comfortable to the eye, it is not complicated for someone who does not know anything about the medical stuff" [P3], "I really liked it, it was very easy simple and straight to the point" [P4]. Moreover, two participants stated that the application was aesthetically pleasing, and one participant said that the color coding was nice and important for him. One participant was satisfied with the personal greet at the home page: "I liked the colors, and that it greeted me it felt personal" [P4]. 


\subsection{Perceived issues and modifications.}

Under this theme, we collected all negative feedback on the UI. One participant articulated that in the daily questionnaire, in which patients fill out their daily symptoms, there was no severity scale for each symptom: "Regarding the questionnaire, it would be good if I can add other symptoms. And I would like to have like a drop-down menu to add the degree or from 1-10 how bad it is, a scale to show the severity of my symptom." [P3]. Also, the same participant shared their feedback on the chat box color coding, where the sender had a grey color and the receiver had a green color, "For the messages it is better to change the color of the sender to green as this is the usual color, we are used to for sender in many social network apps" [P3]. On the same color-coding note, the participant also suggested that the graph should be color oriented: it should turn red when the curve is low and green when the curve is high, so he can have a fast understanding of his health status from the colors and without looking at each number. Another participant stated the need for having an average for her health information, where she can view the average rate of her monthly health "I want to know the range of my data for the month" [P4].

\subsubsection{Overall opinion on the system UI and wearable prototype for out-patients.}

Under this theme, participants expressed their overall opinion on using the application and a wearable health-tracking device to monitor out-patients. Participants thought it was a good idea, useful, applicable, and that they would recommend it to patients, "I think it is a good idea it makes the patient more comfortable that they are being monitored without being in the hospital, because usually I don't like going to a hospital but when I am home or wherever I can be in a getaway location and still be monitored" [P3]. 
"It is a nice idea, because it will be with you all the time and track your health 24 hour" [P4].

\subsection{Discussion}

In this section, we will discuss and reflect on our findings from the usability study. To better discuss this, we have divided this section into, first, reflections based on the wearable prototype, then, reflections based on results from the UI usability study.

\subsubsection{Reflections on wearable prototype results}

Since most hospitals have been reaching over capacity from the start of the pandemic, many hospitals and health authorities have been trying to find solutions to accommodate the increase in bed occupation, especially beds occupied with COVID-19 in-patients. COVID-19 in-patients, that is COVID-19 patients who stay in the hospital, are usually monitored 24/7. However, as mentioned earlier, not all COVID-19 patients need to be admitted to hospitals; therefore, one of our primary goals in designing this prototype was to provide a service for COVID-19 patients to be monitored from home instead of utilizing a bed at the hospital. It was important to design a wearable device that was comfortable and light enough so that patients can wear it and be monitored at all times and under any circumstances.

Most participants pointed out that the wearable prototype was extremely light and comfortable; but all male participants mentioned that the prototype was loose and not fully secure on the wrist. It seems that the prototype size was more of a fit for female users than men, which suggests that the wearable device should be size adjustable to fit all patients. 
Although our prototype did not have the final look and feel, in terms of materials, it was noticed from our results that participants were not satisfied with how the wearable looked. They would have preferred the wearable to look more like a bracelet than a watch so that they can wear it with their personal wristwatch and accessories. We initially wanted the design to be as invisible as possible; for instance, we wanted to use miniature sensors which can be attached to the skin directly using sticky elastic bands. However, this idea was disregarded due to several factors. One of them was that sticky elastic bands might not be acceptable to some participants, especially those with hairy arms. Nonetheless, by assuming that the wearable device will be owned by the hospital, and they will provide it to their out-patients, it seems more hygienic and durable to have a band that can be easily sanitized and recycled. However, we still wanted to use miniature sensors to achieve a small size and light weight design, so instead of attaching the sensors to sticky elastic bands, we decided to attach it to a normal non-sticky plastic band.

With regard to health awareness, we assumed that by wearing a wearable device, participants will be more mindful of their health during their daily life; however, from our results it was interesting to see that on the contrary, the wearable device did not increase their health consciousness. Although patients being aware of their wellbeing and being constantly reminded about their health is beneficial to help them make more accountable for their health choices during the day, it was important for us to design a wearable device that felt extremely light and almost invisible to the user.

\subsubsection{Reflections on UI prototype results}


Since our wearable prototype was non interactive, and we live in a time where almost everyone owns a smart phone, it was important to design a UI which projects all monitored data and can be easily used by all users. In systems where data is important and must be shared, it is challenging to present data to users without overwhelming them with a screen loaded with information, especially when the information is medical in nature and might be perceived as complicated and ambiguous. Hence, graphs are always a good means to showcase complicated data and make it understandable for readers. Although most participants easily comprehended the graph and what it represented, one participant articulated an important idea, that of using colors in the graphs to reflect the overall range of their vital signs.

This reminded us of the psychology behind color and how color can hold information and reduce cognitive load. Another interesting feedback was related to input flexibility - one user wanted to be able to enter more details of his symptoms. This suggests that users want to have more freedom when entering their data, especially health-related data where more information helps in better diagnosis. In this regard, however, sometimes, having too much freedom in data entry can also increase the possibility of error. Even though input flexibility is important, there must be constraints to data entry in order to protect the user from inputting erroneous data.

\subsection{Limitations}

In the context of the global pandemic, our participants were household members due to ethics regulations and COVID-19 restrictions at that time. Hence, it is important to address the possibility of bias problems with this type of participants. In addition to that, we 
expected that during the semi structured interviews and in-person usability tests it might have caused the "Hawthorne effect" (i.e., when participants behave in a different way under observation). With that in mind, our results can only help in directing us to better understanding user's perspective in this context. For future work usability testing must be conducted with larger and more diverse participant groups to avoid such limitations. 


\section{Chapter 5: Discussion}

In this chapter we share several findings from both the survey studies presented in the initial study and the usability study which are worth noting and discussing. We will also share our main research contributions, limitations that we have faced and suggestions for future work.

In the process of designing a home monitoring device and application specified for COVID-19 out-patients, we included two primary stakeholder groups. From our first survey group (general users) we found that most participants were more accepting toward wrist worn wearables. Although generally there was no significant difference between the acceptance of wearable positioning and age or gender; however, in some body placements such as the wrist there was a significant difference in the rate of acceptance, wherein the highest acceptance was across the age 18-25, and the lowest was 56 yrs. It would have been interesting to dig deeper into other reasons and relations to why participants have chosen the wrist as the most acceptable position. For instance, do individual from certain educational background have an effect into what is perceived acceptable? Another interesting finding was that the most unacceptable body placement was on the neck, where $95.6 \%$ of male participants did not accept wearing a sensor on the neck area. This was surprising specially after the knowledge that we had from Zeagler's body map on placement acceptability, wherein the map indicates that male participants were more accepting toward that body location. When it came to privacy concerns, on one hand, participants were more accepting on sharing their personal health information such as physiological data with their health provider, and according to [19]'s findings where individual's issue involvement can affect the willingness of sharing their personal 
information. On the other hand, they were less acceptable in sharing more personal data such as GPS, which also confirms [68]'s findings where individuals are less willing on sharing information that had a more personal note. In our second survey, most physicians rated oxygen saturation as the most important COVID-19 metric which is expected since the virus attacks the respiration system. When observing our findings from the physicians' survey, it was interesting to see that certain departments dominantly rated a metric as important while other departments rated it as not. For instance, we found that ICU and ER departments highly rated the importance of blood pressure as a COVID-19 metric, wherein none of the other departments rated as high. One reason that come to mind could be because other departments are more familiar with stable patients, whereas ER and ICU departments are most likely dealing with patients who have unbalanced vital parameters; hence, have a different perception of the importance of a vital metric. From our usability study, it was interesting to see how participants interacted with the UI prototype, and how the ability to interact with the prototype (e.g., click on buttons) allowed them to go through a realistic user experience. Figma [5], one of many other UI design tools was very important in the design process and during the usability testing. Its design capabilities and intuitive design made it easy for us to quickly provide a final look of a realistic working UI. Moreover, its ability to animate each component created a seamless experience which highly supported us during the usability testing. 


\subsection{Contributions}

In this study we contributed to the following:

- User-centered design study of a wearable health-tracking device prototype for COVID-19 out-patients, to understand what the important COVID-19 metrics at that time are, and a way to explore the requirements of COVID-19 home monitoring.

- Utilizing design softwares (i.e., Figma and Principle) and 3D printed objects to be used for early usability testing.

\subsection{Limitations}

Given the timing of our study, we were limited in several ways. First, due to the pandemic, universities were locked and our access to labs and some university materials was restricted. Second, due to COVID-19 restrictions, our time frame and the degree to which the ethics allowed me to operate in my home country and during that phase of the pandemic conducting usability studies on general participants was extremely difficult; hence, we had to limit the study to participants from our inner circle, thus exposing our results to bias. Although we conducted an initial online survey to understand user requirements for wearable devices, for which we gathered more than 200 responses from a diverse audience, we were limited in the number and diversity of participants which might have affected our understanding of users' perception of our product. Moreover, our usability study was limited to five participants, and during the interviews, not all participants provided rich responses; this led us to either remove some questions that had null responses during the data analysis or combine questions that participants had already 
answered in response to other questions. Given that, we cannot predict how the data might differed if we had changed the participant group. Another limitation was that this topic, "wearables to monitor COVID-19 out-patients", was new, and many studies had not yet published their results, so our literature review was limited by this paucity of relevant literature.

Lastly, for this study, our main goal regarding the development of the wearable device was to develop a wearable health-tracking device with miniatured sensors to track at least one or two vital signs; however, while trying to achieve that, it seemed that these sensors were not easily available - they cannot be easily found off the shelf and can only be procured from certain manufacturing companies. Even though we tried contacting these companies, it was not possible due to our low budget and difficulties in implementing such sensors. Given this, our project is more of a usability and acceptability study of wearing a wearable device and using a health application; we believe that even though we were not able to use real miniature sensors, the core objectives of our study remained unaffected.

\subsection{Future Work}

In future, we aim to design a wearable device with real miniature sensors required for monitoring COVID-19 out-patients. We are also interested in including more participants in the study so that they can be a part of a focus group and we could thus gain more input in the design process. Furthermore, it would be interesting to conduct a usability study on real COVID-19 out-patients and learn other possible requirements and feedback. Furthermore, the study could be conducted in different countries to learn if there would be any cultural differences in the findings. 
On a different note, during our study, we also had the idea of creating a transformable wearable device - the wearable device would have a core body which would be fixed and cannot be transformed, but it would contain a set of attachable sensors and the user could attach the sensor when needed into the wearable device. This would be similar to playing with Legos, where you have a set of Lego blocks which can be transformed from one form to another. For instance, the core device would include a battery and a processor, and the attachable segments would include different types of sensors (e.g., photoplethysmography, pulse oximeter, and so on). We believe that having a transformable health-tracking device would make the wearable flexible for multipurpose use, and it could also be used for chronic illness or during another epidemic. In future, we hope to further investigate the idea of using transformable electronics for health monitoring. 


\section{Chapter 6: Conclusion}

During this pandemic, it was crucial to manage beds and plan the intensive care unit to avoid bed crunches and hospital over capacity. Although many COVID-19 patients were hospitalized and required 24/7 monitoring, many others did not require hospitalization. These patients can be monitored from home with the use of smart technologies such as wearable health-tracking devices that tracks the vital signs related to COVID-19 metrics. This can help hospitals better manage their beds and use their resources more effectively. Even though wearable health-tracking devices such as Fitbit exist, they still present a limitation when it comes to tracking all vital signs related to COVID-19. Moreover, when it comes to wearable medical devices, they are usually bulky and not usable or acceptable by end-users; hence, there is a need for co-design and usability studies to understand users' needs and requirements. In this thesis, we asserted the importance of wearable health devices in general and specifically during this pandemic. We emphasized the importance of usability and user acceptance of health devices and the positive effects of including stakeholders in the design process. Furthermore, we learned the importance of prototyping, especially in human and computer interaction studies.

To that end, we first conducted two surveys, to i) understand patients' needs and requirements and ii) learn about COVID-19 metrics and important monitoring actions. In the first study, we understood user requirements and their needs, we learned more about what the device will look like and feel, and we gained a greater understanding of which sensors must be included to monitor COVID-19 patients. According to our findings and preliminary research, we designed a wearable device prototype which employs miniature sensors to deliver a lighter and more comfortable wearable health-tracking device for out- 
patients. Our wearable device was meant to track users' vital signs without direct interaction with the wearable device. Users could only interact with their monitored data through a phone application. Hence, for this study, we developed a UI prototype which was used with our static wearable prototype to allow users to interact with their wearable device and view their monitored vital signs. In the second study, we conducted a usability analysis for both our wearable and UI prototypes on five participants. Due to COVID-19 regulations, our five participants came from our inner social circle. All participants wore the device for 24 hours and completed tasks using our UI; then, we conducted interviews and requested participants to fill out our surveys. We found that users perceived the device to be extremely light and comfortable. Suggestions were offered regarding aesthetics and size adjustability. Overall, our design mostly met user needs and requirements, but there still exists room for modification and further usability testing. On another note, what was most interesting during our study was that some participants felt secure while wearing the wearable device, one participant mentioned casually after the usability test was completed "I like knowing what was going inside my body". This statement expressed how wearable health tracking devices can be tools used to seek knowledge from within, have a deeper connection with our own bodies and understand its physiological aspects. 


\section{Appendices}

Appendix A

\section{A.1 Recruiting E-Poster}

General users E-poster 


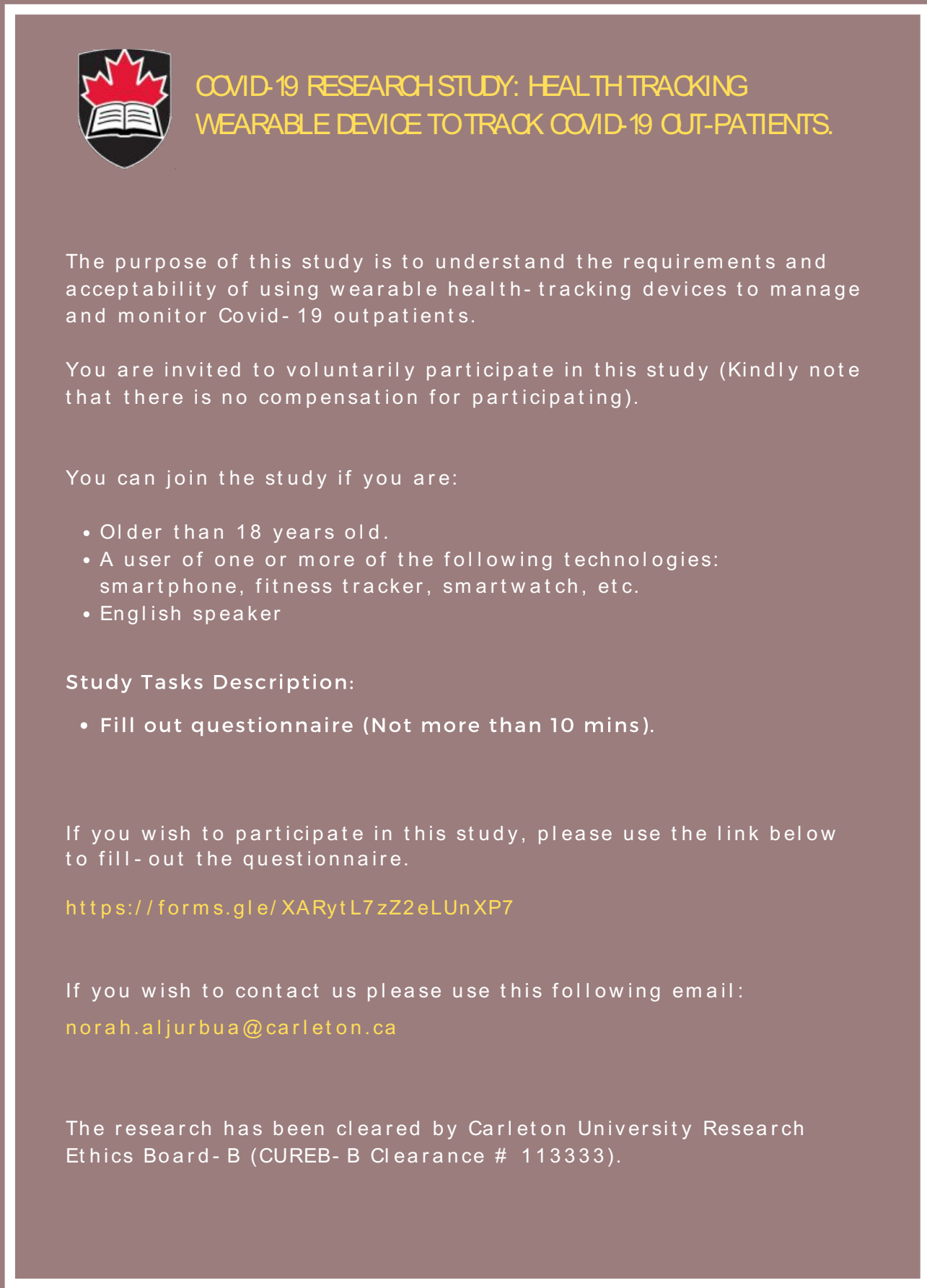

\section{Physicians E-poster}




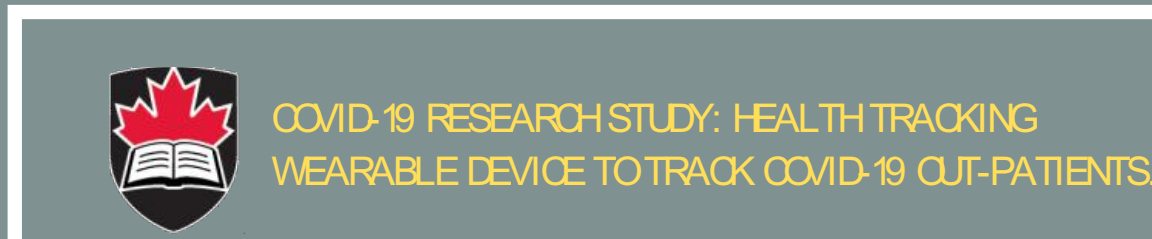

The purpose of this study is to understand the requirements and acceptability of using wearable health-tracking devices to manage and monitor Covid-19 outpatients.

You are invited to voluntarily participate in this study (Kindly note that there is no compensation for participating).

You can join the study if you are:

- Attending staff whom are working with covid-19 patients.

- English speaker

Study Tasks Description:

- Fill out questionnaire (Not more than 10 mins).

If you wish to participate in this study, please use the link below to fill-out the questionnaire.

ht t ps:// forms.gle/ rXyGRjPz3 85 CSJRQ7

If you wish to contact us please use this following email: norah.aljurbua@carleton.ca

The research has been cleared by Carleton University Research Ethics Board-B (CUREB-B Clearance \# 113333).

\section{A.2 Questionnaires A (General Users)}


Questionnaire A designed for general users. A consent form has been embedded in the questionnaire form.

\section{Consent Form}




\section{Wearable Health-Tracking Device to Monitor Covid-19 Out-patients}

This is a questionnaire designed to understand the most important user requirements for using health tracking wearable device to monitor outpatients.

* Required

\section{Informed Consent Form}

Name and Contact Information of Researchers:

Norah AlJurbua, Carleton University, Graduate Student, Human and Computer Interaction

Tel: 819-318-3695

Email: norahaljurbua@cmail.carleton.ca

Name and Contact Information of Academic Supervisor:

Dr. Victoria McArthur, Carleton University, School of Journalism and Communication, Faculty of Public Affairs

Tel.: $613-520-2600$ ext. 2520

Email: victoria.mcarthur@carleton.ca

Project Title Wearable Health-Tracking Device to Monitor Covid-19 Outpatients

Project Sponsor and Funder (if any)

TBA

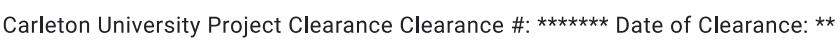

Invitation

You are invited to take part in a research project. The information in this form is intended to help you understand what we are asking of you so that you can decide whether you agree to participate in this study.

Your participation in this study is voluntary, and a decision not to participate will not be used against you in any way. As you rea this form, and decide whether to participate, please ask all the questions you might have, take whatever time you need, and consult with others as you wish. 


\section{Consent Form}

What is the purpose of the study?

We would like to learn more about your experience when health tracking wearable devices (specifically as an outpatient). We ai to apply an inclusive design methodology of health tracking wearables that are used to manage Covid-19 outpatients. The stud! will help us understand user requirements of monitoring Covid-19 outpatients using a wearable health-tracking device. This is $t l$ first phase of our research which will be primarily exploring and learning the needs and requirements from physicians and endusers (patients). The resulted data will help us in the designing phase of the health-tracking prototype.

What will I be asked to do?

If you agree to take part in the study, we will ask you to: Version 2019-03-28

- To fill out a demographics questionnaire (i.e. gender, age, level of education, ethnicity and technology skills).

- Fill out a questionnaire which includes 12 questions related to wearable device acceptance, privacy and control, features and functionalities, price, design and material.

Risks and Inconveniences

We do not anticipate any risks to participating in this study.

Possible Benefits

The benefit of this study is to include all stakeholders in the design loop and understand their needs, requirements and criteria , health-tracking wearable devices. Further, the wearable device will benefit not only patients of Covid-19 but also the manageme of health system. Patients can be monitored from the comfort of their home and hospital wards will be less crowded and effectively managed.

Compensation/Incentives

NA

No waiver of your rights

By signing this form, you are not waiving any rights or releasing the researchers from any liability

Withdrawing from the study

If you withdraw your consent during the course of the study, all information collected from you before your withdrawal will be discarded. To withdraw from this study, please email or phone the Principal Investigator at the contact information listed above within 30 days of completing the study.

Confidentiality

We will treat your personal information as confidential, although absolute privacy cannot be guaranteed. No information that discloses your identity will be released or published without your specific consent. Research records may be accessed by the 


\section{Consent Form}

Wearable Health-Tracking Device to Monitor Covid-19 Out-patients

2020-07-05, 2:15 PM

Carleton University Research Ethics Board in order to ensure continuing ethics compliance. All data will be kept confidential. Th results of this study may be published or presented at an academic conference or meeting, but the data will be presented so thi will not be possible to identify any participants.

We are using Google forms to collect your data. Survey data will be downloaded from the form and stored on a passwordprotected, encrypted hard drive. You will be assigned a pseudonym so that your identity will not be directly associated with the data you have provided.

Data Retention

Data collected in this study will be deleted 5 years after its completion.

New information during the study

In the event that any changes could affect your decision to continue participating in this study, you will be promptly informed.

Ethics review

This project was reviewed and cleared by the Carleton University Research Ethics Board B. If you have any ethical concerns witt the study, please contact Carleton University Research Ethics Board (by phone at 613-520-2600 ext. 4085 or by email at ethics@carleton.ca).

1. By clicking on the following checkbox, I have given my consent to participate in this study. *

Check all that apply.

I agree to complete the questionnaire. (Required)

\section{Demographics}




\section{Demographics and Background}

Wearable Health-Tracking Device to Monitor Covid-19 Out-patients

2020-07-05, 2:15 PM

2. Please choose your age group from the following:

Mark only one oval.

$18-25$
$26-35$
$36-45$
$46-55$
$56-65$
$66-75$
$75+$

3. Please choose your gender from the following:

Mark only one oval.

Female
Male
Prefer not to say
Other:

https://docs.google.com/forms/u/0/d/1u6qZp3cTwvo66qTmdgSiDh0CZQv1RIFVrS5EZTLw8xY/printform

Page 4 of 13 


\section{Demographics and Background}

Wearable Health-Tracking Device to Monitor Covid-19 Out-patients

2020-07-05, 2:15 PM

4. What is the highest level of education you have completed? (Please choose from the dropbox Mark only one oval.

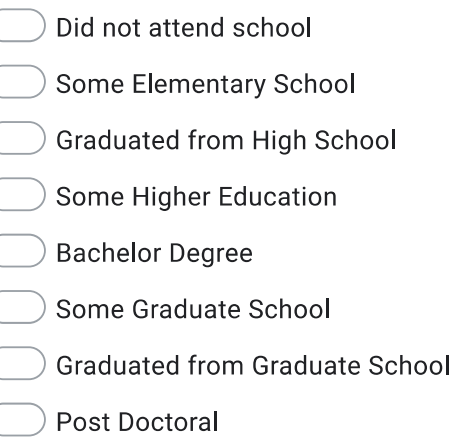

5. How would you rate your level of technology experience? (Where 1 is "Novice user" and 5 is "Tech savvy")

Mark only one oval.

\begin{tabular}{lllllll}
1 & 2 & 3 & 4 & 5 & \\
Novice User $\square$ & $\square$ & $\square$ & $\square$ & $\square$ \\
\hline
\end{tabular}

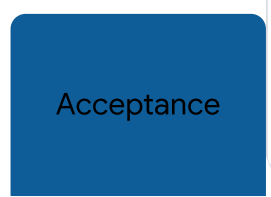

It is important for us to know the level of acceptance towards positioning of wearable device on the patient's body (e.g. wrist, finger, etc). This will help us design a more suitable and acceptable wearabl. health-trackers. 


\section{Acceptance}

Wearable Health-Tracking Device to Monitor Covid-19 Out-patients

2020-07-05, 2:15 PM

6. Rate your acceptance on wearing a health-tracking device on each of the following positions: (See Figure 1 below for reference)

Mark only one oval per row.

Not acceptable Less acceptable Neutral Acceptable Very acceptable

Positions for wearable device on body: 
Acceptance

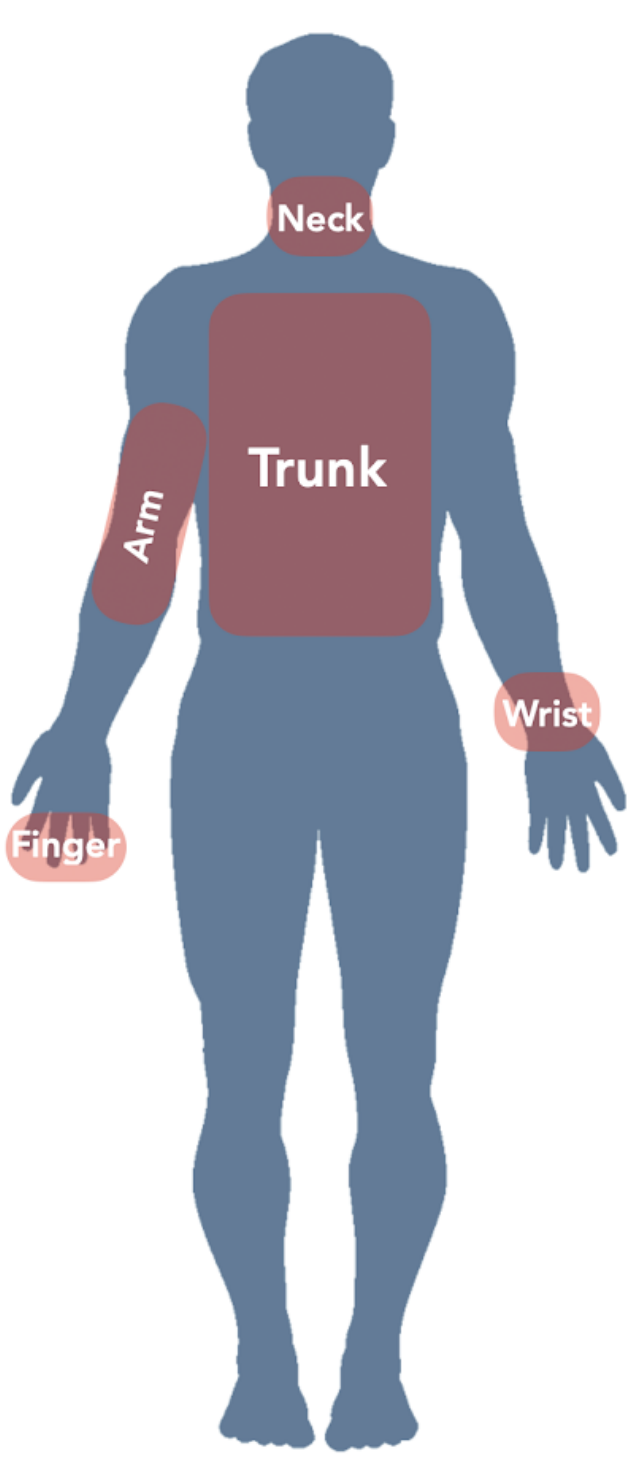




\section{Acceptance}

Wearable Health-Tracking Device to Monitor Covid-19 Out-patients

2020-07-05, 2:15 PM

7. Would you accept wearing more than one device to track your health? (e.g. wearing a ring to track level of oxygen, neck monitor to track cough patterns, and chest monitor to track heart rate)

Mark only one oval.
$\bigcirc$ Yes
No
Maybe
Other:

\section{Privacy and Control}

\section{Privacy and Control}

8. Is it important to control sharing vital signs with your physician? (For example, you control sharing your pulse rate with your physician)?

Mark only one oval.
Yes
$\bigcirc$ No
Maybe
Other: 


\section{Privacy and Control}

Wearable Health-Tracking Device to Monitor Covid-19 Out-patients

2020-07-05, 2:15 PM

9. Please rate your agreeableness on sharing the following data with healthcare physicians:

Mark only one oval per row.

Vital Signs (Biological
Parameters)
Age
Body Mass Index (BMI)
GPS Location

\section{Wearable Features and Functionalities}

\section{Wearable Features and Functionalities}

10. Is it important to access your data directly from wearable device or phone application? Mark only one oval.
Wearable Device
Phone Application
Both
Not Sure
Other: 


\section{Wearable Features and Functionalities}

11. Would having an active wearable device (i.e. able to interact with data from wearable) affect your self-awareness?

Mark only one oval.
Yes
No
Maybe
Other:

12. Is it important to have alerts on your wearable device? (e.g. you will be alerted if your level of oxygen drops)

Mark only one oval.

$\bigcirc$ Yes

$\bigcirc$ No

$\longrightarrow$ Maybe

13. Please choose from the following the most important functionality specifications of wearabl device:

Check all that apply.

$\square$ Long Battery Life

$\square$ Daily Activity Monitoring

Automated Fall detection

Accept Multiple Languages

24/7 Access to Technology Support

None of the above

Other: 


\section{Price}

Wearable Health-Tracking Device to Monitor Covid-19 Out-patients

2020-07-05, 2:15 PM

\section{Price}

14. Please rate the level of importance on price of wearable device: (Where 1 is "Not important, : "Moderately important" and 5 is "Very important")

Mark only one oval.

$\begin{array}{lllll}1 & 2 & 3 & 4 & 5\end{array}$

Not Important $\square \bigcirc \bigcirc \bigcirc$ Very Important

15. What is an acceptable price range for a wearable health tracking device? Mark only one oval.

Less than $\$ 100$

\101- $\$ 400$

$\$ 401-\$ 600$

$\$ 601-\$ 1000$

Any price is acceptable

Other:

\section{Design and Material}


16. Please rate the level of importance on aesthetics and design of wearable device: (Where 1 is "Not important, 3 is "Moderately important" and 5 is "Very important")

Mark only one oval.

\begin{tabular}{lllllll} 
& 1 & 2 & 3 & 4 & 5 & \\
\hline Not Important & $\square$ & $\square$ & $\square$ & $\square$ & $\square$ \\
\hline
\end{tabular}

17. Please choose from the following the most important design specifications of wearable device:

\section{Check all that apply.}

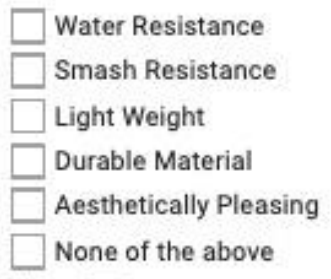

Other:

This content is neither created nor endorsed by Google.

\section{Google Forms}

This is Appendix A, Sub-Appendix 1. 


\section{A.3 Questionnaire B (Physicians)}

\section{Consent Form}

\section{Wearable Health-Tracking Device to Monitor Covid-19 Outpatients}

This is a questionnaire designed for physicians to understand the most important biological parameters for monitoring Covid-19 outpatients using health tracking wearable device.

* Required

\section{Informed Consent Form}

Name and Contact Information of Researchers:

Norah AlJurbua, Carleton University, Graduate Student, Human and Computer Interaction

Tel: 819-318-3695

Email: norahaljurbua@cmail.carleton.ca

Name and Contact Information of Academic Supervisor:

Dr. Victoria McArthur, Carleton University, School of Journalism and Communication, Faculty of Public Affairs

Tel.: $613-520-2600$ ext. 2520

Email: victoria.mcarthur@carleton.ca

Project Title Wearable Health-Tracking Device to Monitor Covid-19 Outpatients

Project Sponsor and Funder (if any)

TBA

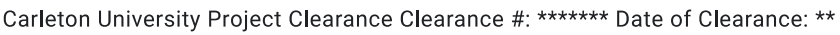

Invitation

You are invited to take part in a research project. The information in this form is intended to help you understand what we are asking of you so that you can decide whether you agree to participate in this study.

Your participation in this study is voluntary, and a decision not to participate will not be used against you in any way. As you rea this form, and decide whether to participate, please ask all the questions you might have, take whatever time you need, and consult with others as you wish. 


\section{Consent Form}

Wearable Health-Tracking Device to Monitor Covid-19 Outpatients

2020-07-05, 2:16 PM

What is the purpose of the study?

We would like to learn more about your experience when health tracking wearable devices (specifically as an outpatient). We air to apply an inclusive design methodology of health tracking wearables that are used to manage Covid- 19 outpatients. The stud! will help us understand user requirements of monitoring Covid-19 outpatients using a wearable health-tracking device. This is $t$ first phase of our research which will be primarily exploring and learning the needs and requirements from physicians and endusers (patients). The resulted data will help us in the designing phase of the health-tracking prototype.

What will I be asked to do?

If you agree to take part in the study, we will ask you to: Version 2019-03-28

- To fill out a demographics questionnaire (i.e. gender, age, level of education, ethnicity and technology skills).

- Fill out a questionnaire which includes 12 questions related to wearable device acceptance, privacy and control, features and functionalities, price, design and material.

Risks and Inconveniences

We do not anticipate any risks to participating in this study.

Possible Benefits

The benefit of this study is to include all stakeholders in the design loop and understand their needs, requirements and criteria । health-tracking wearable devices. Further, the wearable device will benefit not only patients of Covid-19 but also the manageme of health system. Patients can be monitored from the comfort of their home and hospital wards will be less crowded and effectively managed.

Compensation/Incentives

NA

No waiver of your rights

By signing this form, you are not waiving any rights or releasing the researchers from any liability.

Withdrawing from the study

If you withdraw your consent during the course of the study, all information collected from you before your withdrawal will be discarded. To withdraw from this study, please email or phone the Principal Investigator at the contact information listed above within 30 days of completing the study.

Confidentiality

We will treat your personal information as confidential, although absolute privacy cannot be guaranteed. No information that discloses your identity will be released or published without your specific consent. Research records may be accessed by the 


\section{Consent Form}

Carleton University Research Ethics Board in order to ensure continuing ethics compliance. All data will be kept confidential. Th results of this study may be published or presented at an academic conference or meeting, but the data will be presented so thi will not be possible to identify any participants.

We are using Google forms to collect your data. Survey data will be downloaded from the form and stored on a passwordprotected, encrypted hard drive. You will be assigned a pseudonym so that your identity will not be directly associated with the data you have provided.

Data Retention

Data collected in this study will be deleted 5 years after its completion.

New information during the study

In the event that any changes could affect your decision to continue participating in this study, you will be promptly informed.

Ethics review

This project was reviewed and cleared by the Carleton University Research Ethics Board B. If you have any ethical concerns with the study, please contact Carleton University Research Ethics Board (by phone at 613-520-2600 ext. 4085 or by email at ethics@carleton.ca).

1. By clicking on the following checkbox, I have given my consent to participate in this study. *

Check all that apply.

I agree to complete the questionnaire. (Required)

\section{Demographics}


2. Please choose your speciality:

Mark only one oval.

Internal Medicine (Including infectious diseased and pulmonology)

Intensive Care Unit (ICU)

Emergency Medicine (EM)

Family Medicine

Other:

\section{Vital Parameters for COVID-19}

\section{Vital parameters for}

Covid-19
From the following please rate the vital parameters that are required for monitoring patients with Covid-19.

3. Data to be measured:

Mark only one oval per row.

Body Temperature
Blood Pressure
$\begin{aligned} & \text { Peripheral Capillary Oxygen } \\ & \text { Paturation (SpO2) }\end{aligned}$ Respiration Rate
Cough Patterns


4. Please indicate if there is any vital sign that was not mentioned in the previous question and must be included:

\section{Measurement Frequency of Vital Parameters}

5. How frequent should vital parameters of Covid-19 outpatients be measured? Mark only one oval.

Every 4 hours

Every 6 hours

Every 8 hours

Every 12 hours

Every 24 hours

Other:

\section{Monitoring Vital Signs}


6. Is it important to monitor Covid-19 outpatients during sleep?

Mark only one oval.

\begin{tabular}{lllllll}
1 & 2 & 3 & 4 & 5 & \\
Not Important $\square$ & $\square$ & $\square$ & $\square$ \\
\hline
\end{tabular}

7. Is it important to be able to remotely access outpatient's data at anytime?

Mark only one oval.

\begin{tabular}{lllllll}
1 & 2 & 3 & 4 & 5 & \\
Not Important $\square$ & $\square$ & $\square$ & $\square$ \\
\hline
\end{tabular}

8. Is it important to have time-stamped measurements?

Mark only one oval.

\begin{tabular}{llllll}
1 & 2 & 3 & 4 & 5 \\
Not Important $\square$ & $\square$ & $\square$ \\
\hline
\end{tabular}

9. Is it important to locate Covid-19 outpatient position by GPS? Mark only one oval.

\begin{tabular}{lllllll}
1 & 2 & 3 & 4 & 5 & \\
Not Important & $\square$ & & \\
\hline
\end{tabular}




\section{Monitoring Vital Signs}

Wearable Health-Tracking Device to Monitor Covid-19 Outpatients

2020-07-05, 2:16 PM

10. Is it important to be able to send alerts and messages to patients?

Mark only one oval

\begin{tabular}{lllllll} 
& 1 & 2 & 3 & 4 & 5 \\
\hline Not Important & & & & & &
\end{tabular}

This content is neither created nor endorsed by Google.

\section{Google Forms}




\section{Appendix B}

\section{B.1 Screenshots of wearable prototype samples}
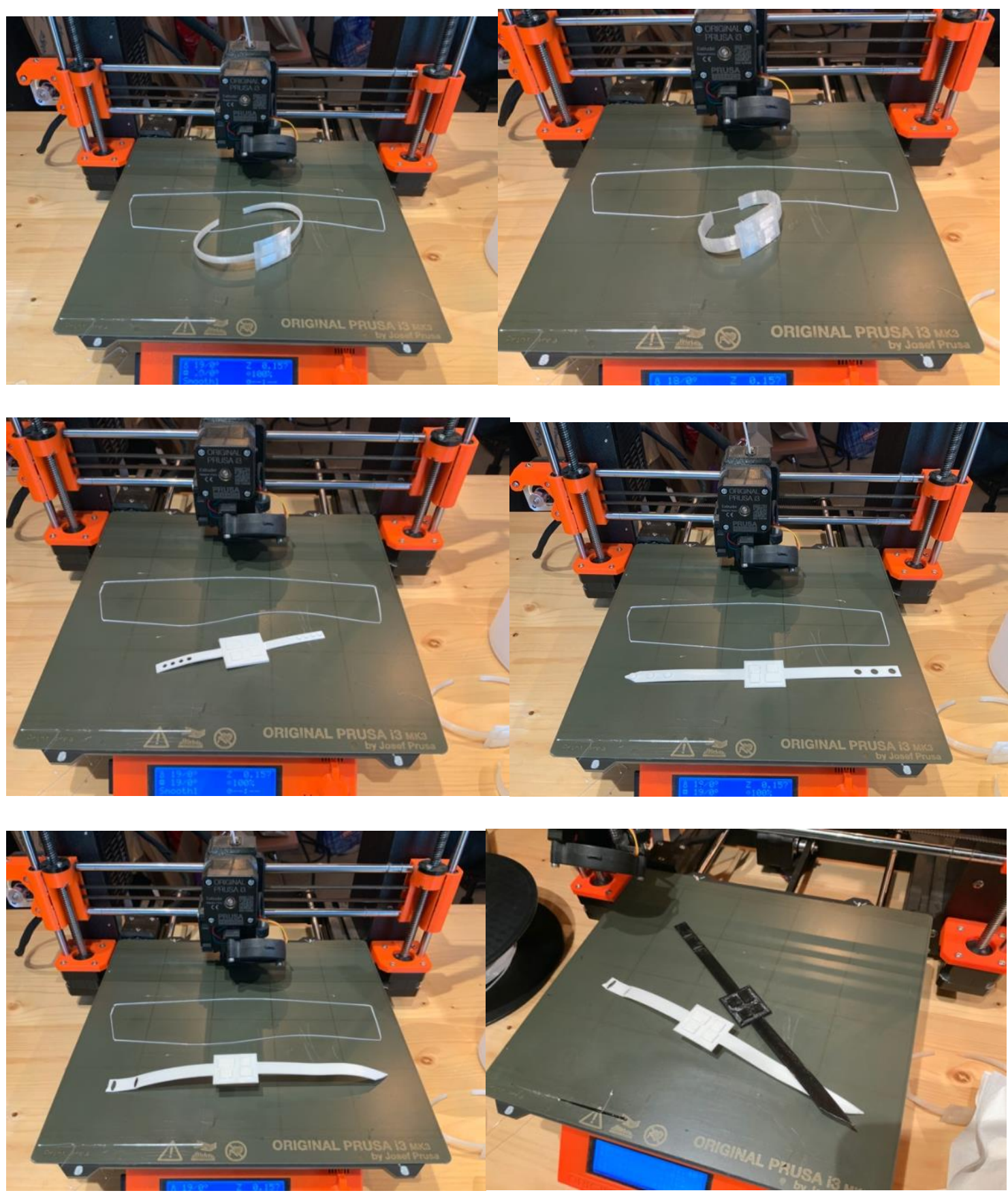


\section{Appendix C}

Here, all questionnaires and interview questions used in the usability study have been presented.

\section{C.1 Usability study outline}




\section{Usability Test Outline}

1. Greeting + Overview

2. Background Survey

3. Start with App test:

1. Explain Think aloud, and overview

2. Ask to explore the application

3. Check R.R and Share with a Friend

4. Check Heart.R (Daily, Weekly, Monthly)

5. Read Unread messages

6. Fill out daily questionnaire (ex. Having fever, cough and sore through symptoms).

7. Change privacy settings to all ON.

\section{C.2 Background questionnaire}




\section{Background Survey}

1. Gender

Mark only one oval.

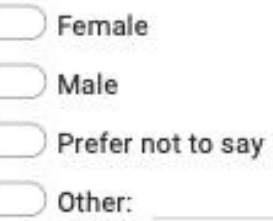

2. Age

3. Are you familiar with wearing a health tracking device?

Mark only one oval.

This content is neither created nor endorsed by Google. 


\begin{tabular}{|l} 
C.3 Wearable prototype usability and acceptability quest \\
\hline usability and Acceptability of Wearable Heath-Tracking Device \\
Usability and Acceptability of Wearable \\
Health-Tracking Device \\
* Required \\
$\begin{array}{l}\text { Usability - } \\
\text { Acceptability Scale }\end{array}$ \\
$\begin{array}{l}\text { Please rate the following statement where } 1 \text { is "Strongly Disagree" } \\
\text { and } 5 \text { is Strongly Agree" }\end{array}$
\end{tabular}

1. I liked wearing the wearable device. *

Mark only one oval.

\begin{tabular}{lllllll} 
& 1 & 2 & 3 & 4 & 5 & \\
\hline Strongly Disagree & $\longrightarrow$ & $\longrightarrow$ & & & &
\end{tabular}

2. The wearable device helped me think about my health during the day. *

Mark only one oval.

\begin{tabular}{lllllll} 
& 1 & 2 & 3 & 4 & 5 \\
\hline Strongly Disagree & $\square$ & $\square$ & & &
\end{tabular}

https://docs.google.com/forms/u/0/d/1onxvy__KihNeeTs5BbhueyqsFPfx2rCthbBzreo9CmE/printform

Page 1 of 4 
3. I would recommend a wearable device to out-patients. *

Mark only one oval.

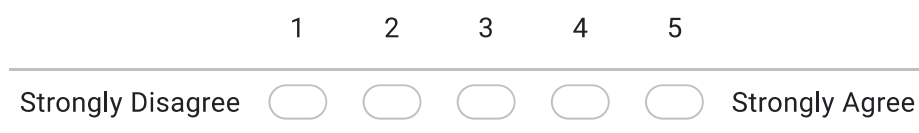

4. I would wear this device daily. *

Mark only one oval.

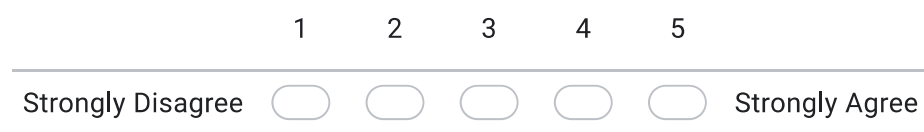

5. I feel the device was light weight. *

Mark only one oval.

$\begin{array}{lllllll} & 1 & 2 & 3 & 4 & 5 & \\ \text { Strongly Disagree } & \square & \square & & & & \end{array}$


6. I felt comfortable wearing the device. *

Mark only one oval.

\begin{tabular}{llllllll} 
& 1 & 2 & 3 & 4 & 5 & \\
\hline Strongly Disagree & $\square$ & & & & & & \\
\hline
\end{tabular}

7. I like how the device looked. *

Mark only one oval

\begin{tabular}{llllllll} 
& 1 & 2 & 3 & 4 & 5 & \\
\hline Strongly Disagree & $\square$ & & & & & & \\
\hline
\end{tabular}

This content is neither created nor endorsed by Google.

\section{Google Forms}

\section{C.4 UI usability and acceptability questionnaire}




\section{Health App - Usability Evaluation}

In this questionnaire we will evaluate the health application used with the wearable prototype.

\section{Overall \\ Questionnaire \\ (SUS)}

Please score the following 10 statements from 1 to 5 , where 1 is strongly disagree and 5 is strongly agree.

1. I think that I would like to use this system frequently.

Mark only one oval.

\begin{tabular}{lllllll} 
& 1 & 2 & 3 & 4 & 5 & \\
\hline Strongly Disagree & $\square$ & $\square$ & $\square$ & $\square$ & &
\end{tabular}

2. I found the system unnecessarily complex.

Mark only one oval.

\begin{tabular}{lllllll}
1 & 2 & 3 & 4 & 5 & \\
Strongly Diagree & $\longrightarrow$ & & \\
\hline & & &
\end{tabular}


3. I thought the system was easy to use.

Mark only one oval.

\begin{tabular}{lllllll} 
& 1 & 2 & 3 & 4 & 5 & \\
\hline Strongly Diagree & $\longrightarrow$ & $\square$ & $\square$ & &
\end{tabular}

4. I think that I would need the support of a technical person to be able to use this system.

Mark only one oval.

\begin{tabular}{lllllll}
1 & 2 & 3 & 4 & 5 & \\
\hline Strongly Diagree & $\square$ & $\square$ & $\square$ & & &
\end{tabular}

5. I found the various functions in this system were well integrated.

Mark only one oval.

\begin{tabular}{lllllll}
1 & 2 & 3 & 4 & 5 \\
\hline Strongly Diagree & $\longrightarrow$ & $\longrightarrow$ & \\
& $\longrightarrow$ & &
\end{tabular}


6. I thought there was too much inconsistency in this system.

Mark only one oval.

\begin{tabular}{lllllll} 
& 1 & 2 & 3 & 4 & 5 & \\
\hline Strongly Diagree & $\longrightarrow$ & $\square$ & $\square$ & &
\end{tabular}

7. I would imagine that most people would learn to use this system very quickly.

Mark only one oval.

\begin{tabular}{lllllll}
1 & 2 & 3 & 4 & 5 & \\
\hline Strongly Diagree & $\longrightarrow$ & $\square$ & & & &
\end{tabular}

8. I found the system very cumbersome to use.

Mark only one oval.

\begin{tabular}{lllllll}
1 & 2 & 3 & 4 & 5 & \\
\hline Strongly Diagree & $\longrightarrow$ & $\square$ & $\square$ & & &
\end{tabular}


9. I felt very confident using the system.

Mark only one oval.

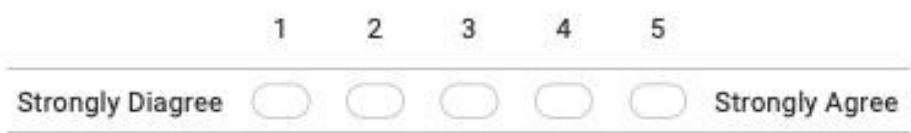

10. I needed to learn a lot of things before I could get going with this system.

Mark only one oval.

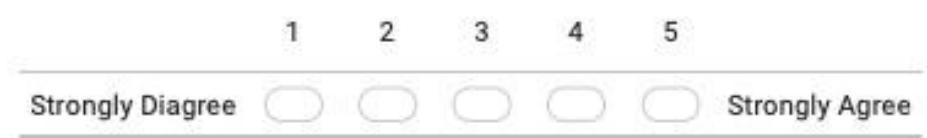

This content is neither created nor endorsed by Google.

\section{Google Forms}

\section{C.5 Semi-structured interview questions}




\section{Semi Structured Interview}

Q1: Tell us what you liked about the wearable device and the app?

Q2: Tell us what you disliked about the wearable device and the app?

Q3: How would you change the design of the device and app to make it more usable and acceptable?

Q4: What were the issues you faced when wearing this device and using the app?

Q5: What are your thoughts about using a wearable device to monitor out-patients? 


\section{Bibliography}

[1] "2020 Device Approvals | FDA." [Online]. Available: https://www.fda.gov/medical-devices/recently-approved-devices/2020-deviceapprovals. [Accessed: 11-Aug-2021].

[2] "Can the Ava fertility tracker device detect early signs of COVID-19? | Request PDF.” [Online]. Available: https://www.researchgate.net/publication/340687441_Can_the_Ava_fertility_trac ker_device_detect_early_signs_of_COVID-19.[Accessed: 22-Dec-2020].

[3] “CQUni helps investigate respiratory rate pattern and relationship with COVID-19 symptoms - - CQUniversity." [Online]. Available: https://www.cqu.edu.au/cquninews/stories/research-category/2020research/cquni-helps-investigate-respiratory-rate-pattern-and-relationship-withcovid-19-symptoms. [Accessed: 22-Dec-2020].

[4] "Detect Viral Outbreaks: COVID-19 | Scripps Research.” [Online]. Available: https://www.scripps.edu/covid-19/detect/. [Accessed: 22-Dec-2020].

[5] "Figma: the collaborative interface design tool." [Online]. Available: https://www.figma.com/. [Accessed: 13-Mar-2021].

[6] "Germany launches smartwatch app to monitor coronavirus spread." [Online]. Available: https://finance.yahoo.com/news/germany-launches-smartwatch-appmonitor-123109671.html?guccounter=1. [Accessed: 12-Dec-2020].

[7] "Oura Ring: Accurate Health Information Accessible to Everyone." [Online]. Available: https://ouraring.com/. [Accessed: 25-Nov-2020]. 
[8] "Philips Survey Reveals One in 10 Americans Believe Online Health Information Saved Their Life." [Online]. Available: https://www.usa.philips.com/aw/about/news/archive/standard/news/press/2012/20121212_Philips_Survey_Healt h_Info_Tech.html. [Accessed: 31-Mar-2021].

[9] “Principle.”[Online]. Available: https://principleformac.com/. [Accessed: 13-Mar2021].

[10] "Rhino - Rhinoceros 3D." [Online]. Available: https://www.rhino3d.com/. [Accessed: 04-Jun-2021].

[11] "Rigid PCB Circuit Board - Definition, Types, and Applications - JHYPCB." [Online]. Available: https://www.pcbelec.com/rigid-pcb. [Accessed: 14-Jan-2021].

[12] "Taking an ECG with the ECG app on Apple Watch Series 4, Series 5, or Series 6 - Apple Support.” [Online]. Available: https://support.apple.com/en-sa/HT208955. [Accessed: 13-Mar-2021].

[13] “TemPredict | UCSF Osher Center for Integrative Medicine.” [Online]. Available: https://osher.ucsf.edu/research/current-research-studies/tempredict. [Accessed: 22Dec-2020].

[14] "WHO Coronavirus (COVID-19) Dashboard | WHO Coronavirus (COVID-19) Dashboard With Vaccination Data." [Online]. Available: https://covid19.who.int/. [Accessed: 09-May-2021].

[15] "WHOOP - The World's Most Powerful Fitness Membership." [Online]. Available: https://www.whoop.com/overview/?utm_expid=.n_tr1RX5SYCPIsXGq_9Mlw.1 
\&utm_referrer=https\%3A\%2F\%2Fwww.google.com\%2F. [Accessed: 25-Nov2020].

[16] A. Jayatilaka, Q. H. Dang, S. J. Chen, R. Visvanathan, C. Fumeaux, and D. C. Ranasinghe, "Designing batteryless wearables for hospitalized older people," Proc.

- Int. Symp. Wearable Comput. ISWC, pp. 91-95, 2019, doi: $10.1145 / 3341163.3347740$.

[17] A. S. Fauci, H. C. Lane, and R. R. Redfield, "Covid-19 - Navigating the Uncharted,”N. Engl. J. Med., 2020, doi: 10.1056/nejme2002387.

[18] A. T. Özdemir, "An analysis on sensor locations of the human body for wearable fall detection devices: Principles and practice,” Sensors (Switzerland), 2016, doi: $10.3390 / \mathrm{s} 16081161$.

[19] Abdelhamid M, Gaia J, Sanders GL. Putting the focus back on the patient: How privacy concerns affect personal health information sharing intentions. J Med Internet Res. 2017;

[20] Adams Anne, Lunt Peter, and Cairns Paul, "A qualitative approach to HCI research,” Res. Methods Human-Computer Interact., 2008.

[21] Amazfit Official | Smartwatches, TWS Earbuds, Smart Scale and Treadmills to improve your Health \& Fitness [Internet]. [cited 2020 Nov 25]. Available from: https://www.amazfit.com/en/

[22] B. Buxton, Sketching User Experiences: Getting the Design Right and the Right Design. 2007.

[23] B. L. Smarr et al., "Feasibility of continuous fever monitoring using wearable devices,” Sci. Rep., 2020, doi: 10.1038/s41598-020-78355-6. 
[24] C. Harrison, B. Y. Lim, A. Shick, and S. E. Hudson, "Where to locate wearable displays?," p. 941, 2009, doi: 10.1145/1518701.1518845.

[25] C. P. Adans-Dester et al., "Can mHealth Technology Help Mitigate the Effects of the COVID-19 Pandemic?," IEEE Open J. Eng. Med. Biol., 2020, doi: 10.1109/ojemb.2020.3015141.

[26] C. Zeagler, "Where to wear it," pp. 150-157, 2017, doi: $10.1145 / 3123021.3123042$.

[27] D. Dias and J. P. S. Cunha, "Wearable health devices-vital sign monitoring, systems and technologies," Sensors (Switzerland), vol. 18, no. 8, 2018, doi: $10.3390 / \mathrm{s} 18082414$.

[28] D. J. Miller et al., "Analyzing changes in respiratory rate to predict the risk of COVID-19 infection," medRxiv. 2020, doi: 10.1101/2020.06.18.20131417.

[29] D. K. Ming et al., "Continuous physiological monitoring using wearable technology to inform individual management of infectious diseases, public health and outbreak responses," Int. J. Infect. Dis., vol. 96, no. 2019, pp. 648-654, 2020, doi: 10.1016/j.ijid.2020.05.086.

[30] D. Maulsby, S. Greenberg, and R. Mander, "Prototyping an intelligent agent through Wizard of Oz," in Conference on Human Factors in Computing Systems Proceedings, 1993, doi: 10.1145/169059.169215.

[31] D. Norman, The Design of Everyday Things. 2016.

[32] D. R. Seshadri et al., "Wearable Sensors for COVID-19: A Call to Action to Harness Our Digital Infrastructure for Remote Patient Monitoring and Virtual 
Assessments," Front. Digit. Heal., vol. 2, no. June, pp. 1-11, 2020, doi: 10.3389/fdgth.2020.00008.

[33] D. Raskovic, T. Martin, and E. Jovanov, "Medical monitoring applications for wearable computing,” Comput. J., 2004, doi: 10.1093/comjnl/47.4.495.

[34] D. Wang, Z. Xiang, and D. R. Fesenmaier, "Adapting to the mobile world: A model of smartphone use,” Ann. Tour. Res., 2014, doi: 10.1016/j.annals.2014.04.008.

[35] Dribbble - Discover the World's Top Designers \& Creative Professionals [Internet]. [cited 2021 Sep 21]. Available from: https://dribbble.com/

[36] E. J. Emanuel et al., "Fair Allocation of Scarce Medical Resources in the Time of Covid-19,” N. Engl. J. Med., 2020, doi: 10.1056/nejmsb2005114.

[37] F. Gemperle, C. Kasabach, J. Stivoric, M. Bauer, and R. Martin, "Design for wearability,” Int. Symp. Wearable Comput. Dig. Pap., vol. 1998-Octob, no. November 1998, pp. 116-122, 1998, doi: 10.1109/ISWC.1998.729537.

[38] Fitbit Official Site for Activity Trackers \& More [Internet]. [cited 2020 Nov 25]. Available from: https://www.fitbit.com/global/us/home

[39] G. E. Burnett and D. Ditsikas, "Personality as A-Criterion for Selecting Usability Testing Participants," no. December, pp. 1-1, 2007, doi: 10.1109/itict.2006.358235.

[40] Garmin International | Home [Internet]. [cited 2020 Nov 25]. Available from: https://www.garmin.com/en-US/

[41] H. Iman K Al-Azwani, "Integration of Wearable Technologies into Patient's Electronic Medical Records," Audit Trends, vol. 24, no. 4, 2016. 
[42] H. Jeong, J. A. Rogers, and S. Xu, "Continuous on-body sensing for the COVID19 pandemic: Gaps and opportunities," Science Advances. 2020, doi: 10.1126/sciadv.abd4794.

[43] I. S. Khayal, "Designing Technology and Healthcare Delivery Systems to Support Clinician and Patient Care Experiences: A Multi-Stakeholder Systems Engineering Co-Design Methodology," in International Symposium on Technology and Society, Proceedings, 2019, doi: 10.1109/ISTAS48451.2019.8937932.

[44] J. A. Behar et al., "Remote health diagnosis and monitoring in the time of COVID19," Physiological Measurement. 2020, doi: 10.1088/1361-6579/abba0a.

[45] J. Allen, "Photoplethysmography and its application in clinical physiological measurement," Physiological Measurement. 2007, doi: 10.1088/09673334/28/3/R01.

[46] J. Dunn, R. Runge, and M. Snyder, "Wearables and the medical revolution," Personalized Medicine. 2018, doi: 10.2217/pme-2018-0044.

[47] J. Kim et al., "Miniaturized Flexible Electronic Systems with Wireless Power and Near-Field Communication Capabilities," Adv. Funct. Mater., vol. 25, no. 30, pp. 4761-4767, 2015, doi: 10.1002/adfm.201501590.

[48] J. M. Radin, N. E. Wineinger, E. J. Topol, and S. R. Steinhubl, "Harnessing wearable device data to improve state-level real-time surveillance of influenza-like illness in the USA: a population-based study," Lancet Digit. Heal., 2020, doi: 10.1016/S2589-7500(19)30222-5. 
[49] J. Nielsen and T. K. Landauer, "Mathematical model of the finding of usability problems," in Conference on Human Factors in Computing Systems - Proceedings, 1993, doi: 10.1145/169059.169166.

[50] L. J. Mengelkoch, D. Martin, and J. Lawler, "A review of the principles of pulse oximetry and accuracy of pulse oximeter estimates during exercise," Physical Therapy. 1994, doi: 10.1093/ptj/74.1.40.

[51] M. Batalden et al., "Coproduction of healthcare service," BMJ Qual. Saf., 2016, doi: 10.1136/bmjqs-2015-004315.

[52] M. Gao and P. Kortum, "The relationship between subjective and objective usability metrics for home healthcare devices," Proc. Hum. Factors Ergon. Soc., vol. 2015-Janua, pp. 1001-1005, 2015, doi: 10.1177/1541931215591286.

[53] M. J. Muller and S. Kuhn, "Participatory design," Commun. ACM, 1993, doi: $10.1145 / 153571.255960$

[54] M. Z. Poh, K. Kim, A. Goessling, N. Swenson, and R. Picard, "Cardiovascular monitoring using earphones and a mobile device," IEEE Pervasive Comput., 2012, doi: 10.1109/MPRV.2010.91.

[55] N. S. Anderson, D. A. Norman, and S. W. Draper, "User Centered System Design: New Perspectives on Human-Computer Interaction,” Am. J. Psychol., 1988, doi: $10.2307 / 1422802$.

[56] Ovulation Tracking Bracelet | Ava [Internet]. [cited 2020 Nov 25]. Available from: https://www.avawomen.com/

[57] P. Ehn and Y. Sundblad, "Cooperative Design — perspectives on 20 years with ' the Scandinavian IT Design Model CID-104, KTH, Stockholm, Sweden 2000 Co- 
operative Design — perspectives on 20 years with ' the Scandinavian IT Design Model ' Susanne Bødker, Pelle Ehn, Dan Sjögren,” no. January, 2000.

[58] P. H. Charlton, T. Bonnici, L. Tarassenko, D. A. Clifton, R. Beale, and P. J. Watkinson, "An assessment of algorithms to estimate respiratory rate from the electrocardiogram and photoplethysmogram," Physiol. Meas., 2016, doi: 10.1088/0967-3334/37/4/610.

[59] Pinterest [Internet]. [cited 2021 Sep 21]. Available from: https://www.pinterest.com/

[60] Prusa3D - Open-Source 3D printers by Josef Prusa [Internet]. [cited 2021 Sep 20]. Available from: https://www.prusa3d.com/

[61] S. Mchome, S. Sachdeva, and S. Bhalla, "A brief survey: Usability in healthcare," ICEIE 2010 - 2010 Int. Conf. Electron. Inf. Eng. Proc., vol. 1, no. Iceie, pp. $463-$ 467, 2010, doi: 10.1109/ICEIE.2010.5559675.

[62] S. Mueller, “3D printing for human-computer interaction," Interactions, 2017, doi: $10.1145 / 3125399$.

[63] S. Mueller, B. Kruck, and P. Baudisch, "LaserOrigami: Laser-cutting 3D objects," in Conference on Human Factors in Computing Systems - Proceedings, 2013, doi: $10.1145 / 2470654.2481358$.

[64] S. R. Steinhubl, D. Feye, A. C. Levine, C. Conkright, S. W. Wegerich, and G. Conkright, "Validation of a portable, deployable system for continuous vital sign monitoring using a multiparametric wearable sensor and personalised analytics in an Ebola treatment centre," BMJ Glob. Heal., 2016, doi: 10.1136/bmjgh-2016000070. 
[65] T. Loncar-Turukalo, E. Zdravevski, J. M. da Silva, I. Chouvarda, and V. Trajkovik, "Literature on wearable technology for connected health: Scoping review of research trends, advances, and barriers," Journal of Medical Internet Research. 2019, doi: 10.2196/14017.

[66] T. Mishra et al., "Early Detection Of COVID-19 Using A Smartwatch," 2020, doi: 10.1101/2020.07.06.20147512.

[67] T. Tamura, Y. Maeda, M. Sekine, and M. Yoshida, "Wearable photoplethysmographic sensors-past and present," Electronics . 2014, doi: $10.3390 /$ electronics3020282.

[68] Whiddett R, Hunter I, Engelbrecht J, Handy J. Patients' attitudes towards sharing their health information. Int J Med Inform. 2006;

[69] Watch - Apple (SA) [Internet]. [cited 2020 Nov 25]. Available from: https://www.apple.com/sa/watch/?\&cid=wwa-ksa-kwgo-watch-slid---productid---Announce-\&mtid=209258dq65577\&aosid=p238\&mnid=sIW4b30GYdc_mtid_209258dq65577_pcrid_465394839343_pgrid_114513917252_

[70] X. Chen et al., "Stretchable and Flexible Buckypaper-Based Lactate Biofuel Cell for Wearable Electronics,” Adv. Funct. Mater., vol. 29, no. 46, pp. 1-8, 2019, doi: 10.1002/adfm.201905785.

[71] Z. Huang et al., "Three-dimensional integrated stretchable electronics," Nat. Electron., 2018, doi: 10.1038/s41928-018-0116-y. 